\title{
Cross case analysis of shipping and logistic industry supply chains: Blockchain qualities in stakeholder value propositions
}

\author{
By \\ Tina Khamenehmohammadi
}

A thesis submitted to the Faculty of Graduate and Postdoctoral Affairs in partial fulfillment of the requirements for the degree of

Master of Applied Science

In

Technology Innovation Management

Carleton University

Ottawa, Ontario

Copyright (C) 2021 Tina Khamenehmohammadi 


\begin{abstract}
Supply chain management in the shipping and logistic industry is increasingly facing severe problems such as rising costs and a lack of transparency. In the recent years, firms in the industry have started adopting blockchain technology to help resolve these problems. However, there is a gap in the extant literature regarding how organizations incentivize their supply chain partners to join and contribute to their platforms. Hence, this study uses the stakeholder perspective to examine what blockchain enabling qualities are used by firms in the shipping and logistic industry to create value propositions that incentivize their partners and stakeholders to contribute. Analyzing five case companies in the industry, the study identifies various blockchain qualities and how those qualities are reflected in the companies' stakeholder value propositions. The findings reveal that firms use a variety of enabling qualities, including contract management and tokenization, enhanced data storage and movement, and enhanced tracking and tracing to create stakeholder value proposition. Further, some firms provide innovative solutions for restraining qualities such as high set-up costs.
\end{abstract}




\section{Acknowledgements}

The current study would not have been possible without the support and help provided by Dr. Mika Westerlund. He has supported me through my studies in the Technology Innovation Management (TIM) program at Carleton University as my professor, academic advisor, and thesis supervisor. Without his guidance and help the current study would never have been completed.

This thesis has been modified and enhanced based on feedback received from other TIM professors, namely Dr. Tony Bailetti, Dr. Steven Muegge, Dr. Michael Weiss, and Dr. Stoyan Tanev. I would like to thank these individuals for their help and support and for guiding me with their feedbacks throughout the completion of this research.

I also would like to use this opportunity to thank my fellow students in the TIM program. I had the honor of studying alongside these talented individuals and work with them on completing different course assignments and projects. They were an important part of my education at Carleton University. I am deeply thankful.

Finally, I would like to thank my family for their constant support and patience while I was completing my studies and this research. 


\section{Table of content}

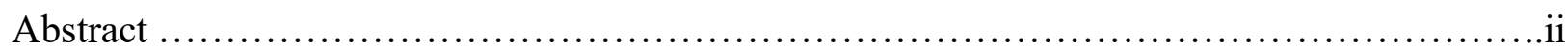

Acknowledgment .......................................................................... ii

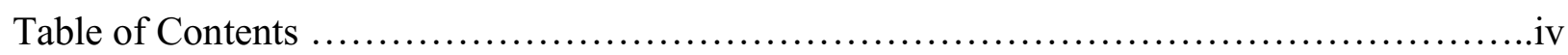

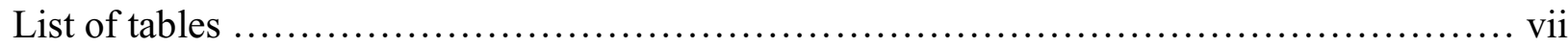

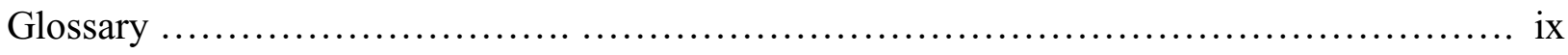

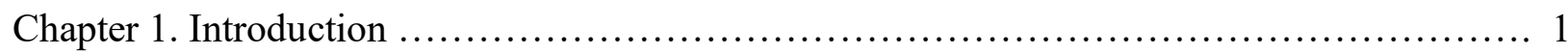

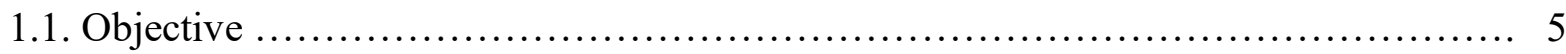

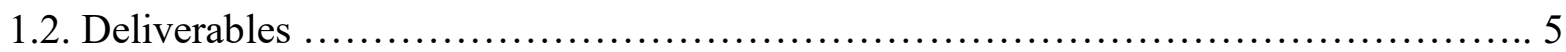

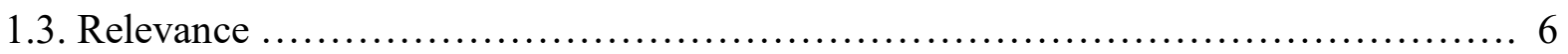

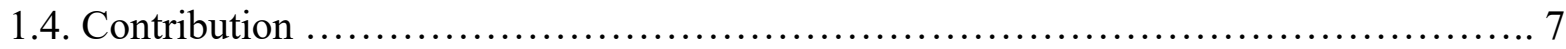

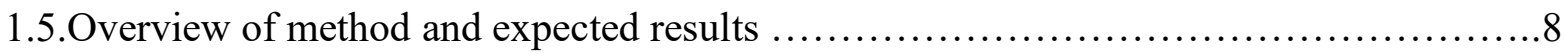

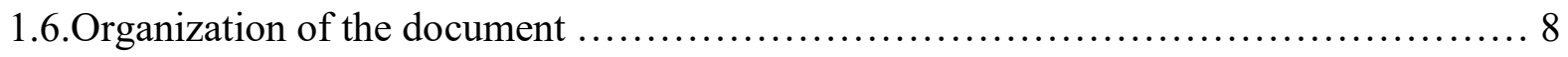

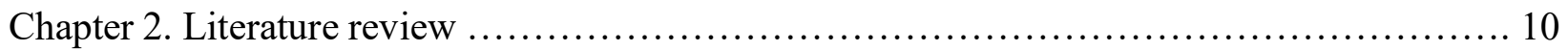

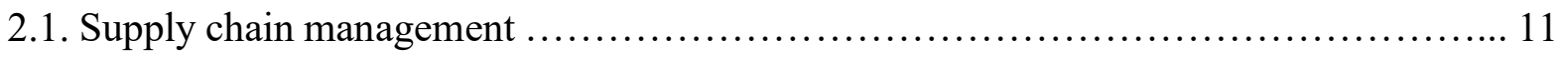

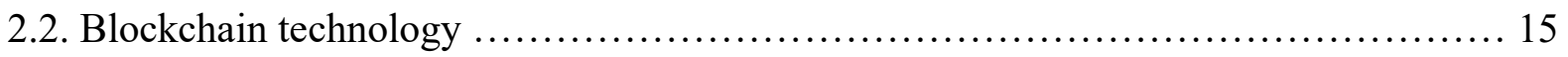

2.2.1. Technology introduction ............................................... 15

2.2.2. Blockchain versus other databases ......................................... 17

2.2.3. Blockchain application in supply chain management ....................... 18

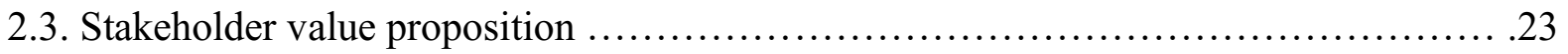

2.4. Blockchain qualities when applied in supply chain management ................... 28

2.4.1. Enhanced transparency in tracking and tracing .............................. 35

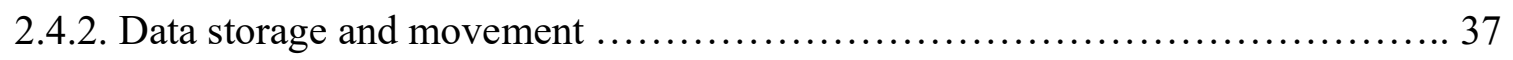

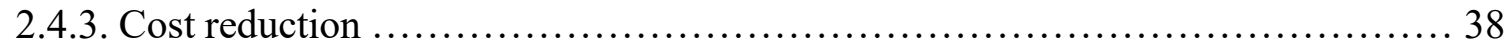




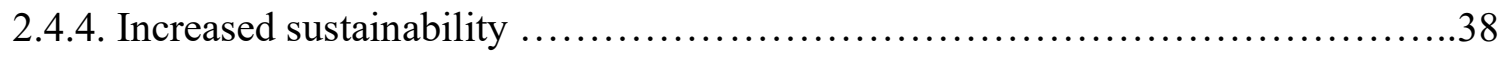

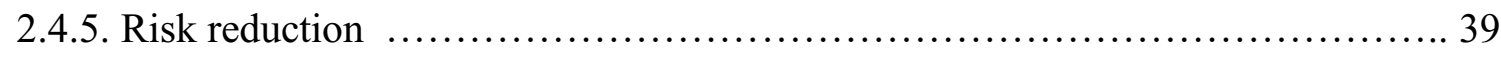

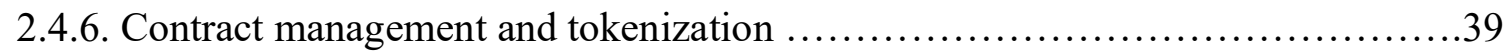

2.4.7. Creating new E-Market ....................................................... 39

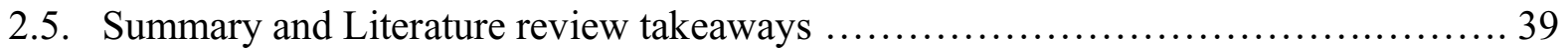

Chapter 3. Research Design and method ..............................................43

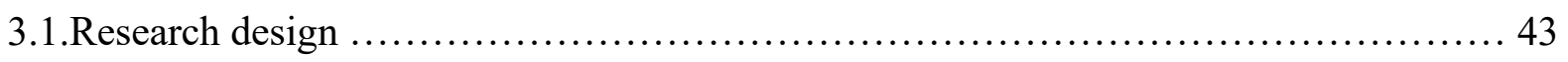

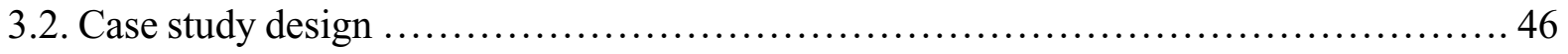

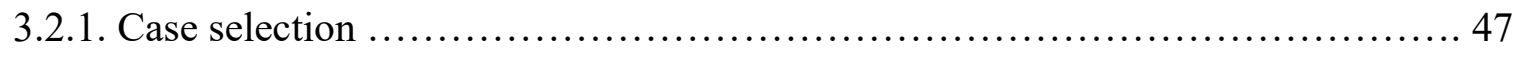

3.2.2. Stakeholder selection .................................................... 48

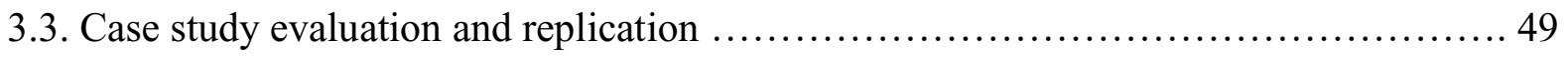

3.4. Data collection ............................................................ 49

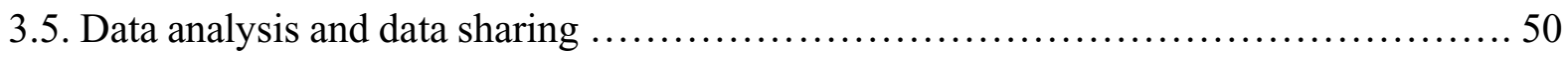

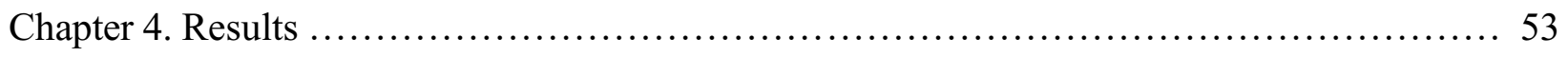

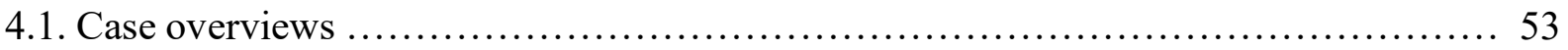

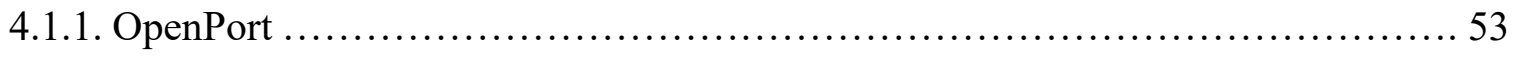

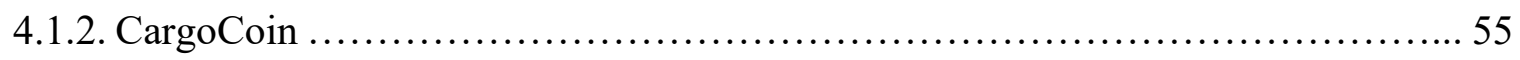

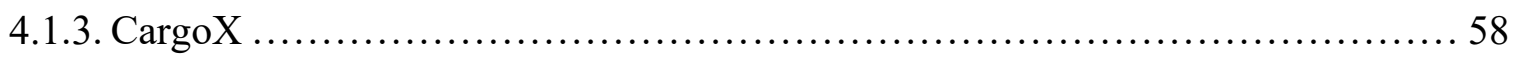

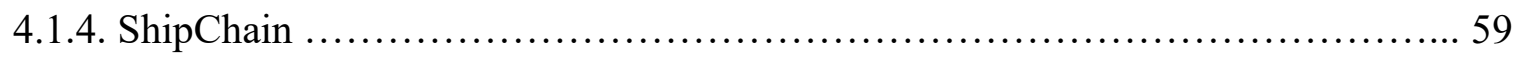

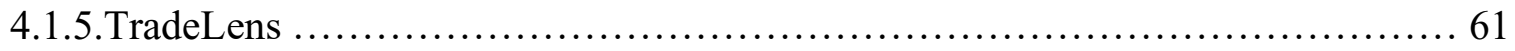

4.2. Problems identification and tokenization..................................... 62

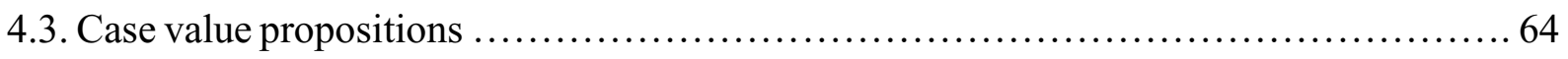

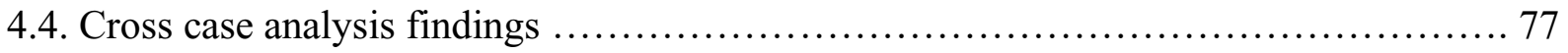


4.5. Guidelines

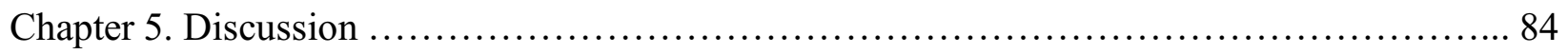

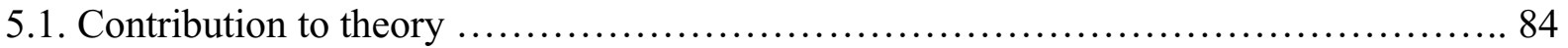

5.1.1. What blockchain qualities are used to create stakeholder value proposition in shipping

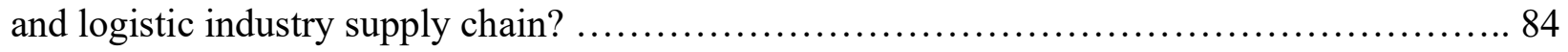

5.1.2 What are the steps in creating stakeholder value propositions? ................. 87

5.1.3 What are the blockchain enabling and restraining qualities when adopted in supply

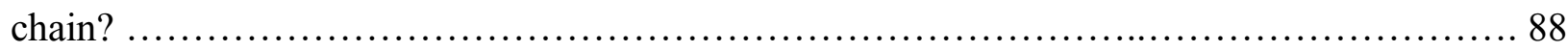

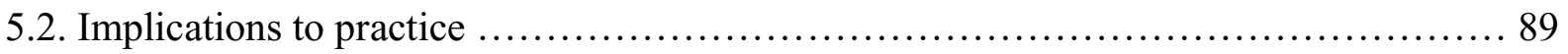

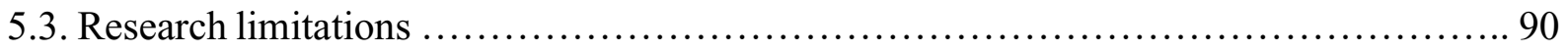

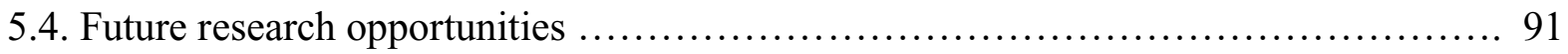

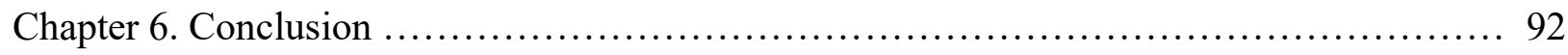

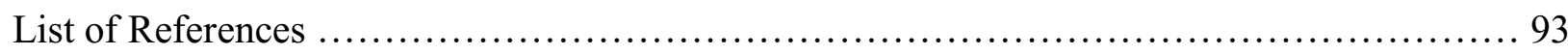

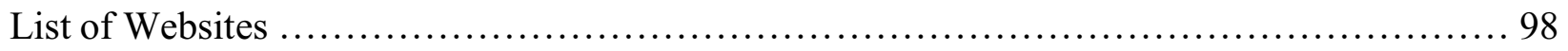

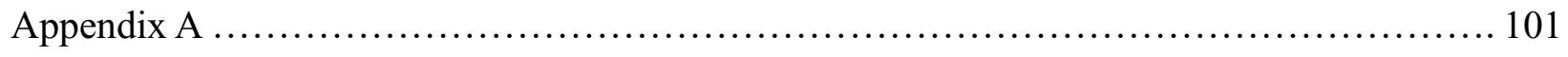

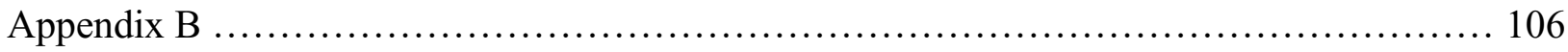

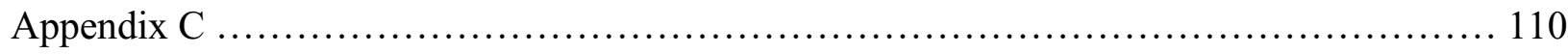

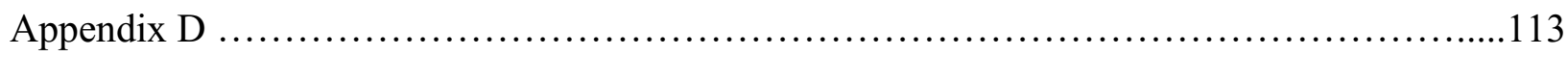

Appendix E ................................................................. 117 


\section{List of Tables}

Table I.I. Glossary of key terms and concepts .......................................... ix

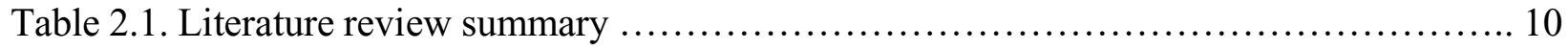

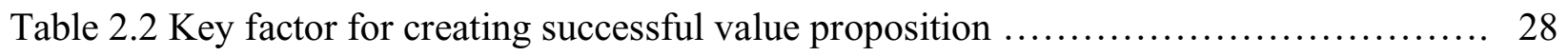

Table 2.3. Blockchain enabling and restraining qualities in supply chain management ......... 33

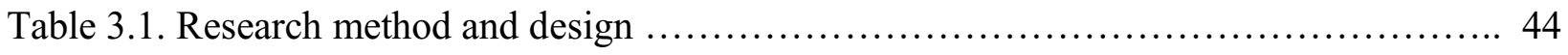

Table 3.2. Stakeholders identified by the cases .................................... 48

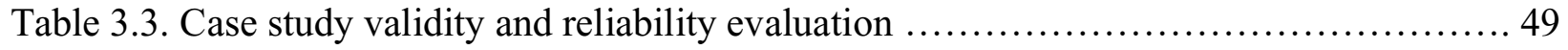

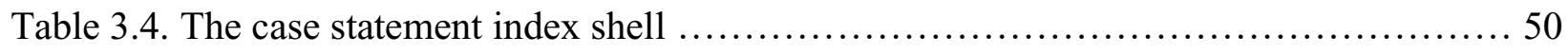

Table 3.5. Case value proposition shell f.............................................. 51

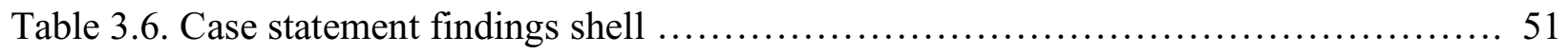

Table 3.7. Cross case general statement shell ...................................... 52

Table 3.8. Cross case stakeholder statement shell ....................................... 52

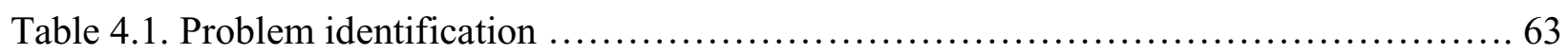

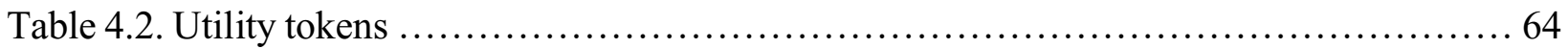

Table 4.3. OpenPort value Proposition .............................................. 65

Table 4.4. CargoCoin value propositions ........................................... 68

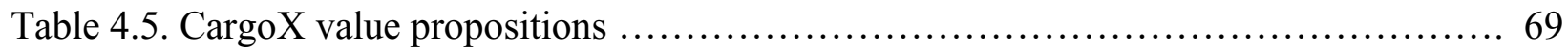

Table 4.6. ShipChain value proposition ............................................... 71

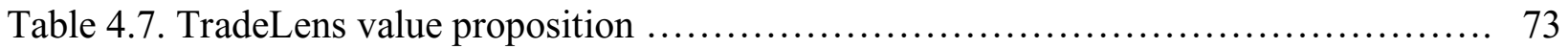

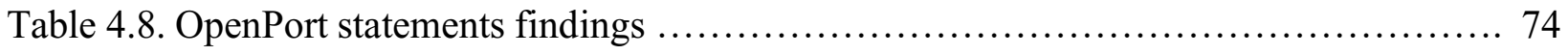

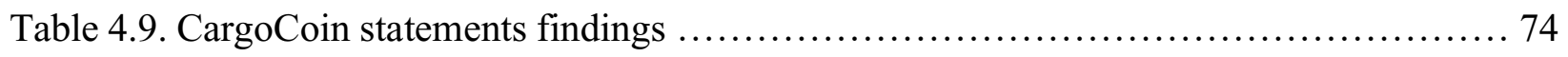

Table 4.10. Cargo X statements findings ............................................... 75 
Table 4.11. ShipChain statement findings

Table 4.12. TradeLens statements findings .......................................... 76

Table 4.13. General statements cross case analysis ..................................... 77

Table 4.14. Stakeholder cross case analysis ............................................ 78 


\section{Glossary}

Table I.I. Glossary of key concepts

\begin{tabular}{|l|l|l|}
\hline Concept & Definition & References \\
\hline $\begin{array}{l}\text { Supply chain } \\
\text { management } \\
\text { (SCM) }\end{array}$ & $\begin{array}{l}\text { Activities and steps taken by a network of stakeholders that } \\
\text { work together to bring value to customers in the form of } \\
\text { products and services. }\end{array}$ & $\begin{array}{l}\text { Kumar (2001); } \\
\text { Fiala (2005) }\end{array}$ \\
\hline Stakeholders & $\begin{array}{l}\text { Individuals and groups that may be effected by or effect an } \\
\text { organisation's achievements. }\end{array}$ & Freeman (1984) \\
\hline $\begin{array}{l}\text { Value } \\
\text { proposition }\end{array}$ & $\begin{array}{l}\text { Promises made by companies or organizations to their } \\
\text { customers to deliver specific values. }\end{array}$ & $\begin{array}{l}\text { Martinez \& } \\
\text { Bititci (2006) }\end{array}$ \\
\hline Business) & $\begin{array}{l}\text { Contains opportunity space, supply chain -related } \\
\text { companies and different levels of organizations, such as } \\
\text { industry associations, competitors, and policymakers. }\end{array}$ & $\begin{array}{l}\text { Rong \& Shi } \\
\text { (2014) }\end{array}$ \\
\hline $\begin{array}{l}\text { Blockchain } \\
\text { technology }\end{array}$ & $\begin{array}{l}\text { Immutable digital decentralized ledgers that store } \\
\text { transactions data on a chain of blocks where the data is } \\
\text { secured through hash and digital signature. }\end{array}$ & $\begin{array}{l}\text { Kamble et al. } \\
\text { (2019); Chang et } \\
\text { al. (2019) }\end{array}$ \\
\hline $\begin{array}{l}\text { Blockchain } \\
\text { qualities }\end{array}$ & $\begin{array}{l}\text { Positive and negative managerial effects of the blockchain } \\
\text { technology and its specific architectural properties, which } \\
\text { enable or restrain firms from achieving their goals when } \\
\text { blockchain technology is adopted in supply chain } \\
\text { management. }\end{array}$ & $\begin{array}{l}\text { Hald \& Kinra } \\
\text { (2019); Kshetri } \\
\text { (2018) }\end{array}$ \\
\hline
\end{tabular}


Introduction

\section{Chapter1. Introduction}

Supply chain management (SCM) refers to activities taken by a network of stakeholders such as manufacturers, retailers, freight forwarders, warehouse providers, transporters, insurance providers, and banks to deliver values (goods and services) to customers (Kumar, 2001; Fiala 2005; Hussain et al., 2016). Recently, SCM in industries such as shipping and logistic has increasingly been faced by many challenges and problems with the rapid expansion of volumes in trade beyond borders. Such problems include, e.g., lack of transparency, tracking and tracing issues, slow processes, inefficient communication and data sharing process, emergence of too many intermediaries, and high costs (Hussain et al., 2016; Konovalenko \& Ludwig, 2019).

The markets are changing due to the increasing globalization, and the varied market needs impact on the work of managers in supply chains (SC) (Hussain et al., 2016). The advancements in technologies, the emergence of e-commerce, and the need for environmentally responsible actions have put managers in the position to adopt technology to solve or overcome some of the challenges facing SC (Konovalenko \& Ludwig, 2019; Dobroszek, 2020; Yu et al., 2017; Esfahbodi et al., 2017). Indeed, using novel technologies may help managers in real time decision making and tracking products within the supply chain, while providing the data to other participants in the chain or the end customers (Konovalenko \& Ludwig, 2019; Hong et al., 2018). One of the technologies that is increasingly being applied to resolve these problems is the blockchain technology.

Blockchain is a decentralized immutable trust-less digital ledger. It is formed of blocks set after one another that are connected to each other through hash cryptography and digital signature (Pournader et al., 2019). The data and information regarding transactions are recorded in each block, hence making the data secure and immutable. This technology was first introduced through 
Introduction

cryptocurrency such as Bitcoin; however, it has also been adopted by companies in different industries for varied purposes - including the SCM - since its introduction (Pournader et al., 2019; Cole et al., 2019). It is argued that because this technology reduces and eliminates the risk of data manipulation and because it is a decentralized technology, it can help solve or overcome many persistent problems in SC, including eliminating the need for intermediaries, enabling tracking and tracing, and reducing transaction costs (Cole et al., 2019).

There is an emerging body of literature on blockchain adoption in SCM. Some of the previous studies focus on the values that blockchain can deliver to SC (Angelis \& Da Silva, 2019; Kshetri, 2018; Hald \& Kinra, 2019). Others focus on more specific topics; for instance, there are several studies around blockchain adoption and the enhancement of tracking and tracing (Chang et al., 2019). Yet others focus on the role of policies and integration of smart contracts with government regulations (Allen et al., 2019). Finally, there are also several articles providing summative literature reviews based on the recent research on blockchain adoption in SCM (Pournader et al., 2019; Queiroz et al., 2019).

Kshetri (2018) argues that blockchain technology plays a role in achieving SC goals by altering and enhancing one or more of critical supply factors such as cost, speed, dependability, risk reduction, sustainability, and flexibility. Angelis and Da Silva (2019) introduce four different stages of blockchain, arguing that each of them provides specific benefits and that organizations can adopt the technology at the stage they need. Further, there are value opportunities in areas such as transparency, immutability, privacy, durability, reliability, fault tolerance, democratization, security, risk control, and tokenization (Angelis \& Da Silva, 2019). On the other hand, Hald and Kinra (2019) discuss both enabling and restraining qualities of blockchain technology adoption in SCM. The enabling qualities can be summarized as data availability, immutability and consistency, 
Introduction

increased visibility and traceability, reduced errors and attacks, enhanced SC coordination, enhanced contract management and SC governance, and reduced structural complexities (Hald \& Kinra, 2019). The restraining qualities include the lack of privacy due to increased transparency, problems in integrating smart contracts with current legal systems, and updating smart contracts when they have been initiated (Hald \& Kinra, 2019).

While the extant studies cover sufficiently how blockchain can deliver value to SCM, they do not discuss how a company or an organization uses blockchain qualities to create value proposition for their stakeholders. There are no studies that would explain whether companies introduce blockchain qualities as value proposition to their stakeholders when this technology is adopted, and which blockchain qualities are used to create the stakeholder value proposition (SVP). The current study aims to fill this gap by studying if active companies in the shipping and logistic industry have created SVPs that are modified from blockchain qualities.

SVP is a relatively new topic that has received increased attention among scholars over recent years (Martinez \& Bititci, 2006; Payne et al., 2017; Frow \& Payne, 2011). SVP is a tool to convey how a company or an organization delivers specific values to their stakeholders, and, depending on the relationship that exists between stakeholders and organization, the process of creating and introducing the value proposition (VP) can become more complicated. Studies that have focused on the creation of SVP, argue that the identification of the stakeholders at an early stage is essential, mapping the SC and understanding the market and industry are key for creating strong SVPs (Martinez \& Bititci, 2006; Payne et al., 2017; Frow \& Payne, 2011).

Stakeholder is a vast concept that can be considered as individuals and groups that may be effected by or effect the achievements of organisations. This concept includes not only the economic concept of stakeholders but also the concepts of corporate social responsibility (CSR) 
Introduction

and environmental and social governance (ESG) (Freeman, 1984). However, for the purpose of this thesis, only the economic concept is studied and other concepts that cover social factors are not included within the scope of this thesis.

This thesis contributes to the field of blockchain technology by offering results from the analysis of five company cases in the shipping and logistic industry. The investigated companies have adopted blockchain technology to solve or overcome SCM challenges, thus providing us with insights on how novel technology can play a role in creating stakeholder value in supply chains. The value propositions offered by companies that relate to blockchain qualities are identified, and insights are delivered from a cross case analysis. In particular, the insights contribute to the blockchain quality concept by introducing the variety of qualities used in firms' SVP creation.

In this study, two types of blockchain qualities - enabling and restraining - are introduced after reviewing the extant literature on the matter. Further, seven enabling blockchain qualities and four restraining blockchain qualities are introduced (Angelis \& Da silva, 2019; Hald \& Kinra, 2019; Kshetri, 2018; Chang et al., 2019; Allen et al., 2019). The necessary steps that need to be taken by companies in creating successful SVPs are also identified (Martinez \& Bititci, 2006; Bailetti \& Tanev, 2020, Bailetti et al., 2020; Frow \& Payne, 2011; Frow et al., 2017).

A descriptive overview for each case is created. Then, an index is formed for each case company to show company statements and VP that relate to enabling blockchain qualities. The findings presented in the end of the study indicate that data storage and movement, contract management and tokenization, and tracking and tracing are enabling qualities that are used by companies operating in shipping and logistic industry to create SVPs for their blockchain based platforms. The insights from the study also suggest that companies not only use enabling 
Introduction

blockchain qualities to create SVP but also create VP by addressing restraining qualities such as reduced privacy for companies and high set up costs when blockchain is adopted in SC.

\subsection{Objective}

The objective of this research is to study blockchain qualities used by companies to create SVPs when blockchain is adopted in the shipping and logistic industry. A multiple case study approach was selected to guide the research, and the case data were gathered from company websites, white papers, news sites, and academic articles.

The following research question and two sub questions have been conducted to act as the guide in choosing the research methodology for this study.

Research question: What blockchain qualities are used to create stakeholder value propositions in shipping and logistic industry supply chains?

1. What are the steps in creating stakeholder value proposition?

2. What are the enabling and restraining blockchain qualities when adopted in supply chain management?

Using the multiple case study approach and by reviewing the literature on blockchain applications regarding SCM and SVP, the above questions have been answered in the discussion and conclusion of this thesis.

\subsection{Deliverables}

There are two main deliverables to this study. First, five cases - companies that have adopted blockchain technology in the shipping and logistic industry - are introduced. Second, a combination of insights from comparing the five company cases are provided. The cases include 
Introduction

descriptive overviews and an index of statements made by companies about blockchain qualities. The insights focus on the concept of blockchain qualities by identifying and introducing the enabling and restraining qualities used to create SVPs within these cases.

- Five company cases in shipping and logistic industry

- Synthesis of insights from comparing five company cases.

\subsection{Relevance}

The study and its findings are anticipated to be of significant value to the following three groups.

1. Scholars: It is argued that the most successful blockchain based platform is an end to end one in which all the actors within the chain are participants, and the first step in building a successful blockchain platform for a supply chain is to convince participants in the supply chain to join the platform (Tönnissen \& Teuteberg, 2019).

2. Top management teams: While it is important to find incentives for organizations to participate in, operationalizing stakeholder value propositions (SVPs) are more difficult than initially thought. Payne et al. (2017) argues that while the concept of SVP has been widely discussed and used, operationalizing SVP is a difficult task. To be able to provide accurate SVPs that will resonate with their stakeholders, organizations must consider the industry, market, and competitive environment (Payne et al., 2017).

3. Entrepreneurs: As blockchain is a decentralized ledger, many startups that integrate it in their businesses are not bound by state borders (Zalan, 2018), but rather are born global, and there is a growing number of startups that are using blockchain for different applications. 
Introduction

\subsection{Contribution}

This research provides several contributions to theory and practice. The study adds to the blockchain application in the field of SCM by examining the use of blockchain qualities in creating SVP in the shipping and logistic industry. Previous studies focus on the values that blockchain can deliver to SCM, as well as the enabling and restraining blockchain qualities when applied in SCM. However, there is a lack of research on how the blockchain qualities, both enabling and restraining, can be used to create SVP and incentivize stakeholders to contribute and participate on blockchain platforms. Since the survival of these platforms is contingent on stakeholder participation, there is a need to fill this gap and the current research provides the first step at filling this gap.

By evaluating how blockchain qualities are used to create companies' SVP, the research also contributes to the scholarly field interested in SVP. Of note, SVP is remarkably less studied compared to CVP, however in the recent years it has attracted the attention of scholars who have created steps and guidelines for successful SVP creation. The current study reviews the existing research and adds to it by providing empirical evidence of SVP creation and offers examples of companies that have used innovative solution to turn restraining blockchain qualities into SVPs.

Furthermore, the research contributes to theory and practice by introducing a guideline that joins blockchain qualities and SVP creation steps. This guideline can add to the fields of blockchain technology and SVP from the theory point of view and help practitioners in identifying and creating successful SVP when they adopt blockchain in SCM. The following provides a summary of research contributions in bullet point format.

- Identify the enabling and restraining blockchain qualities when adopted in supply chains.

- Identify the enabling qualities leveraged in creating SVPs. 
Introduction

- Provide insights for practitioners through cross-case analysis of real case value propositions against blockchain qualities.

- Introduce a new guideline for practitioners to help them in creating successful value propositions when adopting blockchain technology in supply chains.

\subsection{Overview of method and expected results}

This study begins by reviewing the current literature on stakeholder value propositions (SVP) and enabling and restraining qualities of blockchain technology. Then, five case companies are chosen based on set criteria, and two stakeholders are chosen as the focus of this study within these cases. For each case, a statement index is created based on the company's white papers that present their value propositions in the form of statement. The statement index is used to determine which enabling quality the statements are linked to and whether the statements are directed at specific stakeholders. In addition, there is a case overview conducted for each company based on different sources of information. The statements index is summarized, and the findings are presented in 5 different tables, one for each case. The statement indexes are also evaluated in a relative numerical count to show which enabling qualities are used more than the others in creating SVPs. These findings are presented in two cross-case analysis tables in the result chapter.

\subsection{Organization of the document}

This document is conducted in six chapters: introduction, literature review, research methodology, results, discussion, and conclusion. Each chapter includes several subsections, and the references and Appendix are placed in the end of the document. 
Introduction

The next chapter provides a review of articles on supply chain management, blockchain technology, blockchain applications in supply chain management, and stakeholder value propositions. Then, the methodology chapter explains the research methods chosen for this study, as well as the actions taken to answer the research questions. Thereafter, the chapter on results presents the findings from case overviews and statements indexes, and the chapter entitled discussion answers the research question, explains contributions to theory and practice, as well as provides research limitations, future research opportunities, and advice to practitioners. Finally, the study concludes by summarizing the key findings and notions about the research topic. 
Literature Review

\section{Chapter 2. Literature Review}

This chapter is conducted in five main sections. The first four sections review the utilized streams of literature. Table 2.1 introduces these literature streams, their key highlights and essential references. The four literature streams are: 1) Supply chain management, 2) Blockchain technology, 3) Stakeholder value proposition, and 4) Blockchain qualities when applied to supply chain management. The last section summarizes the key lessons and concludes this chapter.

Table 2.1. Literature review summary

\begin{tabular}{|c|c|c|c|}
\hline & Stream & Key highlights of the stream & Key references \\
\hline 1 & $\begin{array}{l}\text { Supply Chain } \\
\text { management }\end{array}$ & $\begin{array}{l}\text { Activities, plans, and initiatives that help supply } \\
\text { chains deliver goods and services to customers are } \\
\text { supply chain management. } \\
\text { - The success of individual firms is entangled with the } \\
\text { success of the supply chain. } \\
\text { - Change in market, globalization, and advances in } \\
\text { information and communication technologies (ICT) } \\
\text { is changing supply chain management. }\end{array}$ & $\begin{array}{l}\text { Kumar (2001); } \\
\text { Hussain et al. } \\
(2016) \text {; } \\
\text { Seth et al. } \\
(2006)\end{array}$ \\
\hline 2 & $\begin{array}{l}\text { Blockchain } \\
\text { Technology }\end{array}$ & $\begin{array}{l}\text { Blockchains are a form decentralized ledgers } \\
\text { introduced through Bitcoin cryptocurrency. } \\
\text { Blockchains store information on transactions on } \\
\text { blocks set after one another. } \\
\text { Blockchain is immutable and hence the chances for } \\
\text { manipulations are low. }\end{array}$ & $\begin{array}{l}\text { Pournader et al. } \\
(2019) \text {; } \\
\text { Cole et al. } \\
\text { (2019); Bedin et } \\
\text { al. (2021) }\end{array}$ \\
\hline 3 & $\begin{array}{l}\text { Stakeholder value } \\
\text { proposition }\end{array}$ & $\begin{array}{l}\text { Value propositions (VPs) are used to explain how } \\
\text { value is delivered to customers. } \\
\text { - There are arguments that the best stakeholder value } \\
\text { propositions (SVPs) are born out of co-creation. } \\
\text { There are five main steps taken to create successful } \\
\text { SVPs. } \\
\text { Mapping the supply chain, identifying the } \\
\text { stakeholder, and researching the market are some of } \\
\text { these steps. }\end{array}$ & $\begin{array}{l}\text { Martinez \& } \\
\text { Bititci (2006); } \\
\text { Bailetti et al. } \\
\text { (2020); } \\
\text { Rodriguez et al. } \\
\text { (2018); } \\
\text { Payne et al. } \\
\text { (2017) }\end{array}$ \\
\hline 4 & $\begin{array}{l}\text { Blockchain qualities } \\
\text { when applied in } \\
\text { supply chain } \\
\text { management }\end{array}$ & $\begin{array}{l}\text { Many believe the blockchain technology can } \\
\text { transform supply chain management by facilitating a } \\
\text { paperless information transfer. } \\
\text { Different stages of blockchain deliver different } \\
\text { values. } \\
\text { Blockchain will help supply chain management meet } \\
\text { certain objectives such as cost reduction, } \\
\text { transparency, facilitating communication and } \\
\text { increasing speed. }\end{array}$ & $\begin{array}{l}\text { Allen et al. } \\
\text { (2019); Queiroz } \\
\text { et al. (2019); } \\
\text { Saberi et al. } \\
\text { (2018); Yang } \\
\text { (2019); Hald \& } \\
\text { Kinra (2019) }\end{array}$ \\
\hline
\end{tabular}


Literature Review

\subsection{Supply chain management}

Kumar (2001) explains supply chain management (SCM) as delivering goods and services to customers and arguing that delivering goods or services is delivering value to customers. Therefore, Kumar (2001) defines supply chain as different organizations working together to bring these values (goods and services) to the customer. In the context of the shipping and logistic industry, a network of organizations including manufacturers, retailers, transportation and logistics firms, banks, insurance services, warehouse and freight services, and suppliers work together directly or indirectly to bring value to customers (Kumar, 2001; Fiala, 2005).

Delivering the goods and services to the customer does not mean that the goals of the supply chain have been achieved. Part of the value brought to customers are the help desk, maintenance, and recycling activities (Kumar, 2001). Therefore, the efficiency of the SC to great extend effects how successful individual firms are, as individual firms are part of the network of organizations that form the supply chains. SCM therefore, is all activities, programs and initiatives that help the supply chain deliver the right goods and services, through the right channels, with the right costs, to the right customer in the right time (Hussain et al., 2016; Kumar, 2001).

There are at least three reasons for the need to manage supply chains efficiently. First, the expansion of markets across borders has resulted in the creation of large and complex supply chains (Kumar, 2001). Second, the customer is demanding more value from the supply chain in varied and often individualized forms, including low costs. And third, the advancements of modern information and communication technologies (ICT) make it possible to have an overview of the entire supply chain and reduce costs. Furthermore, the varied and high demand, high costs, uncertainty, distances, and time lags make it even more important to manage the SCs effectively 
Literature Review

and efficiently. Kumar (2001) argues that the appropriate use of ICT can create a balance of value advantage and cost advantage and enhance the efficiency of the supply chain.

It is also important to note that the global market has created an environment where the real competitive advantage of the firms lies not only with an individual organization but in the network of actors and organizations, where the firm is a part of (Seth et al., 2006; Huemer, 2012). Therefore, it is not only individual organizations that compete against each other, but rather supply chains competing against each other, and hence it is very important that the supply chain is well managed (Seth et al., 2006). Seth et al. (2006) also argue that in the era of increasing globalization, outsourcing takes place through global supply networks, and the relationships between third-party logistics firms and the supply chain are highly important.

Supply chain management is a process of connecting different stakeholders that help get a product to the end consumer. Activities in the SCM include transfer of the goods and services, knowledge and information sharing between stakeholders, money transfer, and even customer service (Hussain et al., 2016). There is an interest in efforts to help SCs become sustainable. In the matter of sustainability, SCs are divided into two groups: 1) product-based supply chains, where goods and products are produced and transferred to the end consumer, and 2) service supply chains. In product-based supply chains the focus is on reducing the byproducts, waste, and pollution along the product life cycle, while in service-based supply chains the focus is on corporate green policies, social and environmental impacts (Hussain et al., 2016). Of note, product-based and service-based SCs overlap when it comes to sustainability, since many services are offered along products and activities. For example, recycling is adopted by many organizations and their supply chains, regardless of whether they are product-based or service-based (Hussain et al., 2016). 


\section{Literature Review}

With the adoption of SCM, logistics and transportation have become an integral part of the product for many companies, enabling them to outsource some activities and choose the logistic partners they want to establish long term relationship with (Evangelista \& Sweeney, 2006). Hence, the logistic organizations that play a key role in the movement of products and information are looking for ways in which they can offer transparent services in real time. This is the reason the use of ICT has seen a rapid increase in the SCM (Evangelista \& Sweeney, 2006). However, it is argued that in leveraging ICT to enhance performance in logistics, large and medium size corporations have been more successful in comparison to small size entities (Evangelista \& Sweeney, 2006).

One of the challenges of the modern supply chain systems are the existence of different stakeholders with different legal or reward systems; hence, it can be a challenge to find a process in which stakeholders can all work and cooperate with one another and receive their desired benefits as well (Ballou et al., 2000). The cooperation of different stakeholders along the supply chain can lead to information asymmetry and create information flow problems (Van Donk, 2008), Therefore, it is argued that supply chain partnerships and the use of information technologies simultaneously can resolve the information flow problem, and enable shorter lead times (Fiala, 2005; Zhang et al., 2011).

Another challenge that SCs face frequently comes from the volatile marketplace. Demand in today's market is more difficult to predict, as product life cycles have shortened, resulting in more turbulent market and increased uncertainty in SCs (Christopher \& Lee, 2004). Increasing speed, reducing costs, addressing the silos within organizations that lead to information asymmetry, establishing trust that will last after the initial people in partner organizations have 
Literature Review

moved on, and tracking and tracing products through the supply chain are only a few of the many challenges faced in SCM (Beth et al., 2003).

The advancements in technology are constantly changing SCM practices and activities, forcing managers to adopt new technological solutions to gain competitive advantage (Konovalenko \& Ludwig, 2019). Using new technologies enables stakeholders of real-time decision making and business process management. New technologies are providing the possibility of real-time tracking of the products in supply chains and providing such data to the customer efficiently in real time (Konovalenko \& Ludwig, 2019).

Globalization and corporate social responsibility are other factors driving managers toward change and advancement as well as adoption of new technologies. The needs of the market and its numerous participants change the needs in the SC constantly, forcing managers to plan and take new approaches of doing things (Dobroszek, 2020). Another factor influencing the SC and logistics is the emergence and advancements in E-Commerce which consists of business to customer (B2C) and business to business (B2B operations (Yu et al., 2017).

$\mathrm{SC}$ is often used as a tool to control costs and achieve economical advancement by managers; however, the recent interest in environmental issues and concerns about firm transparency are forcing managers to look beyond economical achievements and change their processes, business models, and SC to become more environmentally responsible (Hong et al., 2018). Many world leaders have already started taking steps to achieve this goal. For instance, companies such as Unilever and Apple aim to buy from socially and environmentally responsible suppliers (Hong et al., 2018). The governments also set policies forcing firms to adopt sustainable processes and procedures, which may reduce the economic achievements of the companies. Firms 
Literature Review

have to change their activities just to comply with sustainability regulations, which magnifies the importance of adopting technologies to gain competitive advantage (Esfahbodi et al., 2017).

\subsection{Blockchain Technology}

This section includes three subsections. The first subsection introduces the blockchain technology. The second subsection discusses the differences between blockchain and other databases. The third subsection explains blockchain application in supply chain management.

\subsubsection{Technology introduction}

Blockchain technology was introduced to the world through the launch of Bitcoin and is also associated with other cryptocurrencies, including Ethereum and Ripple. However, blockchain technology can exist independent of cryptocurrency and be applied in different fields (Pournader et al., 2019). Blockchains are digital, decentralized ledgers that store data and transactions in trustless environments. Transactions are recorded in blocks that are set one after another and each block is connected to the previous block through hash cryptography and digital signatures. Transactions in blockchain are verified through nodes attached to each block, hence removing the need for intermediaries. Blockchain users are given a public and a private key that will help create a digital signature that cannot be forged (Pournader et al., 2019; Chang et al., 2019; Casado-Vera et al., 2018; Kamble et al., 2019).

The nature of blockchain technology makes it decentralized, immutable, transparent, and secure (Pournader et al., 2019). The technology also offers opportunities for the use of smart contracts and tokenization of assets. Smart contracts are protocols that are set to introduce an agreement between two parties in blockchain, and when executed, they can assure that the 
Literature Review

conditions of the agreement are met and transfers of goods and currency can also be automated (Pournader et al., 2019).

In blockchains, data can be updated in real time, removing the challenges and barriers of errors that can occur within each organization. Hence, each party and stakeholder have greater visibility into the activities of the network (Cole et al., 2019). Blockchains can also be a source of Big Data, and for this reason and other characteristics associated with it, blockchain technology has attracted the attention of supply chain managers and academics (Cole et al., 2019).

Blockchains can be public or private, also known as permissionless and permissioned. Private blockchains have restrictions on membership and not everyone can join the network, while the public blockchains are accessible by everyone (Cole et al., 2019). One challenge with public blockchains is maintaining the large-scale distributed ledger. Each node in the network must complete a cryptographic problem called Proof of Work (PoW) to achieve consensus (Cole et al., 2019). Meanwhile, in private blockchains participants must have invitation and be granted access to the network. Supply chains usually use this type of blockchains (Cole et al., 2019).

It is argued that permissioned blockchains can create collaboration between different business partners, thus leading to tighter business bonds (Bedin et al., 2021). Blockchain is known for its security and immutability, since the adoption of smart contracts and advancements made to this technology, but recently there have been signs of security breaches and vulnerabilities in different blockchains. A study by Li et al. (2020) evaluated the security and privacy risks, as well as vulnerabilities in the Ethereum blockchain, and suggested that future studies on the matter should urgently take place, focusing on security problems created in blockchain through the introduction of smart contracts. 
Literature Review

Cahill et al. (2020) focused on the market reaction to the companies that adopt blockchain, and noticed an immediate rise in returns after firms announced the adoption of blockchain technology, with the return rates picking at 2016 and 2017 and declining after 2018. The study finds a link between blockchain and bitcoin and how well the market reacts when companies announce the adoption of blockchain when bitcoin is doing well (Cahill et al., 2020). Cahill et al. (2020) further argue that many companies use blockchain technology for rent seeking purposes, especially those that announce the adoption of blockchain technology when bitcoin is experiencing a good market. It is therefore imperative that more research be conducted in the adoption of blockchain and the advancements made to the technology.

\subsubsection{Blockchain versus other databases}

While blockchain is a type of database, it differs from relational databases in a few areas. The independent execution of smart contract in blockchains by peers needs to be deterministic, while this is not true for similar functions in relational databases (Nathan et al., 2019). Transactions in the blockchain are signed by the creator of the transaction, making them non-repudiable, and there is a user management system in place for permissioned blockchains (Nathan et al., 2019). While relational databases also have user management systems, transactions are not signed by the invoker. Blockchains are immutable ledgers that record transactions in blocks that include a hash of the previous block, making it impossible to change and alter the data in each block. Conversely, it is often not possible to detect changes made to the relational databases and they are not immutable (Nathan et al., 2019).

In addition to the immutability factor, because of the decentralized consensus mechanism where participating nodes validate transactions, the need for a third party to validate transactions is eliminated where in most traditional databases the need for this party still exists (Chowdhury et 
Literature Review

al., 2018). Because of the decentralized mechanism blockchains also have higher fault tolerance than other databases; in particular, if one node cannot function, another will replace it (Chowdhury et al., 2018). However, this also means that the higher the number of the participants in the blockchain, the higher the security level of the blockchain will be. In blockchains a transaction will be accepted as valid of 51 percent of the nodes deem it as valid. This means that if 51 percent of nodes in the blockchain are under malicious control, an invalid transaction can become a valid transaction (Chowdhury et al., 2018).

In summary, a few properties differentiate blockchains from alternative databases. The most important factors and properties that are the focus of this thesis, are as follows: First, blockchains are immutable, meaning they cannot be altered and have high resistance toward security risks. If a mistake is made in a transaction in blockchain, the transaction cannot be fixed or altered but a new correction transaction can be issued. Second, the transactions are signed by the invoker or issuer of the transaction. Third, the decentralised nature of blockchains eliminates the need for intermediaries and third parties (Chowdhury et al., 2018; Nathan et al., 2019). While these are not the only factors that differentiate blockchains from other databases, for the purpose of this study they are the emphasised.

\subsubsection{Blockchain applications in supply chain management}

Blockchain technology, Internet of Things (IoT), and artificial intelligence (AI) are predicted to transform supply chains, logistics and transportation by 2023 (Pournader et al., 2019). Pournader et al. (2019) reviewed previous literature on blockchain applications in supply chain management and introduced four distinct literature streams, arguing that all the published work in this field can be categorized into those streams. These four streams are 1) technology, 2) trust, 3) trade and 4) traceability/transparency (Pournader et al., 2019). 


\section{Literature Review}

The first stream ("technology") focuses on the use of hardware technologies such as IoTs, RFID, and their use in maximizing the benefits that blockchain will deliver to SCM. These hardware help deliver and feed data to supply chains; however, the resources surrounding their integration and implementation are scarce (Pournader et al., 2019). The second stream ("trust") studies the need of information sharing between SC partners and how blockchain can assist in sharing the right and accurate information in a timely manner (Pournader et al., 2019). The third stream ("trade") highlights that through facilitation of payments using cryptocurrency and smart contracts - which help with product transfer and contractual agreements - blockchain technology can have a great impact on trade (Pournader et al., 2019). Finally, the fourth stream ("traceability/transparency") argues that tracking and tracing the products through the value chain is one of the most important topics and such efforts have several practical implications, ranging from being able to track faulty products back to their origin in real time, to avoiding higher costs and helping to provide proof for contractual obligations (Pournader et al., 2019).

Many believe that blockchain can transform supply chains that involve different actors in varies countries, facilitating a paperless transfer of information across borders in trade. It is reported that the APEC region is likely to benefit from a great reduction in information costs using blockchain technology in supply chain management (Allen et al., 2019). For instance, the Korean company Samsung is already using blockchain system to transport 488,000 tons of air cargo and over a million shipping containers each year. However, there is a need for governments to adapt to blockchains, setting the proper policies and regulation, and recognizing the new technology. (Allen et al., 2019). Of note, the success of blockchain applications is rare; of 26,000 blockchain projects started in 2016, only 8\% were still active in 2017 (Schmidt, \& Wagner, 2019). 
Literature Review

Blockchain is a technology that will enhance transparency and the real time transaction in supply chains that have varied actors and are not just operated by one company. There are a few challenges associated with the adoption of blockchains in the SCM domain, including the lack of an organized ecosystem and platforms to enable the entire supply chain to adopt the blockchain technology. There are also unaddressed problems regarding know-how of the technology and data governance, as well as privacy policies that need to be resolved (Kamble et al., 2019).

Due to decentralization qualities in blockchain technology, the need for intermediaries can be eliminated. Smart contracts are a feature in blockchain technology, which can transfer assets once a predetermined condition is met. This feature can transform the supply chain management industry and create an environment where producer and consumer can engage in transactions without the need for an intermediary (Queiroz et al., 2019).

Challenges around blockchain applications are often wrapped around the uncertainties regarding the new technology, scalability problems, and development costs. However, it is argued that blockchain can face a similar path to internet, ultimately becoming a major base technology used anywhere and everywhere in our daily lives. Similar to the internet bubble in 2000, blockchain technology may experience a setback; however, blockchain can still revolutionize many industrial fields, including SCM, its relations and structure (Schmidt \& Wagner, 2019).

It is argued that since blockchain is an expensive technology that needs expertise to be adopted, it should only be used when necessary. In situations where the products' safety and quality are critical, or when there is possibility of counterfeiting and product recalls, taking place in, for example, pharmaceutical and food industries, adopting blockchain technology is justified (Cole et al., 2019). Another justifiable use of blockchain is where the supply chain is global with an extended network and many stakeholders. Also, in industries where social sustainability is an 
Literature Review

issue and can damage the organizational reputation, such as the fashion industry, blockchain can provide visibility through the chain and bring transparency (Cole et al., 2019).

Four main streams of barrier for blockchain adoption in SCM has been identified by Saberi et al. (2018). These four streams are: 1) intra-organizational barriers, 2) inter-organizational barriers, 3) system related barriers, and 4) external barriers; it is argued that they not only affect the relationship between supply chain partners, but also their employees and their stakeholders (Saberi et al., 2018).

Financial constraints, lack of management commitment and support, lack of internal policies, lack of knowledge and expertise, difficulty in changing the organizational culture, hesitation to convert to the new system, and lack of tools for implementing the blockchain technology have been identified as major intra-organizational barriers (Saberi et al., 2018). Interorganizational barriers include lack of customer awareness, problems in collaboration and information disclosure policies, challenges in integrating sustainable practices through SCM, and cultural differences of supply chain partners (Saberi et al., 2018). System related barriers can be introduced as security challenges, access to technology, negative public perception of blockchain adoption, immutability, and immaturity of blockchain technology (Saberi et al., 2018). Finally, lack of governmental policies, market competition, uncertainty, lack of external stakeholder's involvement, lack of industry involvement in ethical and safe practices, and lack of rewards and encouragement programs are considered the external barriers for blockchain adoption in SCM (Saberi et al., 2018).

There are many incentives and motivations for companies to adopt blockchain technology (Saberi et al., 2019). After studying 137 companies that include both SMEs and large corporations, most of which are privately owned, Saberi et al. (2019), found that these incentives include the 


\section{Literature Review}

need for collaborations with supply chain partners, customer and market pressures, need for information security, reducing operation costs and possible traceability (Saberi et al., 2019). Overall, the most important drivers and motivations for adopting blockchain are reducing costs of operation and enhancing collaboration between supply chain partners (Saberi et al., 2019).

Shipping provides low cost-efficient transportation services; however, maritime shipping involves complex processes and includes different stakeholders across a vast network. Stakeholders deal with different documentation that can halter the product transportation and service delivery (Yang, 2019). Adopting blockchain in this field reduces the high costs and shapes the global trade and benefits stakeholders such as shipping companies, port operations, freight forwarders, shipping agencies, and other operators. It is argued that companies should start the use of this technology before the competitive advantage is fallen into the hands of their competitors (Yang, 2019). Factors such as customs clearance and management, digitalizing paperwork, tracking and tracing, standardization and platform development, business model, and regulations can affect the desire to use blockchain. For instance, offering facilitation in customs clearance is a great incentive to adopt the technology. The technology can also affect cross border trade security and safety (Yang, 2019).

Smart logistics have emerged after the use of technologies such as IoT, AI and cloud computing has increased in logistics industry. There are incentives for the use of blockchain technology in smart logistics (Issaoui et al., 2019). These incentives can be categorized into four groups, namely 1) information, 2) transport, 3) finance, and 4) management. Information sharing is a priority in logistics, and adopting blockchain can facilitate internal and external communication for organization, collecting and generating dependable data for forecasting and classifying feedback (Issaoui et al., 2019). Adopting blockchain in transport can increase 
Literature Review

sustainability within the supply network and from a social standpoint, reduce fraud and paperwork delays and locate problems in a timely manner (Issaoui et al., 2019). Finalizing payments and transactions in the absence of intermediaries ("finance") and improving the process and enhancing the data which will enable managers to make better decisions on time ("management") are the other incentives for using blockchain technology in smart logistics (Issaoui et al., 2019).

\subsection{Stakeholder value proposition}

Stakeholders can be seen as "individuals and groups that effect or can be effected by an organization's achievements" (Freeman, 1984). This definition includes both economic and social actors, and the stakeholder concept can be studied from not only the economic and monetary viewpoint, but also from the corporate social responsibility (CSR) and environmental and social governance (ESG) viewpoints, in which the actors do not have a direct monetary or economical gain (Freeman, 1984). In the contest of this study, stakeholders are examined merely from an economic point of view and the scope of this thesis does not include the social aspect of the stakeholder concept.

Value proposition is introduced as a promise made by a company or organization to deliver certain values. Often the value proposition is the idea of value creation for both the customer and supplier which is achieved through collaboration between different stakeholders in the supply chain. Value proposition and the manners in which they impact markets, stakeholder relationship, market research, and new product development, have attracted the interest of both practitioners and scholarly researchers (Martinez \& Bititci, 2006).

Value proposition research focuses on well established companies and assume that these companies have a customer base, distribution channels, market knowledge and established relationships and networks. It does not consider the new companies that lack the access to these 


\section{Literature Review}

assets and whose majority of assets are in the form of external investors, yet they have potential and business plan for rapid growth or scaling (Bailetti et al., 2020). In addition to not having many assets and capital to rely on, new companies need to convince different stakeholders, with different needs and objectives that the value proposition the company offers will benefit them in a certain amount of time (Bailetti et al., 2020).

Bailetti et al. (2020) argue that the successful delivery and improvement of the value proposition to stakeholders can determine whether a company can become an actual functioning business or remain a mere opportunity. Therefore, the group of value propositions developed by the company for their different stakeholders is one of the most important assets of a company (Bailetti et al., 2020). These value propositions - while developed for different stakeholders that have varies needs and objectives - must be aligned to meet the ultimate objectives of the company (Bailetti et al., 2020; Martinez \& Bititci, 2006).

Bailetti et al. (2020) attribute two distinct features to value propositions that new companies develop for different stakeholders. These value propositions anchor business transactions between the company and stakeholders without the need for intermediaries, and they attract investments to create and develop value propositions. Well developed and well executed value propositions can have three benefits for new companies. They enable the company to scale more easily, increase the demand for increase the demand for company products and services, and increase the external stakeholder investments in company value proposition (Bailetti et al., 2020).

Unlike customer value proposition (CVP), stakeholder value proposition (SVP) has not received the necessary attention in the literature and the topic has been neglected. However, there are studies, including that of Rodriguez et al. (2018) who, through a case study, examined the value propositions for stakeholder within the software engineering industry. It is evident that to 
Literature Review

understand and study SVP, one must focus on the industry, and identify the stakeholders first (Rodriguez et al., 2018).

Frow and Payne (2011) studied value proposition from stakeholder point of view and introduced certain values, such as price, that they believe stakeholders deem important and pay attention to specially in service industries (Frow \& Payne, 2011). It is argued that the organizations with other businesses as their customers have a difficult time selling their products considering that the customer seeks the most value with the least price. So, how to persuade them to buy a certain product, for a higher price? The answer is to create and offer a value proposition by researching the customers operations and understanding their requirements, and then persuade them by arguing that the firm's product will deliver the value most important to the customer (Anderson et al., 2006).

It is noteworthy to mention that, if the customer is another business or a corporation, the incentive must offer a targeted specific value that will resonate with the stakeholder. Payne et al. (2017) argue that a supplier firm must acquire skills required to deliver specific targeted value propositions, and that acquiring these skills may be costly. Not to mention that there is a confusion as where in the organization the responsibility of identifying the VPs lies. Payne et al. (2017), therefore suggest that both top management, middle management and marketing must participate in finding the right value propositions.

Further, Payne et al. (2017) argue that while the concept of value proposition has been widely discussed and used, operationalizing VP is a difficult task. To be able to provide accurate VPs that will resonate with their stakeholders, organizations must consider the industry, market, and competitive environment (Payne et al., 2017). Managers should also be familiar with different 
Literature Review

perspectives on VPs and decide which perspective is relevant to them, their products, and their stakeholders (Payne et al., 2017).

In introducing the concept of value-based selling (VBS), Töytäri and Rajala (2015) focus on the role of value in B2B operations. In the VBS concept, early engagement with the stakeholder is encouraged to achieve an influence over stakeholder's perceptions of the potential value of a relationship, and expand on a shared value concept and commit to the shared value until both parties receive the desired value (Töytäri, \& Rajala, 2015). While the focus of value proposition concept lies within an exchange where a service or a product is offered for a price, there is an argument that in service industry this exchange system might not be effective and hence, the concept of value co-creation is introduced (Vargo et al., 2008). In this context, it is suggested that participants, share, access, and integrate their resources to create value (Vargo et al., 2008).

According to Martinez and Bititci (2006), the core competencies of the supply chain management is held by the key or strategic stakeholders in supply chain and the value proposition of these key stakeholders should be aligned to enhance the value proposition of the entire chain. Non-key members of the supply chain, while can have different value proposition, should support the overall value proposition of the supply chain (Martinez \& Bititci, 2006).

Martinez and Bititci (2006) created a six-part value proposition matrix. This matrix includes innovators' brand managers, price minimizers, simplifiers, technological integrators, and socializers. Each general value is studied from two sides: 1) what will customers get and 2) what will the companies have to focus on to deliver this certain value. This matrix can be used in the tool kit introduced by Martinez and Bititci (2006), called the "value chain tool kit", where seven steps are taken to determine the value creation process in the supply chain. In this tool kit, first the supply chain is mapped, then the current competencies and capabilities and the value proposition 
Literature Review

of each stakeholder are identified. Thereafter, the value propositions of the stakeholders are studied against the value proposition matrix to help identify the misalignments and gaps in competencies, and then, in the final step, a road map is created to minimize the problems and gaps in alignment (Martinez \& Bititci, 2006).

Bailetti and Tanev (2020) argue that the actions that new companies take to scale rapidly can be divided into six topics: 1) fundraising (arrange returns to investors' capital with scaling opportunity), 2) enabling (making others successful), 3) positioning (strengthen the position of the company within the its network), 4) communicating (eliminating communication barriers), 5) innovating (delivering innovative products and services), and 6) complementing (align benefits to customers, resource owners and other key stakeholders). Bailetti and Tanev (2020) studied value proposition assertions found in the SERS community; after running topic modeling they identified 11 assertions that are connected to the six actions or "initiatives", and found that the majority of those assertions are connected to innovating and complementing.

It is argued that in identifying and developing value propositions where the customer is a business (i.e., B2B context), the focus should be on collaboration between the different parties, and that the value proposition in these instances is created from the collaboration (Eggert et al., 2018). While Wouters et al. (2018) support this argument, they also argue that a new company should provide at least two value propositions for its business customers. One value proposition should convey the typical innovative solution and the other should communicate what the other party will gain in return for providing support and resources (Wouters et al., 2018). 
Literature Review

Table 2.2. Key factors for creating successful stakeholder value proposition

\begin{tabular}{|c|l|c|}
\hline & Factors in creating stakeholder value proposition & Adopted from \\
\hline 1 & $\begin{array}{l}\text { Researching the customer operation and \& understanding their } \\
\text { requirements will help create a stronger VP }\end{array}$ & Anderson et al. (2006) \\
\hline 2 & $\begin{array}{l}\text { To create value proposition, companies must consider industry, } \\
\text { market, and competitive environment } \\
\text { To create powerful VP in supply chain industry, the supply chain } \\
\text { must be mapped, and the competencies and capabilities of key } \\
\text { stakeholders must be identified }\end{array}$ & Payne et al. (2017) \\
\hline 4 & $\begin{array}{l}\text { Where the customer is another business, strong VPs can be } \\
\text { created from collaboration between the parties involved including } \\
\text { the customer }\end{array}$ & Eggert et al. (2018) \\
\hline 5 & $\begin{array}{l}\text { Early engagement with the customer is key for developing a } \\
\text { successful value proposition }\end{array}$ & Töytäri \& Rajala (2015) \\
\hline 6 & $\begin{array}{l}\text { Identifying the stakeholder is necessary when developing value } \\
\text { proposition within a supply chain }\end{array}$ & Rodriguez et al. (2018) \\
\hline 7 & $\begin{array}{l}\text { For value proposition to resonate with the customer it must } \\
\text { convey targeted specific value }\end{array}$ & Payne et al. (2017) \\
\hline 8 & $\begin{array}{l}\text { creating a minimum of two value propositions is necessary when } \\
\text { the customer is another business. One VP must convey the } \\
\text { innovative solution and the second must convey what the customer } \\
\text { will gain for their collaboration }\end{array}$ & Wouters et al. (2018) \\
\hline
\end{tabular}

Table 2.2 shows the key factors and takeaways from the literature (along with supportive literature references) that companies must take into consideration when creating and developing their stakeholder value proposition. Two of the eight points in the above table 2.2 give insights into creating value propositions within supply chain. These key findings indicate that for a successful value proposition creation in a supply chain, first the supply chain must be mapped; second, the key stakeholders must be identified; and third, the key competencies and capabilities of the stakeholders must be identified (Martinez \& Bititci, 2006; Rodriguez et al., 2018).

\subsection{Blockchain qualities when applied in supply chain management}




\section{Literature Review}

While the research in blockchain applications in SCM is in its novice stages, there are a few articles written that provide insights into blockchain features and managerial implementations when the technology is adopted in supply chain management. These studies look at blockchain characteristics and provide arguments on how these characteristics provide value to SCM (Hald \& Kinra, 2019; Angelis \& Da Silva, 2019; Kshetri, 2018). The current study aims to review the mentioned articles, and based on the gathered understanding, create one unified framework of blockchain elements that introduces the negative and positive features of blockchain applications in supply chain management. Blockchain qualities are positive and negative effects of blockchain when this technology is applied to SCM. The positive effects are the "enabling qualities" and the negative effects are the "restraining qualities" (Hald \& Kinra, 2019).

To explain the values driven from blockchain technology, Angelis and Da Silva (2019) first introduced four different stages of blockchain and explained what values each stage offers. The first stage, "blockchain 1.0", is focused on transactions and is adopted to provide cryptocurrency, currency transfer, and digital payment systems. The second stage, "blockchain 2.0", in addition to providing the services of "blockchain 1.0", provides services such as privacy, smart contracts and blockchain tokens (Angelis \& Da Silva, 2019).

The third stage, "blockchain 3.0", in addition to the services in the two previous stages, also incorporates decentralized applications (dApp) which consist of back-end code that run on a peer-to-peer network and connect users and providers directly; of note, the use of blockchain tokens in these applications are common. Finally, "blockchain 4.0" refers to the application of artificial intelligence creates the fourth stage of blockchain values (Angelis \& Da Silva, 2019).

In their study, Angelis and Da Silva (2019) argue that 1) transparency, 2) immutability, 3) privacy, 4) durability and reliability, 5) fault tolerance, 6) democratization, 7) security, 8) risk 


\section{Literature Review}

control, and 9) tokenization are the values that organizations can receive when they adopt blockchain technology in SCM. Angelis and Da Silva (2019) further explain that in blockchain technology, contrary to most other technologies, there is no need to first adopt the first stage of the technology and then update to other stages. Instead, based on the needs of the organization and the values driven from each stage of blockchain, the most appropriate stage can be adopted from the start (Angelis \& Da Silva, 2019). They also argue that a blockchain solution should only be adopted when there is no other way to solve the organizational problems.

Considering that the research in blockchain applications in SCM is in novice stages, there is a lack for one single consensus in positive and negative blockchain elements in supply chain management. However, Hald and Kinra (2019) conducted a theoretical research building on this specific topic. In their research, Hald and Kinra (2019) discuss how the same blockchain characteristics can have enabling and constraining managerial implications.

According to Hald and Kinra (2019), the use of blockchain in supply chain enables: 1) data availability, Immutability and consistency, 2) increases visibility and traceability, 3) reduces errors and attacks, 4) enhances SC coordination, 5) enhances contract management and SC governance, 6) reduces structural complexity, 7) enables SC restructuring and innovations and sustainability innovations, and 8) enhances the potential to earn relational rents from SC partnerships. Overall, the blockchain qualities are managerial effects of adopting the technology in SCM.

The same characteristics that turn blockchain into an enabling technology in SC, can also turn the technology into a constraint. As transparency increases in supply chain, it may increase data privacy issues and provide information to internal parties ("competition") or external parties ("governments"). Once the powerful organizations set up permissioned blockchains and invite others to join, monopolies may emerge over time, thus blockchain may strengthen hierarchies and 
Literature Review

centralize power. Therefore, Hald and Kinra (2019) argue that blockchain applications in SC may increase surveillance and the enforcement of power and lead to segregation.

There are also questions surrounding the use of smart contracts in blockchains and how they may result in more constraints. There is the issue of who will create and write this contract, and whether it will be possible to adapt them to current legal frameworks. The other issue is that the smart contracts are set from the beginning, and they are difficult to modify when the need arises. Yet another issue is the need for additional computer power that is required when adopting advanced distributed technology like blockchain; current computing power may in some cases and for some stakeholders be not sufficient. Hence, Hald and Kinra (2019) argue that blockchain may reduce adaptability in SC in this regard.

Finally, it is argued that blockchain will help reduce intermediaries due to automation. Many middlemen and lower income workers in areas such as accounting, verification, banking and other disciplines may completely be eliminated. The structure of work commitments and functions may completely become automated and replaced with procedures, which results in Hald and Kinra (2019) arguing that blockchain may reduce worker skills and SC competencies.

In another important study in the role of blockchain in meeting supply chain objectives, Kshetri (2018) introduces six distinct features of SCM, namely 1) cost, 2) speed, 3) dependability, 4) risk reduction, 5) sustainability, and 6) flexibility Kshetri (2018) argues that blockchain has a positive impact on these six features in supply chain management.

There are also studies that focus on the differences between using blockchain over more traditional databases and evaluate how adopting blockchain can benefit the supply chain. Chang et al. (2019) find seven factors that blockchain can help enhance in SC, including 1) traceability, 


\section{Literature Review}

2) data storage, 3) privacy, 4) cost reduction, 5) cash liquidity, 6) payments, and 7) degree of automation. Similarly, Kumar et al. (2019) compared blockchains and Inter-organizational System Technologies (IOS). They (Kumar et al., 2019) found that blockchain is advantageous in network topology, data governance, business contract and governance provenance, visibility and power, and trust; however, it comes with high set up costs (Chang et al., 2019). Min (2019) brings attention to main factors that blockchain helps achieve in supply chains: 1) enhanced security, 2) reduced transactions, 3) visibility improvement, 4) improvement in connecting trading partners, 5) secure and error free order fulfillment, and 6) cybersecurity (Min, 2019).

While the above discussed articles provide a wholistic view on this matter and study how blockchain can help supply chain achieve its objectives, there are some articles that are focused on one or two values and that serve a more focused purpose. For example, Tönnissen and Teuteberg (2019) studied the claims that blockchain application would lead to intermediary elimination in supply chain in the logistic industry. They (Tönnissen \& Teuteberg, 2019) found that in some cases the service providers were added as new intermediaries and in one case existing intermediaries were replaced by new intermediary. They (Tönnissen \& Teuteberg, 2019) also put forward factors that may present as challenge and hinder the values that blockchain can provide for SC. These factors include stakeholder participation and the fact that if not successful in convincing the majority of stakeholder to join the platform, the current members will not receive the values promised (Tönnissen \& Teuteberg, 2019). Another challenge is that some organizations may not see benefits in transparency and would be leaning into protecting their data (Tönnissen \& Teuteberg, 2019).

One important way blockchain can benefit supply chains is by reducing the costs associated with information transfer and storage. Blockchain enables the tracking of data and information as 


\section{Literature Review}

they pass through different parties and stakeholders in the chain (Allen et al., 2019). These data could range from transaction information, ownership data, time stamping, location data, and other product specific information. Through blockchain governments, producers, consumers, and other stakeholders can access these data given they have been given permission by the platform which will help with identifying counterfeits. (Allen et al., 2019). Using Internet of Things such as GPS and RFID sensors can enable controlling and tracking information such as pressure, temperature, and location in an immutable manner and by using smart contracts accountability will improve (Allen et al., 2019).

Table 2.3. provides a summary of enabling and restraining blockchain qualities extracted from seven highly relevant articles. The table was constructed to help create a single consensus on blockchain qualities that help supply chain achieve its objectives.

Table.2.3. Enabling and restraining blockchain qualities in SCM

\begin{tabular}{|l|l|l|}
\hline & \multicolumn{1}{|c|}{$\begin{array}{l}\text { Blockchain enabling \& restraining qualities in supply } \\
\text { chains }\end{array}$} & Adopted from \\
\hline 1 & $\begin{array}{l}\text { Four stages of blockchain are: Blockchain 1.0, Blockchain } \\
\text { 2.0, Blockchain 3.0, and Blockchain 4.0. }\end{array}$ & Angelis \& Da Silva (2019) \\
$\begin{array}{l}\text { Enabling qualities: 1) Transparency, 2) Immutability, 3) } \\
\text { Privacy, 4) Durability and reliability, 5) Fault tolerance, 6) } \\
\text { Democratization, 7) Security, 8) Risk control, 9) } \\
\text { Tokenization }\end{array}$ & $\begin{array}{l}\text { Enabling qualities: 1) Data availability, immutability and } \\
\text { consistency, 2) increase visibility \& traceability, 3) reduce } \\
\text { errors and attacks, 4) Enhance SC coordination, 5) Enhance } \\
\text { contract management \& SC governance, 6) Reduce } \\
\text { structural complexity, 7) Enables SC restructuring, } \\
\text { innovation and sustainability innovation, 8) Enhance the } \\
\text { potential to earn relational rent from SC partners. }\end{array}$ \\
\hline $\begin{array}{l}\text { Restraining qualities: 1) Privacy struggles due to } \\
\text { transparency, 2) Integrating smart contracts with current } \\
\text { legal frameworks, 3) No possibility of adjusting the smart } \\
\text { contracts once they have been set in motion }\end{array}$ & Hald \& Kinra (2019) \\
\hline
\end{tabular}


Literature Review

\begin{tabular}{|r|l|c|}
\hline 3 & $\begin{array}{l}\text { Enabling qualities: 1) Cost reduction, 2) Increase speed, 3) } \\
\text { Increase dependability, 4) Risk reduction, 5) Increase } \\
\text { sustainability, 6) increase flexibility }\end{array}$ & Kshetri (2018) \\
\hline 4 & $\begin{array}{l}\text { Enabling qualities: 1) Traceability, 2) Data storage, 3) } \\
\text { Privacy, 4) Cost reduction, 5) Cash liquidity, 6) Payment, 7) } \\
\text { Degree of automation }\end{array}$ & Chang et al. (2019) \\
\hline 5 & $\begin{array}{l}\text { Enabling qualities: 1) Network topology, 2) Data } \\
\text { governance, 3) Business contracts and governance } \\
\text { provenance, 4) Visibility, 5) Power and trust }\end{array}$ & $\begin{array}{l}\text { Kumar et al. (2019) } \\
\text { Restraining qualities: High set up costs }\end{array}$ \\
\hline 6 & $\begin{array}{l}\text { Enabling qualities: 1) Enhanced security, 2) Reduced } \\
\text { transactions, 3) Visibility improvement, 4) Improvement in } \\
\text { connecting trading partners, 5) Secure and error free order } \\
\text { fulfillment, 6) Cybersecurity, }\end{array}$ \\
\hline 7 & $\begin{array}{l}\text { Enabling qualities: enhancing tracking of data and } \\
\text { information }\end{array}$ & Allen et al. (2019) \\
\hline
\end{tabular}

Using the mentioned resources, this study introduces a wholistic view on enabling and restraining qualities of blockchain when adopted in supply chain. This study introduces the enabling qualities in the following manner:

- Enhanced transparency in tracking and tracing

- Enhanced data storage and movement

- Cost reduction

- Increased sustainability

- Risk reduction

- Contract management \& tokenization

- Creating new E-markets

Some factors introduced in the literature, such as speed, visibility and security are introduced as part of the above qualities instead of each being considered as a separate quality, 
Literature Review

since they float between the above qualities. For instance, enhanced speed can be achieved by the possibility of real time tracking and tracing, as well as fast data movement or through contract management, since due to using smart contracts, there is a possibility of fast payments.

Many researchers in the past have included immutability as an enabling quality. However, since blockchain has an immutable character, this immutability can result in cost reduction and enhanced data accuracy. Many scholars have introduced privacy as a positive enabler in blockchain adoption due to immutability (Angelis \& Da Silva, 2019; Chang et al., 2019), and while in permissioned blockchains this is true and can result in accurate data transfer and storage, which has been mentioned as an enabling quality in this study, there are also arguments made that increased transparency will threaten the privacy of firms and decrease their incentive for collaboration (Hald \& Kinra, 2019).

While blockchain has many enabling qualities that will help supply chain achieve their objectives, there are also restraining qualities including:

- Decreased participation by companies due to privacy threads because of the enhanced transparency (Hald \& Kinra, 2019)

- No definite route of integrating the smart contracts and enhanced contract managements with the current legal frameworks (Hald \& Kinra, 2019)

- No proof of possibility of adjusting smart contracts once they have been set in motion (Hald \& Kinra, 2019)

- High set up costs (Kumar et al., 2019)

\subsubsection{Enhanced transparency in tracking and tracing}


Literature Review

Blockchain and Internet of Things (IoT) applications, including radio-frequency identification (RFID) tags, sensors, barcodes, GPS tags and chips, help so that each package within the supply chain can be tracked and traced at each step of the process and in real time (Kshetri, 2018). Another way to explain tracking can be Hald and Kinra's (2019) visibility explanation where they argue that blockchain technology can enable actors to have more visibility over the blockchain, having access to more accurate data, and can track the product through the chain. They also argue for the ability of tracing in blockchain technology as not only the ability to trace product through the chain and to the point of origin, but also the ability to trace transaction history (Hald \&Kinra, 2019; Song et al., 2019).

As an example, there is a great need in food industry for transparency and tractability as scandals in food industry are caused by mistakes such as putting the wrong label on the package, the spread of diseases such as salmonella, and food spoils. Blockchain is a technology that can help enhance the transparency in the food supply chain by enabling the different actors within the supply chain to track and trace products from producer to retailer and vice versa in a short time. Studying five different cases in food industry, Nene et al.(2019) offer several suggestions for practitioners. First, actors within the food supply chains can start to use blockchain without changing the structure of the business models. Second, it is important that the incentives for all the participants and actors within the supply chain be found to encourage everyone to join the blockchain platform. Third, the blockchain should be expanded so that every part of the supply chain are participants (Nene et al., 2019). 
Literature Review

\subsubsection{Data storage and movement}

Blockchain increases the speed of communication and enhances the quality of communication by digitizing the communication process (Kshetri, 2018; Clauson et al., 2018; Petersen et al., 2018). Today's global market and supply chains call for many middlemen and intermediaries, and this has led to a lack of transparency with a time and cost consuming process.

With blockchain, no central authority has control, and the data in the blockchain can be available to all participants while maintaining the security and immutability of data. This may eliminate the need for certain intermediaries and increase transparency in communication among different actors within the chain (Tönnissen \& Teuteberg, 2019). The possibility of secure data and visibility through the supply chain enables the stakeholders to monitor the product movement and determine the status of transfer documents such as bill of lading, i.e., documents issued by a carrier to acknowledge receipt of cargo for shipment, in real time, thereby enhancing coordination through the SC (Hald \& Kinra, 2019). Hald and Kinra (2019) argue that intermediaries that help validate transactions and help with the exchange of value will be eliminated.

Blockchain enables the supply chain to have access to accurate immutable data that is consistent throughout the supply chain. In the global market, the supply chains are scattered in different countries and across different borders, and thus achieving transparency in data is a goal supply chain managers strive to gain (Hald \& Kinra, 2019). As a distributed ledger that securely stores data of transactions and product transfers across different locations and in the span of different times, blockchain can enhance transparency in data, assuring its immutability and enabling stakeholders to reach the data (Hald \& Kinra, 2019). 
Literature Review

Actors within the supply chain can depend on the accuracy of the measurements on quality and weights as the partners are accountable for their actions because the nature of the blockchain is immutable, not to mention that, in case partners report false data, the source of the risk can be identified in a short time (Kshetri, 2018).

\subsubsection{Cost reduction}

There are multiple ways blockchain applications in SCM will reduce the costs. One way is through reducing the costs associated with calling back the entire product line by tracking and tracing the faulty product and removing the defected product instead of pulling the entire product line. This value is most important in food and drug SCs where identifying the faulty product in time can save millions, not to mention prevent disease related scandals (Kshetri, 2018).

The second way blockchain can help reduce the costs in supply chains is by eliminating the need for paper records and therefore eliminating costs of administration as well as paper supplies (Kshetri, 2018). Blockchains also help reduce costs associated with regulatory compliance and eliminating the possibility of low quality or counterfeit product use (Kshetri, 2018).

There is a high information and regulatory cost associated with trade. To resolve these problems, a variety of attempts have been made and supportive policies have been set in place. For instance, the Asia-Pacific Economic Cooperation (APEC) has a paperless information trade policy which aims to transfer information electronically. One of the mechanisms used to reduce the information costs is the blockchain technology (Allen et al., 2019).

\subsubsection{Increased sustainability}

Blockchains not only can help the supply chains be more sustainable through reducing paper trains, but they can also verify sustainability for instance in food industries. This has become 
Literature Review

increasingly important as the end customer pays more attention to the sources of their food (Kshetri, 2018). Hald and Kinra (2019) argue that with visibility comes the knowledge of the source of products, and this knowledge may encourage organizations to seek more sustainable options when they think about sourcing different components.

\subsubsection{Risk reduction}

For permissioned blockchains, only actors that have permission will engage in transactions, thereby reducing risks (Kshetri, 2018). As blockchain is known to store data securely and immutably, the possibilities for error are lower or even eliminated. When mistakes are made in entering data, the corrections are made in the form of updates that take place across the blockchain at once and that will be recorded in the blockchain. The risk of malicious attacks and hackers are also reduced due to blockchain's decentralized nature (Hald \& Kinra, 2019; Clauson et al., 2018).

\subsubsection{Contract management and tokenization}

Smart contracts help reduce transaction costs and enhance contract enforcement. Smart contracts can be standardized set of rules that dictate the rights and obligations of each party and help enforce it through tying it to transactions (Hald \& Kinra, 2019).

\subsubsection{Creating new E-markets}

Blockchain is a technology that can create new opportunities for value creation for stakeholders. One opportunity can be the emergence of new E-markets where buyers and suppliers can get connected easily and with low costs (Hald \& Kinra, 2019).

\subsection{Summary and literature review takeaways}




\section{Literature Review}

The literature review in this study was conducted by reviewing the available articles on supply chain management, blockchain technology, blockchain applications in SCM, stakeholder value proposition, and enabling and restraining blockchain qualities. In the SCM section, the definitions of supply chain were introduced, and the current challenges of SCs were reviewed.

With the global expansion of the trade, SCs have gotten larger and more complicated, with some SCs moving beyond physical borders. Along with the many stakeholders comes problems of lack of transparency and the existence of middlemen and intermediaries that increase the cost of transaction. Information asymmetry and lack of transparency require the use of middlemen and intermediaries which not only will increase the transaction costs but also increase the transaction processing time.

Lack of transparency also means there is limited chance of tracking and tracing within the supply chains, or the time needed to track and trace products and transactions is too long which in turn can have high costs associated with it. Blockchain is a technology that first was introduced through cryptocurrencies. Blockchain is a digital decentralized ledger consisting of digital blocks that are connecting through cryptography, and due to its characteristics, blockchain is considered a secure technology, making it practically nearly to hack or alter. Transaction data are stored in blocks, and the blockchain makes the data immutable and increases transparency.

The characteristics of the blockchain makes it an ideal solution to solve the lack of transparency, as well as increase speed and lower costs in SCs. Therefore, many companies have started adopting blockchain to offer solutions for supply chains on a platform basis; however, the value of these platforms is in their participants and companies must find incentives for stakeholders to join and contribute to the platforms. This magnifies the importance of stakeholder value 
Literature Review

proposition and bring forward the question of which of blockchain qualities can be used to offer value propositions to stakeholders and incentivize them to join these platforms and collaborate.

While the concept of customer value proposition (CVP) has been studied frequently, the stakeholder value proposition (SVP) has not received the same amount of attention. However, in recent years, some articles have focused on the concept and offered arguments on the best practices in identifying and creating successful value propositions. The findings in section 4 suggest that there are a series of necessary actions required to create the successful SVP. These actions include mapping the supply chain (Martinez \& Bititci, 2006), identifying the stakeholders (Rodriguez et al., 2018), engaging with stakeholders and identifying their capabilities and competencies (Martinez \& Bititci, 2006), studying the industry, market, and competitive environment (Payne et al., 2017), and creating a minimum of two value propositions: one to convey the innovative solution and another to convey what will the stakeholder gain from collaboration (Wouters et al., 2018). These steps are shown in the left side of the framework 2.1, and table 2.2 summarizes the resources these steps were extracted from, along with with their respective references. 
Literature Review

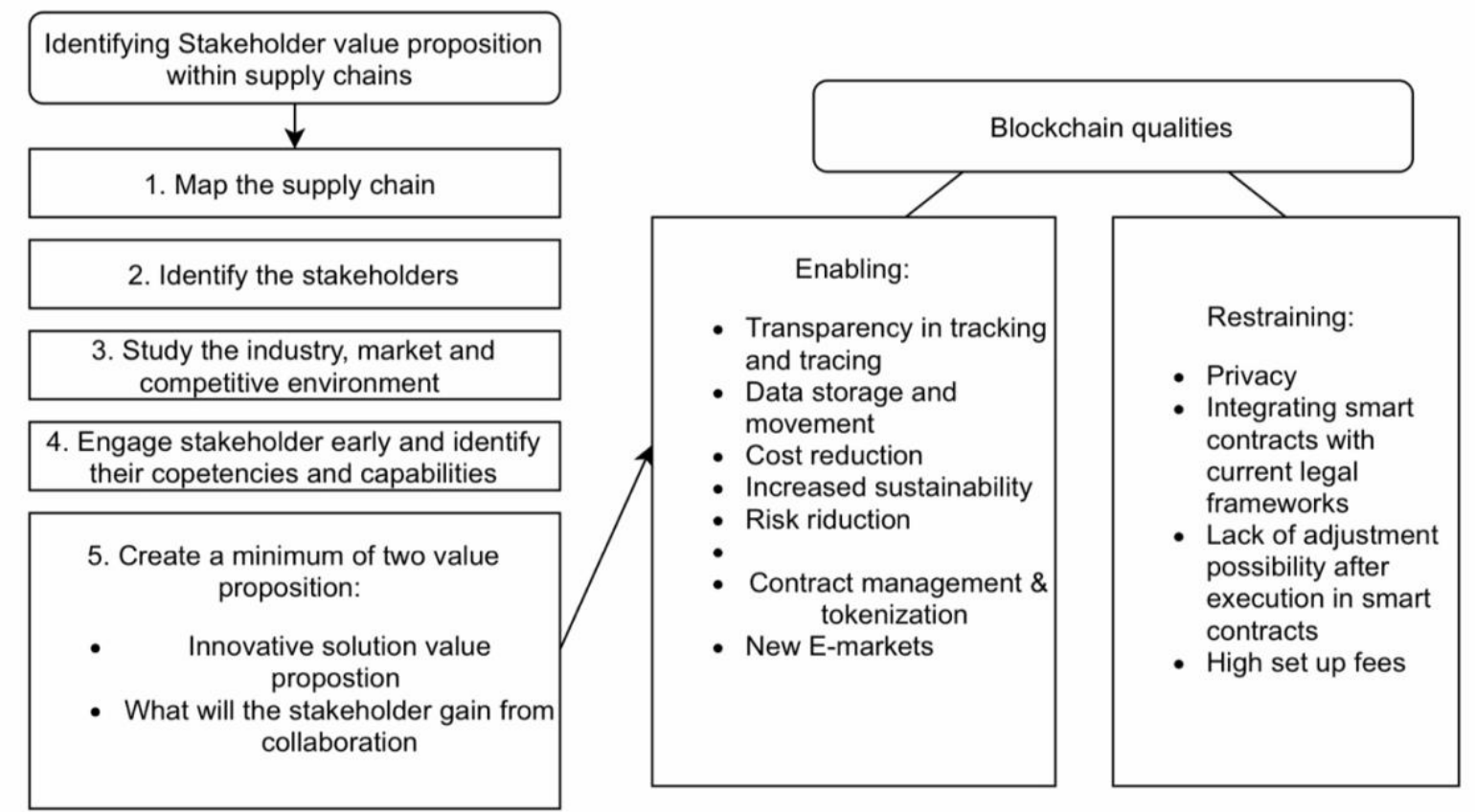

Framework 2.1. Identifying supply chain SVP using blockchain enabling qualities.

To help with creating the value proposition that conveys the innovative solution in supply chain industry where the blockchain technology has been adopted and is part of the creative solution, the enabling and restraining blockchain qualities in SCM were reviewed in section 5 and a consensus of these qualities were created based on the literature. Seven enabling and four restraining qualities were created, where the enabling qualities can benefit and be a starting point in creating a SVP. The blockchain qualities are shown on the right side of the framework 2.1 with the enabling qualities modified from Angelis and Da Silva (2019), Hald and Kinra (2019), Kshetri (2018), Chang et al. (2019), Kumar et al. (2019), Min (2019), and Allen et al. (2019). The restraining qualities are modified from Hald and Kinra (2019) and Kumar et al. (2019). Table 2.3 in this chapter provides a summary on blockchain qualities and the respective references. 


\section{Chapter 3. Research design and method}

The following chapter explains the methodology chosen for this thesis and the steps and actions taken to follow the methodology and evaluate the integrity of the study. This chapter also provides the criteria to choose the case studies and the reasons behind stakeholder selection.

\subsection{Research design}

Building theory from case studies, is "creating theoretical constructs, propositions and midrange theory from case-based, empirical evidence" (Eisenhardt \& Graebner, 2007). There are usually two main methods in constructing the cases. Cases can be historical accounts or contemporary descriptions. Building theory from cases is an inductive approach and the theory emerges when patterns of relationships within the cases and their underlying arguments. The theory building process includes three main steps: recursive cycling among case data, emerging theory and extant literature (Eisenhardt \& Graebner, 2007).

It is argued that inductive and deductive research in this sense complement each other in a way that inductive theory building from cases builds theory, constructs and propositions and deductive research tests the said theories, constructs, and propositions. Some main challenges within this research approach are justifying using this method, case sampling, presenting the cases and writing the theory (Eisenhardt \& Graebner, 2007).

This method is appropriate where the topic at hand is complex, and the existing theory do not help in guiding the research or they cannot help in a productive manner. Hence, the method is appropriate for this study in the manner that there is no theory that can help us understand and study value proposition identifying for stakeholders and there is no theory they can completely 
help us identify the blockchain values in supply chain management and their influence in identifying value propositions (Eisenhardt \& Graebner, 2007).

Table 3.1. Outlines the activities taken to undertake this case study research and the outcome of each activity.

Table 3.1. Research method and design

\begin{tabular}{|l|l|l|}
\hline Step & Activity & Outcome \\
\hline 1 & Identify blockchain enabling qualities in supply chain management & $\begin{array}{l}\text { Literature } \\
\text { background }\end{array}$ \\
\hline 2 & $\begin{array}{l}\text { Setting criteria to choose cases and search data bases to identify a set of } \\
\text { cases based on the criteria, identify data collection and analysis techniques } \\
\text { for cases }\end{array}$ & $\begin{array}{l}\text { Case study } \\
\text { protocol }\end{array}$ \\
\hline 3 & $\begin{array}{l}\text { Build a primary profile on each case study and identify the key stakeholders } \\
\text { in their ecosystems }\end{array}$ & $\begin{array}{l}\text { Descriptive data } \\
\text { on cases }\end{array}$ \\
\hline 4 & $\begin{array}{l}\text { Create case indexes on references to blockchain enabling qualities and } \\
\text { stakeholders from data collection resources, }\end{array}$ & Data index \\
\hline 5 & $\begin{array}{l}\text { Summarize the finding in each index into a table based on literature } \\
\text { background and descriptive data on cases }\end{array}$ & Findings tables \\
\hline 6 & $\begin{array}{l}\text { Two level Cross case examination on the finding in step 5: Cross } \\
\text { examinations of findings related to literature background and cross } \\
\text { examination related to descriptive data }\end{array}$ & $\begin{array}{l}\text { Cross case } \\
\text { analysis }\end{array}$ \\
\hline 7 & Explain insights drawn from the cross case examination & $\begin{array}{l}\text { Explanations } \\
\text { and insights }\end{array}$ \\
\hline 8 & $\begin{array}{l}\text { Introduce a guideline for stakeholder value proposition using blockchain } \\
\text { enabling qualities }\end{array}$ & Guidelines \\
\hline
\end{tabular}

Step 1: In the first step, the blockchain enabling qualities were identified by reviewing the current literature creating a literature background for the study. Seven main articles introduced in second chapter have contributed to the blockchain quality concept in this study.

Step 2: In the second step the case study protocol was set in place by creating a set of criteria to choose the cases (see section 3.2.1), different data bases were viewed to identify the cases that matched the criteria and the data available on the cases were reviewed to create data 
collection and analysis techniques. Secondary form of data was available on companies including website data, their white papers and the academic articles written on the companies.

Step 3: All the data available on the cases were studied to create descriptive overview of each company. This descriptive data includes information on the problems the companies try to solve. The stakeholders they have identified in their ecosystems, the market they operate in, and the services they provide.

Step 4: The selected white papers for the cases include information on companies, such as the problem the companies try to solve, their ecosystems, their stakeholders, their business models, the services they offer, their value propositions, and their management teams. The companies explain blockchain technology and how adopting it in their business plan will help solve the problems they have identified in supply chain and try to offer solutions for. The statements that 1) made a promise to eliminate one of the problems introduced by the companies due to the use of this technology, or the statements that 2) promised to deliver a value and were related to one of the enabling qualities identified in this study were extracted to the index indicating which enabling quality they were related to and if they were directed at a specific stakeholder targeted for this study. The statements that were directed at stakeholders chosen for this study were included in the study as well as general statements that did not target specific stakeholders. Statements that were directed at stakeholders not included in this study were not used. The number of statements extracted include a range of numbers between 20-31 statements.

Step 5: Each index was summarized to include all the promises made by the company to eliminate a problem or deliver value for each blockchain quality. One table was created per company, including a summary of all the statements made in the indexes. The collective statements for each blockchain quality are how the companies claim to deliver value. The tables included both 
general value propositions and the stakeholder targeted value propositions. For the purpose of this study, only statements and value propositions directly related to blockchain qualities were studied. The value propositions that were not related to these qualities and the technology was not examined, and examination of the value propositions that are not related to qualities were beyond the scope of this study.

Step 6: Two types of cross case analysis was conducted from descriptive data and the indexes. The similar pattern in descriptive data was cross examined to provide two types of data on problem identification by companies and the use of token utilities. These analyses have been shared in the from of tables. The number of statements in the indexes were chosen to be cross examined using relative counts. The number of statements found, range from 20 to 31 against seven enabling qualities with 127 total statements. The numbers of statement dedicated for each

enabling quality was cross examined between cases to make the patterns clear. The general statements and the stakeholder statements were cross examined separately.

Step 7: The insights drawn from the patterns that emerged from both descriptive and index data cross case analysis is explained.

Step 8: A guideline is suggested for stakeholder value proposition creation using blockchain qualities in supply chain management based on the findings from literature background and the insights from the cross-case analysis.

\subsection{Case study design}

The multiple case study was chosen as the methodology as this method is the appropriate method of research for studies where an existing theory cannot be used to conduct the research and an exploratory method of research is needed to identify new relationships (Yin, 2018). 
Research design and Method

\subsubsection{Case selection}

The shipping industry was used for this study to enable the researcher in finding information that could relate with as many blockchain qualities as possible rather than limit the research to only two or three qualities and provide the possibility that the finding and results could be generalized to similar industries or to the niche markets within the shipping industry.

To find the best cases in this industry where the company has adopted the blockchain technology in the supply chain, the following criteria was set:

- The company must have identified the stakeholders within their ecosystem.

- The blockchain must be applied in the form of a platform by the company.

- Companies must not be focused on a specific geographical region.

After finalizing the decision on the industry and the criteria on case selection the search for the companies started by searching key phrases such as "Blockchain application in supply chain management", "companies that have adopted blockchain in supply chain management" and "Blockchain applications in supply chain management examples".

The companies introduced in the following listed websites were evaluated against the criteria set for case selection. In the list, the year after each website indicates the year of publication of the articles about the companies:

- Disruptor Daily (2020)

- $\quad$ TechRepublic (2020)

- $\quad$ StartUS Insight (2020)

- $\quad$ Built In (2020) 
Eventually, five companies that met the criteria were chosen for the current study:

$\checkmark$ OpenPort

$\checkmark$ CargoCoin

$\checkmark$ CargoX

$\checkmark$ ShipChain

$\checkmark$ TradeLens

\subsubsection{Stakeholder selection}

Table 3.2 shows the stakeholders identified by each case selected for the study. While most of them have a range of stakeholders they claim their platforms and services benefit, for the purpose of this study the two stakeholders that the cases share shippers and transporters have been chosen. The reason behind this selection lies not only with the fact that all the cases share these two stakeholders, but also with the fact that rarely a shipping and logistics supply chain can be found or survive without shippers and transporters, making these two stakeholders the primary actors within this industry.

Table 3.2. Stakeholders identified by the case

\begin{tabular}{|l|l|}
\hline Case & Stakeholders identified in the ecosystem \\
\hline OpenPort & Shippers, transporters, drivers, retailers \\
\hline CargoCoin & $\begin{array}{l}\text { Shippers, traders, importers, exporters, charterers, freight forwarders, transporters, } \\
\text { container lines, booking agents, insurance companies, warehouse facilities, custom } \\
\text { agents, and suppliers }\end{array}$ \\
\hline CargoX & $\begin{array}{l}\text { Freight forwarders, carriers and transporters, manufacturers, exporters, shippers, carriers, } \\
\text { importers, release agents, banks, and insurance agencies }\end{array}$ \\
\hline ShipChain & Shippers, suppliers, consumers, manufacturers and retailers, carriers and transporters \\
\hline
\end{tabular}


Shippers, freight forwarders, transporters, intermodal operators, authorities, ports,

TradeLens terminals, ocean carriers, financial service providers, software developers

\subsection{Case study evaluation and replication}

Table 3.3 explains methods and tactics that can be used to evaluate the validity and reliability of a case study based on Yin (2018), as well as the actions taken in this study to achieve validity and reliability.

Table 3.3. Case study validity and reliability evaluation

\begin{tabular}{|l|l|l|}
\hline Test & Case study tactic & Actions taken \\
\hline Construct Validity & $\begin{array}{l}\text { Multiple sources of } \\
\text { evidence }\end{array}$ & $\begin{array}{l}\text { Multiple articles were chosen to create the field setting, } \\
\text { Archival data published by and on each case }\end{array}$ \\
\hline Internal Validity & Explanation building & $\begin{array}{l}\text { Relationships were identified based on the findings, } \\
\text { avoiding objectivity and presented in the form of tables }\end{array}$ \\
\hline External Validity & Replication logic & $\begin{array}{l}\text { Multiple case studies were chosen based on criteria that } \\
\text { would help in replicating the result }\end{array}$ \\
\hline \multirow{5}{*}{ Reliability } & Case study Protocol & A case study protocol guided data collection \\
\hline & $\begin{array}{l}\text { Develop case study data } \\
\text { base }\end{array}$ & $\begin{array}{l}\text { Data was stored in the form of descriptive information } \\
\text { and index tables }\end{array}$ \\
\cline { 2 - 4 } & $\begin{array}{l}\text { Maintain chain of } \\
\text { evidence }\end{array}$ & $\begin{array}{l}\text { The data was gathered from reliable resources } \\
\text { published by trustworthy news agencies or the } \\
\text { companies themselves }\end{array}$ \\
\hline
\end{tabular}

\subsection{Data Collection}

The data was collected in two stages. In the first stage the information in the case websites, white papers, journals, news, websites, and weblogs were reviewed to create a descriptive review 
of each case. These reviews provided two insights which are presented in the first section of the result chapters. On the second stage of data collection, the company case white papers were chosen to create statement indexes from.

The white papers are a presentation of the company activities and offerings, where their stakeholders, ecosystems have been identified and it has been explained how the company operation will bring value to their stakeholders. Therefore, quotes and statements were extracted into an index, and it was determined which blockchain quality or qualities were related to each statement. It was also determined whether each statement was directed at a specific stakeholder (shippers and transporters). The shell of these index can be found in the table 3.4.

Table 3.4. The case statement index shell

\begin{tabular}{|c|c|c|c|c|}
\hline Number & $\begin{array}{c}\text { Blockchain } \\
\text { Quality }\end{array}$ & $\begin{array}{c}\text { Statements adopted } \\
\text { from Case X white } \\
\text { paper }\end{array}$ & Page & Stakeholder \\
\hline 1 & & & & \\
\hline 2 & & & & \\
\hline 3 & & & & \\
\hline$\ldots$ & & & & \\
\hline $\mathrm{N}$ & & & & \\
\hline
\end{tabular}

\subsection{Data Analysis and data sharing}

The case indexes, created in the data collection stage, were summarized to provide an indication about the findings for utilizing the variety of blockchain qualities as stakeholder value proposition in each case. A shell example of the table presenting how blockchain qualities were examined one by one can be found in table 3.5 . 
Table 3.5. Case value propositions shell

\begin{tabular}{|l|l|l|}
\hline Blockchain Quality & Value propositions Case X & Stakeholder \\
\hline $\begin{array}{l}\text { Transparency in tracking and } \\
\text { tracing }\end{array}$ & & \\
\hline $\begin{array}{l}\text { Contract management \& } \\
\text { tokenization }\end{array}$ & & \\
\hline data storage and movement & & \\
\hline New E-market & & \\
\hline Cost reduction & & \\
\hline Risk reduction & & \\
\hline Sustainability & & \\
\hline
\end{tabular}

The case indexes were also evaluated on a statistic manner, where it was measured how many statements were found on each blockchain quality and of those statements how many were directed at specific stakeholders. These statistics are presented in tables and a shell of these table formats can be found in table 3.6.

Table 3.6. Case statement findings shell

\begin{tabular}{|c|c|c|}
\hline \multicolumn{3}{|c|}{ Case X Statement findings } \\
\hline $\begin{array}{c}\text { Number of } \\
\text { Statements }\end{array}$ & Blockchain Quality & $\begin{array}{c}\text { Stakeholder identified in } \\
\text { the statements }\end{array}$ \\
\hline 10 & Contract Management \& Tokenization & Yes (5)* \\
\hline & Data Storage \& Movement & \\
\hline & Transparency in Tracking \& Tracing & \\
\hline & New E-Market & \\
\hline & Cost Reduction & \\
\hline & Risk Reduction \\
$*$ & Sustainability \\
& \multicolumn{2}{|c|}{ Number of statements out of the total number in the row that are directed at a } \\
& \multicolumn{2}{|c|}{ specific stakeholder } \\
\hline
\end{tabular}


The quantitative findings then were put together in a cross case analysis to show how many statements all together were found on each blockchain enabling quality. The example for this cross case analysis can be found in table 3.7 .

Table 3.7. Cross-case general statement shell

\begin{tabular}{|l|l|l|l|l|l|l|l|}
\hline & $\begin{array}{l}\text { Contract } \\
\text { Management } \\
\text { \& } \\
\text { Tokenization }\end{array}$ & $\begin{array}{l}\text { Data Storage and } \\
\text { Movement }\end{array}$ & $\begin{array}{l}\text { Transparency } \\
\text { in Tracking } \\
\text { and Tracing }\end{array}$ & $\begin{array}{l}\text { New E- } \\
\text { Market }\end{array}$ & $\begin{array}{l}\text { Cost } \\
\text { Reduction }\end{array}$ & $\begin{array}{l}\text { Risk } \\
\text { Reduction }\end{array}$ & Sustainability \\
\hline Case 1 & & & & & & & \\
\hline Case 2 & & & & & & & \\
\hline Case 3 & & & & & & & \\
\hline Case 4 & & & & & & & \\
\hline Case 5 & & & & & & & \\
\hline $\begin{array}{l}\text { Total of } \\
\text { Statements }\end{array}$ & & & & & & & \\
\hline
\end{tabular}

The statistics also were cross examined in the manner that focus is on the number of statements directed at a specific stakeholder to give insights on the process of value proposition selection. The example of the table these findings are presented at can be found in table 3.8.

Table 3.8. Cross-case stakeholder statement shell

\begin{tabular}{|l|l|l|l|l|l|l|l|l|}
\hline $\begin{array}{l}\text { Contract } \\
\text { Management } \\
\& \\
\text { Tokenization }\end{array}$ & $\begin{array}{l}\text { Data Storage } \\
\text { and } \\
\text { Movement }\end{array}$ & $\begin{array}{l}\text { Transparency } \\
\text { in Tracking } \\
\text { and Tracing }\end{array}$ & $\begin{array}{l}\text { New E- } \\
\text { Market }\end{array}$ & $\begin{array}{l}\text { Cost } \\
\text { Reduction }\end{array}$ & $\begin{array}{l}\text { Total of } \\
\text { Risk } \\
\text { Reduction } \\
\text { directed at } \\
\text { a specific } \\
\text { stakeholder }\end{array}$ \\
\hline Case 1 & & & & & & & \\
\hline Case 2 & & & & & & & & \\
\hline Case 3 & & & & & & & & \\
\hline Case 4 & & & & & & & & \\
\hline Case 5 & & & & & & & & \\
\hline
\end{tabular}


Results

\section{Chapter 4. Results}

This chapter is arranged in five sections. The first section provides the case overviews for each company examined in this study. The second section discusses the problem identification and tokenization. The third section is about the case value propositions section, while the fourth provides the cross case evaluation. Finally, the fifth section offers some valuable guidelines.

\subsection{Case Overviews}

The following section is an overview of each case based on the data gathered from company websites, their white papers, and academic articles.

\subsubsection{OpenPort}

OpenPort is a digital logistics platform that creates a direct transparent relationship between shippers and transporters through their Open Enterprise Logistics (OEL) model. The company specializes in fast moving consumer goods such as soft drinks, toiletries, grocery items and cleaning products and their transport in the Asian marketplace. They have created a platform which connects the movement and transfer of goods with the payment and provide electronic Proof of Delivery (ePOD) through a secure network enhancing speed and security (OpenPort.com, 2020).

They are committed to solving the "cash flow problem" in the supply chain. The cash flow problem is created when the Proof of Delivery (POD) is late, inaccurate or missing, which will cause an increase in administrative costs and transport rates through late invoicing, slow payments, and increased disputes. The local transport and distribution services are fragmented and difficult to manage, using third party logistics providers creates $5-10 \%$ to the costs. Another side of cash flow problem is challenges created for transporters. Transporters face problems with their fuel, 
Results

labor and other operations costs due to late payments when PODs are late or inaccurate or missing. Lack of an IT infrastructure for transportation and logistics services creates a need for subcontracting which will further increase the shipping costs (Openport.com, 2020).

The platform enables data exchange between shipper and the actual transport provider, increasing the visibility and providing a reliable digital Proof of Delivery (POD), hereby acknowledged as ePOD. Traditional PODs are paper based liable to disputes and slow to process and transfer, affecting the cash flow between shippers, retailers and transporters. Identifying the constraints of paper trail and the need for secure timely data transfer to assure cash flow between retailer, brand owner, and transporter, the OpenPort organization has focused on creating a blockchain based platform to store and share transport data and facilitate the ePOD transfers between shipper, transporter, and retailer.

Blockchain is used by OpenPort not only to facilitate creating a secure and immutable ePOD but to create the option of traceability of goods in the supply chain and create a token to connect the payments to the goods movement. The main stakeholders involved in the OpenPort ecosystem identified in their white paper are shipper, transporter, driver, and retailer (OpenPort.com, 2020).

Transporters can publish their rates and collaborate directly with the shippers through the platform eliminating the need for intermediaries and subcontracting, reducing costs creating speed, transparency by tracking and tracing. OpenPort white paper mentions that the company aims to use blockchain to eliminate reliance on intermediaries, enhance transparency and save costs and create an efficient demand and supply-side relationship. OpenPort focuses on delivering five core benefits to their customers Security, trust, Faster, cheaper, and scalable services. They argue that security and trust can be achieved through an immutable ePOD and public ledger with the ability 
Results

to encrypt data for shipment tracking. Improved cash flow allows for better rates and enhances real time visibility delivering faster and cheaper services, and since blockchain technology can be extended across borders and be applied to more than the road transportation and expand through the entire supply chain it is scalable (OpenPort.com, 2020; Finance digest, 2020).

The benefits of using the OpenPort platform is twofold benefiting two main stakeholders, the shippers and the transporters. For transporters, the platform will enhance their cash flow, through digital fast payments and enables them to offer realtime data updates and tracking for shippers, and shippers not only will be able to have more visibility and an immutable ePOD but also can benefit from lower rates since transporter do not face cash flow problem and can offer competitive lower rates (OpenPort.com, 2020; Freight wave, 2020).

OPN is the OpenPort token built as a secondary asset on their smart contracts. it is possible to convert OPN to local currency, it can be exchanged through international qualified exchange agencies, it will help reduce the transaction costs, and increase security. Another benefit presented by OpenPort is enhanced asset utilization. Due to lack of coordination, there is a reduction in cargo carried per transport kilometer which eventually leads to more emissions per $\mathrm{kg}$ than in a more efficient and coordinated manner. Not to mention that truckers can spend days in their destination in search of a new shipment to return to their point of departure. Through OpenPort, shippers can utilize the same trucker for multiple routes hence saving costs and reducing emissions (OpenPort.com, 2020).

\subsubsection{CargoCoin}

CargoCoin is a smart contract, crypto currency platform. The platform provides an environment and utilities for facilitation of trade, transport and exchange of documents and 
Results

payment options at low cost. The platform covers shipping industry, inland transportation, air cargo and other types of transportation such as pipeline transport. The platform will use smart contracts for secure transport and storage methods and as payment unit for services, freight, and cargos. The main stakeholders identified by CargoCoin are traders, importers, exporters, charterers, freight forwarders, container lines, booking agents, insurance companies and brokers, warehouse facilities, customs agents, and suppliers (Thecargocoin.com, 2020; Durr, 2020).

CargoCoin platform has been designed to deliver on security, transparency, traceability and accountability. The customers of the CargoCoin can benefit only from the platform or choose to use more advance utilities such as the smart contracts. CargoCoin has been designed not only to facilitate secure transfer and storage of goods but enhance payment methods by the way of smart contracts and tokens for services, freight, and cargos (TheCagocoin.com, 2020).

CargoCoin introduces some problems in shipping supply chain, including a large industry with minimum use of technology. For all cargo shipments, paper documents are issued, and then these paper documents are sent by couriers, taking a lot of time and money. Another problem is the traditional methods of payment through banks or letters of credit (Medium, 2020). These methods are slow and expensive. The delays in payment and documents arrival, cost money and causes delays in the entire supply chain. CargoCoin aims to resolve or eliminate the following problems by using blockchain technology and smart contracts, reducing fraud, lowering costs, minimizing delays, increasing trust, securing information, and safe archiving (Thecargocoin.com, 2020; Medium, 2020).

CargoCoin has been designed to offer services on a variety of matters in the supply chain covering many stakeholders from traders, importers, exporters, charterers, shippers, freight forwarders, container lines, booking agents, ship owners, custom agents, etc. The platform can be 
Results

used to put cargo orders and receive biddings on the orders, with full transparency by all participants. It can be used as a market for bulk shipment coordination or liquid cargos, and highcapacity shipping (Thecargocoin.com, 2020; Durr, 2020).

One of the focuses of CargoCoin is digitizing the documents that are issued in the supply chain, mainly Bill of Lading $(\mathrm{B} / \mathrm{L})$. B/L is a document issued by the carrier stating three main things, the document title, construct of carriage, and document of receipt. When a consignee (Receiver) signed the $\mathrm{B} / \mathrm{L}$ the ownership changes, making $\mathrm{B} / \mathrm{L}$ one of the most important documents in shipping supply chain. However, the traditional paper B/L is insecure, as many people handle the paperwork while it's in transit, or it may get lost by the courier. It's slow and expensive, since often it is sent by expensive international couriers. In some cases, the shipment arrives in destination before the $\mathrm{B} / \mathrm{L}$ causing further delays. Not to mention the strain issuing paper copies of B/L and its copies have on the environment (Thecargocoin.com, 2020).

The smart $\mathrm{B} / \mathrm{L}$ or the digitized version issued on the CargoCoin platform as a smart utility ensuring the security, instant access and release, confidential, cost effective, that cannot be lost and since it is issued on the blockchain and is a crypto document, it cannot be altered, eliminating fraud (Thecargocoin.com, 2020).

All the services offered in the platform are for free and there are no subscription costs associated with the platform. The goal is to increase the use of the CargoCoin tokens and generate value to ICO supporters. The CargoCoin ecosystem, it's smart contracts and smart B/L provide a foundation for instant crypto transaction by CargoCoin tokens (Medium, 2020). In simple terms, the agreement between different stakeholders is set so that as soon as the conditions of the agreement are fully met, the payment will go through in the form of CargoCoin instantly. Since promoting the use of CargoCoin is the goal of the business, they aim to deliver services such as 
Results

transparency to stakeholders in the supply chain, smart b/L and smart contracts and instant payments to further increase the interest and create a need for the CargoCoin (Thecargocoin.com, 2020).

\subsubsection{CargoX}

Similar to OpenPort, CargoX is a platform that will help shippers and transporters through not only integration but also creating digital form of B/L. CargoX acknowledges that stakeholders can point the many challenges and problems within the supply chain however they focus on the problem of paper based traditional $\mathrm{B} / \mathrm{L}$ in maritime shipping. As mentioned before $\mathrm{B} / \mathrm{L}$ is a document that can transfer ownership of the cargo and is very important in shipping industry. They also identify letter of Credit (L/C and insurance certificates, as other document which are difficult to obtain and are expensive. CargoCoin points to the fact that paper-based B/L lacks speed, can get lost, get delayed, is expensive, and can be subjected to fraud as it is printed on the corporate paper (Cargox.io, 2020; Ortynski, 2020).

The core operation of CargoX at this point is the digitalized crypto B/L. Using their dApp the carrier creates a smart $\mathrm{B} / \mathrm{L}$ and once the expenses are paid, send the $\mathrm{B} / \mathrm{L}$ to the exporter, once the importer has paid for the goods, the exporter will transfer the ownership of the $\mathrm{B} / \mathrm{L}$ to the importer and the importer can claim ownership at the port by presenting the smart $\mathrm{B} / \mathrm{L}$ token to the carrier using the dApp. At the destination once the ownership has been proven the carrier releases the goods to the importer (Cargox.io, 2020; Manaadiar, 2020).

Through CargoX stakeholders can create smart B/L quickly and send it across the globe in minutes. Only involved parties can see the document and the B/L is securely encrypted and stored. Completed B/Ls remain on the archives accessible to their owners. The smart $\mathrm{B} / \mathrm{L}$ is secure, fast, 
Results

paperless, cost effective, auditable and fraud-proof. Freight forwarders, manufacturers, exporters, shippers, carriers and transporters, importers release agents, banks and insurance companies can benefit from the smart B/L (Cargox.io, 2020).

There is no central storage to be hacked as the smart $\mathrm{B} / \mathrm{L}$ is operated on a blockchain based platform, the document is encrypted and stored on the blockchain, accessible by the owner's private keys, it can never be lost or stolen hence it is secure. It can be issued instantly and transferred in minutes using no middleman or couriers making it fast (Ortynski, 2020). Paper B/L are sent at least three times with expensive international couriers hence using the smart B/L not only is faster but more cost effective also. The paper $\mathrm{B} / \mathrm{L}$ is prone to fraud because there is no way to record the transactions on the other hand the CargoX records every transaction on the blockchain eliminating the chances of fraud (Cargox.io, 2020).

CargoX has paying customer only in one group and those are carriers, logistics companies or NVOCC which have the ability to create B/L in real world (Ručigaj, 2020). Other stakeholders such as the exporters and importers, use the platform for free and the payment methods for CargoX are normal fiat currencies. However, CargoX not unlike its competitions, has a utility token called CXO. To create the smart $\mathrm{B} / \mathrm{L}$ the carriers need credit and the only manner to acquire it is to redeem CXO tokens (Cargox.io, 2020; Manaadiar, 2020).

\subsubsection{ShipChain}

ShipChain is also a blockchain based platform that aims to integrate all participants through product supply chains together to increase transparency and speed. The key stakeholders that they have identified are suppliers, manufacturers, shippers, transporters retailers and consumers. ShipChain identifies the major problems in supply chain management as lack if a unified 
Results

communication platform where different stakeholders can interact efficiently. Lack of visibility and tracking of goods throughout the supply chain is another major problem identified by ShipChain. Bad data handling practices result in lack of transparency. Lack of tracking and transparency lead to no accountability where shippers often do not know who is responsible for the cargo. Most of these issues are caused by brokers and middleman (ShipChain whitepaper.io, 2020).

ShipChain aims to unify shipment tracking across the supply chain. In their platform there is aside chain where the data on each transaction is stored and is accessible by the parties involved only (Anzalone, 2020). This not only will give shippers visibility through supply chain but also enables carriers and transporters to communicate without the need for middleman and brokers as the ShipChain platform will fill in where there is need for brokers. Since the data is encrypted and immutable on blockchain, assets can be monitored by the stakeholders with the use of barcodes and RFID chips, reducing the chances of theft and increasing security (ShipChain whitepaper.io, 2020; Anzalone, 2020).

Like other platforms, ShipChain offers smart contracts that can be used by stakeholder to set escrows on the distributed ledger. When a shipment order is placed, a smart contract will be issued, which includes a sum of information that will be stored in the sidechain accessible by the stakeholders. Through their ShipChain marketplace, they provide a way for shippers and carriers to connect, and the system will help the shippers identify the best methods of transportation (By sea, land, air, etc.) (ShipChain whitepaper.io, 2020)

To become a member of the ShipChain and access the platform, the ownership of one SHIP token is necessary. Transactions on the platform are paid by the SHIP token. $20 \%$ of each freight transaction in token values will be given to the driver as incentive for safe and timeless delivery. 
Results

ShipChain aims to help supply chains be more environmentally sustainable by reducing greenhouse gas emissions. Hence, they also provide tokens for responsible safe driving (ShipChain whitepaper.io, 2020).

\subsubsection{TradeLens}

Born out of a partnership between Maersk and IBM, the platform was created as an endto-end solution to bring transparency, speed, and data sharing facilitation to shipping industry supply chain. The stakeholders identified are shippers, freight forwarders, transporters, intermodal operators, authorities, ports, terminals, ocean carriers, financial services and software developers (Docs.TradeLens.com, 2020). TradeLens is and open and neutral supply chain platform built on blockchain technology (Docs.tradelens.com, 2020; IBM.com, 2020).

TradeLens aims to create an ecosystem in which all part of the supply chain is connected to one another and there is collaboration among stakeholders. It helps facilitate data sharing in real time across all parties, and by digitized and through cryptography they ensure the transaction information is immutable and auditable (Express computer, 2020). And by enabling third parties to build and deploy application on the TradeLens platform, they spur innovation (Docs.tradelens.com, 2020).

Shippers and cargo owners can benefit from greater predictability, early notification, of issues, full transparency to validate fees and surcharges and less safety stock inventory by using the platform, ocean carriers can reduce their customer service and network integration costs and decrease their mis-declared cargo. Freight forwarders can benefit from a pre- built connection to the ecosystem, better tools for customer clearance and real- time access to end-to-end supply chain data for the benefit of tracking and tracing (Docs.tradelens.com, 2020; Jensen et al, 2019). 
Results

TradeLens offers a single line of sight across all supply chain activities for shippers and cargo owners. This means goods can get to market in a more reliable fashion, there can be an efficient manner to respond to customer demand, and more collaboration toward automation. Lack of visibility on loading, discharge, transshipment, and empty returns breaks relationship between stakeholders and delayed documents can stop an entire shipment (Docs.tradelens.com, 2020; IBM.com, 2020). But when trusted data is shared through TradeLens, the authenticity of the documents is ensured. By using TradeLens platform, shippers and cargo owners can increase document reliability, built competitive advantage by digitizing, increase speed to market and enhance partner collaboration (Docs.tradelens.com, 2020).

\subsection{Problem identification and tokenization}

The case overviews conducted and presented in the previous chapter presented two main findings. First, there was a pattern across all cases indicating that the companies all identify and present the problems they aim to address. Each problem identified by the companies are presented in table 4.1 two companies have more targeted problems to address. OpenPort tries to solve the cash flow problem, CargoX focuses on digitizing the paper Bill of Lading and Letter of Credits, but the rest of the cases present a more general view of the problems they try to address which include the general challenges faces by supply chains such as lack of visibility, the existence of too many middlemen, high transaction costs, and manual handling of the documents. 
Results

Table 4.1. Problem identification

\begin{tabular}{|l|l|}
\hline Company Name & Problem identified by the company \\
\hline OpenPort & $\begin{array}{l}\text { The cash flow problem due to late, inaccurate or } \\
\text { missing proof of delivery }\end{array}$ \\
\hline CargoCoin & $\begin{array}{l}\text { Large industry, minimum use of technology, time } \\
\text { and money spend on paper documents, traditional } \\
\text { methods of payment which are slow and } \\
\text { expensive }\end{array}$ \\
\hline ShipChain & $\begin{array}{l}\text { Traditional paper Bill of Lading and Letter of } \\
\text { Credit }\end{array}$ \\
\hline TradeLens & $\begin{array}{l}\text { Lack of a unified communication platform, lack of } \\
\text { visibility and tracking of goods throughout supply } \\
\text { chain, no transparency and accountability, high } \\
\text { number of middlemen. }\end{array}$ \\
\hline
\end{tabular}

The second pattern taken out of the case over views is their use of utility tokens on their platform as means to initiate smart contracts and facilitate fast payments. Four out of five cases under examination in this study have presented and introduced their own tokens on their platforms. Table 4.2 shows the name of the token presented by each company and their characteristics. The tokens share characteristics such as being convertible to local currencies, being used to initiate the smart contracts and release smart contracts from escrow. However, some companies such as ShipChain use their tokens as incentives for the carries and drivers for safe and timely delivery or for using routes that helps reduce greenhouse gas emissions. 
Results

Table 4.2. Utility tokens

\begin{tabular}{|l|l|l|}
\hline Company & Tokens & Characteristics \\
\hline OpenPort & OPN & $\begin{array}{l}\text { Convertible to local currency, } \\
\text { possible to exchange using } \\
\text { international agencies, reduces } \\
\text { transaction costs, offers security }\end{array}$ \\
\hline CargoCoin & ORGO & $\begin{array}{l}\text { Enabling instant crypto } \\
\text { transactions, essential to initiate } \\
\text { the smart contracts on the } \\
\text { platform }\end{array}$ \\
\hline ShipChain & CXO & $\begin{array}{l}\text { Acts as a utility that will help } \\
\text { smart contracts get started. }\end{array}$ \\
\hline SHIP & $\begin{array}{l}\text { Ownership of at least one token } \\
\text { is necessary to access the } \\
\text { platform, transaction can be paid } \\
\text { in token, tokens are given as } \\
\text { incentives to drivers for timely } \\
\text { delivery }\end{array}$ \\
\hline
\end{tabular}

\subsection{Case value propositions}

This chapter has five tables, each presenting a summary of the information gathered from the case indexes conducted and presented in the Appendix section of the study from the statements in each company's white paper that indicated the value propositions offered by the company. When the indexes were created it was determined if the statements were a general value propositions offered to all partners or whether the specific stakeholder was identified, and the statement and value proposition is directed at these stakeholders. In addition, the statements were categorized based on the blockchain qualities they were related to.

These enabling blockchain qualities were identified in the second chapter of this study. Each case has its own index. The five tables in this section are a summary of the indexes in the Appendix that shows what blockchain enabling qualities are used in creating value propositions by each company and whether the value propositions were offered to a specific stakeholder or not. 
Results

Table 4.3 shows OpenPort value propositions and provides a summary of all the statements gathered from OpenPort White paper on the OpenPort index in Appendix A. The findings presented in this table indicate that OpenPort leverages all the blockchain enabling qualities except risk reduction. However, factors such as increased speed and visibility are offered as value propositions within the blockchain enabling qualities introduced in this study. This indicates that enhanced speed and visibility are the benefits of blockchain applications in this case however they are linked to the tracking and tracing quality and contract management. It is also noteworthy to mention that cost reduction can be presented as an independent enabling quality but one of the benefits associated with enhanced tracking and tracing and contract management is also cost reduction.

Another takeaway from table 4.3. is that the value propositions in certain occasions have been directed at specific stakeholders within the supply chain, for the purpose of this paper those value propositions that were directed at either shippers or transporters have been evaluated and it was determined that certain statements were directed at both shippers and transporters and that sometimes enhancing a quality for one stakeholder will in turn benefit another stakeholder since in the case of transporters and shippers the two stakeholders are key players and connected at a high level.

Table 4.3. OpenPort Value Propositions

\begin{tabular}{|c|c|c|c|}
\hline $\begin{array}{l}\text { Blockchain } \\
\text { Qualities }\end{array}$ & & Value Propositions (OpenPort) & Stakeholders \\
\hline $\begin{array}{l}\text { Contract } \\
\text { management } \\
\text { tokenization }\end{array}$ & $\&$ & $\begin{array}{l}\text { Enhance Cash Flow, Digital Payment via OPN token, } \\
\text { Facilitating Payment and Clearance process, Digital document } \\
\text { such as Electronic Proof of Delivery (ePOD) included in the } \\
\text { smart contract, Increasing speed in delivery notification and } \\
\text { payment }\end{array}$ & - \\
\hline
\end{tabular}


Results

\begin{tabular}{|c|c|c|}
\hline $\begin{array}{l}\text { Blockchain } \\
\text { Qualities }\end{array}$ & Value Propositions (OpenPort) & Stakeholder \\
\hline \multirow[t]{2}{*}{$\begin{array}{l}\text { Contract } \\
\text { management \& } \\
\text { tokenization }\end{array}$} & $\begin{array}{c}\text { By linking payments to ePODs cash flow increases for both } \\
\text { stakeholders, immutable ePOD triggers payments from retailer to } \\
\text { shipper and from shipper to transporter, the shippers will receive } \\
\text { better rates while the transporter will gain faster payments, } \\
\text { Transporters will be able to receive faster payments and offer } \\
\text { visibility to shippers }\end{array}$ & $\begin{array}{l}\text { Shippers \& } \\
\text { Transporters }\end{array}$ \\
\hline & $\begin{array}{c}\text { The possibilities of corruption are lowered due to the use of OPN } \\
\text { tokens }\end{array}$ & Shippers \\
\hline \multirow{2}{*}{$\begin{array}{l}\text { Data Storage and. } \\
\text { movement }\end{array}$} & $\begin{array}{l}\text { The validity of the shipment document is ensured, the e-POD is } \\
\text { immutable and linked to a smart contract, reduce costs and paper } \\
\text { products }\end{array}$ & - \\
\hline & $\begin{array}{l}\text { The Driver app will allow drivers to receive ePODs with their } \\
\text { phone and transfer shipping data during transport, }\end{array}$ & Transporter \\
\hline \multirow[t]{2}{*}{$\begin{array}{l}\text { Transparency in } \\
\text { Tracking \& } \\
\text { Tracing }\end{array}$} & $\begin{array}{l}\text { Increase traceability of goods by connecting the movement of } \\
\text { goods with payment, increased visibility due to intermediary } \\
\text { elimination, Reliability and security, the shipment tracking can be } \\
\text { sent to the customer's internal system, the tracking of data is } \\
\text { facilitated through an immutable public ledger }\end{array}$ & - \\
\hline & $\begin{array}{l}\text { Shippers can track products through the Driver app installed in } \\
\text { the trucker's phone in real time }\end{array}$ & Shippers \\
\hline \multirow{4}{*}{ New E-Market } & $\begin{array}{l}\text { A data driven procurement market, A marketplace that brings } \\
\text { transparency }\end{array}$ & - \\
\hline & $\begin{array}{l}\text { Create a direct transparent relationship between shippers and } \\
\text { transporters, create visibility by connecting shippers to the actual } \\
\text { transporters }\end{array}$ & $\begin{array}{l}\text { Shippers \& } \\
\text { Transporters }\end{array}$ \\
\hline & Shippers can negotiate with transporters directly & Shippers \\
\hline & Transporters can publish rates directly on the marketplace & Transporter \\
\hline Cost Reduction & $\begin{array}{l}\text { The transaction costs are lowered where in this industry the } \\
\text { margins for transporters are slim }\end{array}$ & Transporter \\
\hline
\end{tabular}


Results

\begin{tabular}{|c|c|c|}
\hline $\begin{array}{l}\text { Blockchain } \\
\text { Qualities }\end{array}$ & Value Propositions (OpenPort) & Stakeholder \\
\hline Cost reduction & $\begin{array}{l}\text { By using the same truck for a continuous route, the costs are } \\
\text { reduced }\end{array}$ & $\begin{array}{l}\text { Shippers \& } \\
\text { Transporters }\end{array}$ \\
\hline Risk Reduction & - & - \\
\hline Sustainability & $\begin{array}{l}\text { By Using the same truck for a continuous route, the costs are } \\
\text { reduced and the environmental footprint is lowered }\end{array}$ & $\begin{array}{l}\text { Shippers \& } \\
\text { Transporters }\end{array}$ \\
\hline
\end{tabular}

Table 4.4 shows the value propositions for CargoCoin and it has been extracted from the CargoCoin white paper statements Index presented in Appendix B. The findings in table 4.4 indicates that of the seven enabling qualities six were used in creating value proposition by CargoCoin leaving out sustainability. Out of the six enabling qualities used, only two have statements directed at specific stakeholders.

Similar to the OpenPort case, increased speed and visibility and cost reduction are also associated with contract management, tracking and tracing and data storage and movement qualities of the blockchain application. In the case of CargoCoin, most value propositions are focused on data storage and movement. It is within data storage and movement that the company offers increased speed and visibility. 
Results

Table 4.4. CargoCoin Value Propositions

\begin{tabular}{|c|c|c|}
\hline $\begin{array}{l}\text { Blockchain } \\
\text { Qualities }\end{array}$ & Value Propositions (CargoCoin) & Stakeholder \\
\hline $\begin{array}{l}\text { Contract } \\
\text { Management \& } \\
\text { tokenization }\end{array}$ & $\begin{array}{l}\text { Secure transfer and storage by using smart contracts, as well as a } \\
\text { payment unit, the smart contract is secure, provides instant access, } \\
\text { and reduces costs, decentralized instant crypto transactions by } \\
\text { tokens, instant funds release and receipt }\end{array}$ & - \\
\hline $\begin{array}{l}\text { Data Storage \& } \\
\text { Movement }\end{array}$ & $\begin{array}{l}\text { Exchange of documents at real time, increased speed in document } \\
\text { exchange, secured storage of information and assurance of privacy } \\
\text { for company data, Visibility for parties while maintaining } \\
\text { confidential, historic data on transactions are stored making them } \\
\text { easily accessible and removing the risk of lost or stolen data, the } \\
\text { smart } \mathrm{B} / \mathrm{L} \text { is in the blockchain at all times, the existence of smart } \\
\mathrm{L} / \mathrm{C} \text { and } \mathrm{B} / \mathrm{L} \text { ensures secure transaction between all participants }\end{array}$ & - \\
\hline $\begin{array}{l}\text { Transparency in } \\
\text { Tracking \& } \\
\text { Tracing }\end{array}$ & $\begin{array}{l}\text { The platform is designed on the basis of security, transparency, } \\
\text { traceability and accountability }\end{array}$ & - \\
\hline \multirow[t]{2}{*}{ New E-Market } & $\begin{array}{l}\text { The platform targets to facilitate interaction among stakeholders, it } \\
\text { connects stakeholders in one single marketplace, while } \\
\text { maintaining a simple form the platform allows for a range of } \\
\text { communication channels }\end{array}$ & - \\
\hline & $\begin{array}{l}\text { The offers are posted on the platform in detail and the shippers can } \\
\text { bid on the services }\end{array}$ & Shippers \\
\hline \multirow{2}{*}{ Cost Reduction } & $\begin{array}{l}\text { The transaction costs are lowered where in this industry the } \\
\text { margins for transporters are slim }\end{array}$ & - \\
\hline & $\begin{array}{l}\text { Transaction costs are significant for both shippers and transporters } \\
\text { but secure payment through CargoCoin reduces costs }\end{array}$ & $\begin{array}{l}\text { Shippers \& } \\
\text { Transporters }\end{array}$ \\
\hline Risk Reduction & $\begin{array}{c}\text { The conjunction between smart } \mathrm{L} / \mathrm{C} \text { and smart } \mathrm{B} / \mathrm{L} \text { eliminated } \\
\text { fraud, eliminates bank failure or delay }\end{array}$ & - \\
\hline Sustainability & - & - \\
\hline
\end{tabular}

Table 4.5. is the CargoX value Proposition table, created from CargoX white paper statement index presented in Appendix C. CargoX has not used the New E-market and 
Results

sustainability enabling qualities and of the five other enabling qualities that have been leveraged to create value propositions none are directed at a stakeholder even though the stakeholders within the ecosystem have been identified by the company in their white paper document.

As the focus of CargoX is on the transfer and storage of two essential documents within the supply chain, the $\mathrm{B} / \mathrm{L}$ and the $\mathrm{L} / \mathrm{C}$, they offer increased speed within the data storage and movement and tracking and tracing. While the other companies focus on tracking and tracing the products and the documents within the supply chain and leverage this enabling quality to offer value proposition, CargoX focuses on enabling stakeholders to track and trace the documents, mainly $\mathrm{B} / \mathrm{L}$ within the supply chain from when it is first created on the platform, until it arrives at its final destination.

Table 4.5. CargoX Value Propositions

\begin{tabular}{|c|c|c|}
\hline $\begin{array}{c}\text { Blockchain } \\
\text { Qualities }\end{array}$ & Value Propositions (CargoX) & Stakeholder \\
\hline $\begin{array}{c}\text { Contract } \\
\text { Management \& } \\
\text { tokenization }\end{array}$ & $\begin{array}{c}\text { CargoX leverages the security of blockchain and smart contracts, } \\
\text { the smart contracts are vetted and audited, the smart B/L works } \\
\text { similarly to tokens, meaning the user can create transfer and claim } \\
\text { ownership, The CXO token acts as a credit to initiate the smart } \\
\text { B/L and can be used as an internal payment system }\end{array}$ & - \\
\hline $\begin{array}{c}\text { Data Storage \& } \\
\text { Movement }\end{array}$ & $\begin{array}{c}\text { Reduce the need for paper document, Smart B/L can be issued } \\
\text { instantly, the transfer of B/L is stored in the blockchain, but real } \\
\text { is private and only visible to the involved stakeholders, the smart } \\
\text { B/L records transaction with a timestamp, offering more security }\end{array}$ & - \\
\hline $\begin{array}{c}\text { Transparency in } \\
\text { Tracking \& } \\
\text { Tracing }\end{array}$ & $\begin{array}{c}\text { Commitment to highest transparency standards, send a B/L across } \\
\text { the globe with speed and track its movements, Transparency and } \\
\text { trackability eliminate the possibility of lost or stolen goods }\end{array}$ & - \\
\hline $\begin{array}{c}\text { New E-Market } \\
\text { Cost Reduction }\end{array}$ & $\begin{array}{c}\text { The decentralized ledger saves cost of transport and archiving } \\
\text { paper B/L }\end{array}$ & - \\
\hline
\end{tabular}


Results

\begin{tabular}{|c|c|c|}
\hline $\begin{array}{c}\text { Blockchain } \\
\text { Qualities }\end{array}$ & Value Proposition (CargoX) & Stakeholder \\
\hline Risk Reduction & $\begin{array}{c}\text { There is no central station to be targeted by hackers, the } \\
\text { documents are accessible only by the owner's private key, and it is } \\
\text { safeguarded by cryptography }\end{array}$ & \\
\hline Sustainability & - & - \\
\hline
\end{tabular}

Table 4.6 shows ShipChain's value propositions extracted from Appendix D which is the index for ShipChain white paper statements. Similar to the OpenPort case, ShipChain leverages six enabling blockchain qualities and except for cost reduction every other quality has value propositions associated with it that is directed at specific stakeholders and one again there are value propositions offered within this case that are directed at both shippers and transporters, indicating that these two stakeholders in this field can benefit when the other benefits in certain situations.

Similar to the previous cases, visibility is offered as an added value that can be obtained through other enabling qualities such as transparency in tracking and tracing. Among the five cases ShipChain is the only case that offers a solution for reducing the high costs associated from adopting blockchain itself. As mentioned previously one of the benefits of adopting blockchain is that it reduces transaction costs, however, there are high costs associated with set up and adoption of the technology itself. ShipChain offers a solution by creating a sidechain were all the transactions detail can be stored but also not on the main blockchain where they will take up space and cost more. However, they are not very clear on the characteristics of this sidechain and how it offers the same benefits of the blockchain while keeping the costs low. 
Table 4.6. ShipChain Value propositions

\begin{tabular}{|c|c|c|}
\hline $\begin{array}{c}\text { Blockchain } \\
\text { Qualities }\end{array}$ & Value Propositions (ShipChain) & Stakeholder \\
\hline \multirow[t]{2}{*}{$\begin{array}{l}\text { Contract } \\
\text { Management \& } \\
\text { tokenization }\end{array}$} & $\begin{array}{l}\text { Tokens fuel the smart contract execution and with the } \\
\text { information kept in the smart contract the process will be quick } \\
\text { and easy, the system will generate a contract upon pick up and } \\
\text { once the delivery is completed the contract will be completed and } \\
\text { the payment held in escrow will be released }\end{array}$ & - \\
\hline & $\begin{array}{l}20 \% \text { of the freight transaction will be provided to drivers as an } \\
\text { incentive after safe and timely delivery of the cargos }\end{array}$ & Transporters \\
\hline \multirow{2}{*}{$\begin{array}{l}\text { Data Storage \& } \\
\text { Movement }\end{array}$} & $\begin{array}{l}\text { Every detail about cargo transfer will be stored on a sidechain, by } \\
\text { recording geographical points the visibility will increase, by } \\
\text { using AI technologies assets can be verified through the chain } \\
\text { and their movement stored in the chain }\end{array}$ & - \\
\hline & $\begin{array}{l}\text { With encrypted immutable data transfer between stakeholder } \\
\text { there will be no need to put blame on either the carrier or the } \\
\text { shipper or the broker }\end{array}$ & $\begin{array}{l}\text { Shippers \& } \\
\text { Transporters }\end{array}$ \\
\hline \multirow{3}{*}{$\begin{array}{l}\text { Transparency in } \\
\text { Tracking \& } \\
\text { Tracing }\end{array}$} & $\begin{array}{c}\text { Full integration across the supply chain, trustless, transparent, } \\
\text { Electronic Log Device that enables tracking and tracing from } \\
\text { farm to table }\end{array}$ & - \\
\hline & $\begin{array}{l}\text { Gives shippers more visibility and reduces miscommunication } \\
\text { between transporters and shippers }\end{array}$ & $\begin{array}{l}\text { Shippers \& } \\
\text { Transporters }\end{array}$ \\
\hline & $\begin{array}{l}\text { By replacing their internal tracking system with the ShipChain } \\
\text { system, Transporters will gain visibility through all their partners }\end{array}$ & Transporter \\
\hline \multirow{4}{*}{ New E-Market } & $\begin{array}{l}\text { Moving toward creating the largest network of US based trucking } \\
\text { freight companies, }\end{array}$ & - \\
\hline & $\begin{array}{l}\text { Connecting shippers to transporters (Carriers), Offering an App } \\
\text { for cargo booking, }\end{array}$ & $\begin{array}{l}\text { Shippers \& } \\
\text { Transporters } \\
\end{array}$ \\
\hline & $\begin{array}{l}\text { The shipper will be able to see the type of transportation needed } \\
\text { for different cargos moving through different routes and can } \\
\text { select the best carriers with the best rates on the marketplace with } \\
\text { no need for intermediaries }\end{array}$ & Shippers \\
\hline & Transporters can schedule hand offs between different carriers, & Transporters \\
\hline Cost Reduction & $\begin{array}{l}\text { Individual tracking points will be stored on a sidechain to help } \\
\text { reduce the costs of data storage on the main blockchain }\end{array}$ & - \\
\hline Risk Reduction & - & - \\
\hline
\end{tabular}


Results

\begin{tabular}{|c|c|c|}
\hline $\begin{array}{c}\text { Blockchain } \\
\text { Qualities }\end{array}$ & Value Proposition (ShipChain) & Stakeholder \\
\hline Sustainability & $\begin{array}{c}\text { Committed to reduce the effects of greenhouse gas emissions, } \\
\text { tokens will be offered as incentives to drivers for ecologically } \\
\text { responsible driving }\end{array}$ & Transporter \\
\hline
\end{tabular}

Table 4.7 is the TradeLens value proposition table extracted from TradeLens white paper statement index presented in Appendix E. TradeLens leverages six enabling qualities and leaves out sustainability. Of all the statements offered as value proposition from TradeLens, only three are offered directly at stakeholders. Two of these value propositions are related to data storage and movement and one is related to transparency in tracking and tracing. TradeLens also offers end to end visibility within another enabling blockchain quality tracking and tracing.

The loss of privacy is on of the restraining qualities of the blockchain adoption in supply chain and this quality has different implications. It is suggested that while increased transparency and visibility can solve many of the problems of blockchain it can also deter stakeholders from participation since protecting their internal data from competition is one of the most important activities of organizations. TradeLens tries to address this issue by making it clear that the privacy of the stakeholders is ensured through sharing the data only with those parties involved. 
Results

Table 4.7. TradeLens Value Propositions

\begin{tabular}{|c|c|c|}
\hline $\begin{array}{l}\text { Blockchain } \\
\text { Qualities }\end{array}$ & Value Propositions (TradeLens) & Stakeholder \\
\hline $\begin{array}{l}\text { Contract } \\
\text { Management \& } \\
\text { tokenization }\end{array}$ & Key Transaction information is secure, immutable, and auditable & - \\
\hline \multirow[t]{3}{*}{$\begin{array}{l}\text { Data Storage \& } \\
\text { Movement }\end{array}$} & $\begin{array}{l}\text { Secure sharing of information across all parties, the data are } \\
\text { published directly by the stakeholder, Data is signed by the } \\
\text { submitter and stored in a tamper proof manner, Privacy is ensured } \\
\text { by sharing the data with the relevant organizations only, Access to } \\
\text { secure information in real time, Flexibility and control over who } \\
\text { the data is shared with, Stakeholders can securely upload } \\
\text { download and edit documents, Consistency check on documents to } \\
\text { ensure consistency through hash checks }\end{array}$ & - \\
\hline & $\begin{array}{c}\text { Shippers and Transporters can share information that can be } \\
\text { tracked and stored in the platform throughout the shipment } \\
\text { journey }\end{array}$ & $\begin{array}{l}\text { Shippers \& } \\
\text { Transporters }\end{array}$ \\
\hline & $\begin{array}{l}\text { Reliable and accessible data movement help shipments move } \\
\text { faster and TradeLens provides real-time publish and subscribe } \\
\text { mechanisms }\end{array}$ & Shippers \\
\hline \multirow[t]{2}{*}{$\begin{array}{l}\text { Transparency in } \\
\text { Tracking \& } \\
\text { Tracing }\end{array}$} & $\begin{array}{l}\text { Enhanced transparency, End to end visibility across shipping lines, } \\
\text { A network of shipping lines and other actors, Full transparency in } \\
\text { validating fees and surcharges and less safety stock inventory, The } \\
\text { Hyperledger permissioned blockchain is used to guarantee } \\
\text { document immutability and traceability and enhance asset tracking }\end{array}$ & - \\
\hline & $\begin{array}{l}\text { Through the Shipment manager user interface or integrating } \\
\text { TradeLens data into their existing systems, shippers can determine } \\
\text { the status of their shipments through the supply chain }\end{array}$ & Shippers \\
\hline New E-Market & $\begin{array}{c}\text { Bringing together all parties in the supply chain and enabling data } \\
\text { sharing on one single platform, and an application as service } \\
\text { marketplace all stakeholder collaboration }\end{array}$ & - \\
\hline Cost Reduction & $\begin{array}{l}\text { Reduced customer service costs, less revenue leakage and less mis } \\
\text { declared cargo die to end to end visibility }\end{array}$ & - \\
\hline Risk Reduction & $\begin{array}{c}\text { Tracking and tracing assets of value reduces risks in the supply } \\
\text { chain }\end{array}$ & - \\
\hline Sustainability & - & - \\
\hline
\end{tabular}


Results

Table 4.8 is a numerical assessment of Appendix A, which shows how many statements are associated with each blockchain enabling quality, and, of those statements, how many are directed at a specific stakeholder.

Table 4.8. OpenPort Statement findings

\begin{tabular}{|c|c|c|}
\hline \multicolumn{3}{|c|}{ OpenPort Statements Findings } \\
\hline Number of Statements & Blockchain Quality & $\begin{array}{c}\text { Stakeholder } \\
\text { identified in the } \\
\text { statements }\end{array}$ \\
\hline 10 & $\begin{array}{c}\text { Contract Management \& } \\
\text { Tokenization }\end{array}$ & Yes (5)* \\
\hline 6 & Data Storage \& Movement & Yes (2)* \\
\hline 9 & $\begin{array}{c}\text { Transparency in Tracking \& } \\
\text { Tracing }\end{array}$ & Yes (1)* \\
\hline 6 & New E-Market & Yes (4)* \\
\hline 2 & Cost Reduction & Yes (2)* \\
\hline 0 & Risk Reduction & Yes (1)* \\
\hline 1 & Sustainability & \\
\hline \multicolumn{3}{|c|}{ Number of statements out of the total number in the row that are directed at a } \\
specific stakeholder
\end{tabular}

Table 4.9 is a numerical assessment of Appendix B the CargoCoin statement index. This table similar to the previous table indicates how many statements are associated with each enabling quality and of those statements how many are associated with a specific stakeholder.

Table 4.9. CargoCoin Statement Findings

\begin{tabular}{|c|c|c|}
\hline \multicolumn{2}{|c|}{ CargoCoin Statement Findings } \\
\hline Number of Statements & Blockchain Quality & $\begin{array}{c}\text { Stakeholder } \\
\text { identified in the } \\
\text { statements }\end{array}$ \\
\hline 6 & $\begin{array}{c}\text { Contract Management \& } \\
\text { Tokenization }\end{array}$ & No \\
\hline 8 & Data Storage \& Movement & No \\
\hline
\end{tabular}


Results

\begin{tabular}{|c|c|c|}
\hline Number of Statements & Blockchain Quality & $\begin{array}{c}\text { Stakeholder } \\
\text { identified in the } \\
\text { statements }\end{array}$ \\
\hline 1 & $\begin{array}{c}\text { Transparency in Tracking \& } \\
\text { Tracing }\end{array}$ & No \\
\hline 5 & New E-Market & Yes (1)* \\
\hline 2 & Cost Reduction & Yes (1)* \\
\hline 4 & Risk Reduction & No \\
\hline 0 & Sustainability & - \\
\hline \multirow{2}{*}{ * Number of statements out of the total number in the row that are directed at a } \\
specific stakeholder
\end{tabular}

Table 4.10 is the numerical assessment of CargoX in Appendix C which show the number of statements associated with each enabling quality and the number of statements directed at a specific stakeholder.

Table 4.10. CargoX Statement Findings

\begin{tabular}{|c|c|c|}
\hline \multicolumn{3}{|c|}{ CargoX Statement Findings } \\
\hline Number of Statements & Blockchain Quality & $\begin{array}{c}\text { Stakeholder } \\
\text { identified in the } \\
\text { statements }\end{array}$ \\
\hline 5 & $\begin{array}{c}\text { Contract Management \& } \\
\text { Tokenization }\end{array}$ & No \\
\hline 11 & Data Storage \& Movement & No \\
\hline 3 & $\begin{array}{c}\text { Transparency in Tracking \& } \\
\text { Tracing }\end{array}$ & No \\
\hline 0 & New E-Market & No \\
\hline 3 & Cost Reduction & No \\
\hline 1 & Risk Reduction & - \\
\hline 0 & Sustainability & \\
\hline & Number of statements out of the total number in the row that are directed at a \\
specific stakeholder
\end{tabular}

Table 4.11 is the numerical assessment for ShipChain case based on ShipChain index in Appendix D. Table 4.12 is the numerical assessment for TradeLens based on Appendix E. 
Results

Table 4.11. ShipChain Statement Findings

\begin{tabular}{|c|c|c|}
\hline \multicolumn{2}{|c|}{ ShipChain Statement Findings } \\
\hline Number of Statements & Blockchain Quality & $\begin{array}{c}\text { Stakeholder } \\
\text { identified in the } \\
\text { statements }\end{array}$ \\
\hline 5 & $\begin{array}{c}\text { Contract Management \& } \\
\text { Tokenization }\end{array}$ & Yes (1)* \\
\hline 6 & Data Storage \& Movement & Yes (1)* \\
\hline 6 & $\begin{array}{c}\text { Transparency in Tracking \& } \\
\text { Tracing }\end{array}$ & Yes (2)* \\
\hline 6 & New E-Market & Yes (5)* \\
\hline 1 & Cost Reduction & No \\
\hline 0 & Risk Reduction & Yes (1)* \\
\hline 1 & Sustainability & \\
\hline \multicolumn{2}{|c|}{ Number of statements out of the total number in the row that are directed at a } \\
specific stakeholder
\end{tabular}

Table 4.12. TradeLens Statement Findings

\begin{tabular}{|c|c|c|}
\hline \multirow{2}{*}{ Number of Statements } & Blockchain Quality & $\begin{array}{c}\text { Stakeholder } \\
\text { identified in the } \\
\text { statements }\end{array}$ \\
\hline 1 & $\begin{array}{c}\text { Contract Management \& } \\
\text { Tokenization }\end{array}$ & No \\
\hline 17 & Data Storage \& Movement & Yes (2)* \\
\hline 8 & $\begin{array}{c}\text { Transparency in Tracking \& } \\
\text { Tracing }\end{array}$ & Yes (1)* \\
\hline 3 & New E-Market & No \\
\hline 2 & Cost Reduction & No \\
\hline 2 & Risk Reduction & - \\
\hline 0 & Sustainability & \\
\hline & \multicolumn{2}{c}{ Number of statements out of the total number in the row that are directed at a } \\
specific stakeholder
\end{tabular}


Results

The comparison and cross-case analysis gathered from the last five tables are presented in the following section.

\subsection{Cross case analysis findings}

Table 4.13 is constructed from putting together the column "Number of Statements" from tables $4.8,4.9,4.10,4.11,4.12$ in the previous section and analyze each case against one another based on the blockchain enabling qualities. This table indicates that in terms of general statements and value propositions that are not offered directly at a specific stakeholder, data storage and movement, has the most statements associated with it across all cases. This can have the implication that at least within these five cases in the shipping and logistic industry the safe storage and movement of data has been used to create and offer value propositions more than the other qualities, putting contract management and tokenization and transparency in tracking and tracing in second place.

Table 4.13. General statement cross case

\begin{tabular}{|l|l|l|l|l|l|l|l|}
\hline & $\begin{array}{l}\text { Contract } \\
\text { Management } \\
\text { \& } \\
\text { Tokenization }\end{array}$ & $\begin{array}{l}\text { Data } \\
\text { Storage and } \\
\text { Movement }\end{array}$ & $\begin{array}{l}\text { Transparency } \\
\text { in Tracking } \\
\text { and Tracing }\end{array}$ & $\begin{array}{l}\text { New E- } \\
\text { Market }\end{array}$ & $\begin{array}{l}\text { Cost } \\
\text { Reduction }\end{array}$ & $\begin{array}{l}\text { Risk } \\
\text { Reduction }\end{array}$ & $\begin{array}{l}\text { Sustainabilit } \\
\text { y }\end{array}$ \\
\hline OpenPort & 10 & 6 & 9 & 6 & 2 & 0 & 1 \\
\hline CargoCoin & 6 & 8 & 1 & 5 & 2 & 4 & 0 \\
\hline CargoX & 5 & 11 & 3 & 0 & 3 & 1 & 0 \\
\hline ShipChain & 5 & 6 & 6 & 6 & 1 & 0 & 1 \\
\hline TradeLens & 1 & 17 & 8 & 3 & 2 & 2 & 0 \\
\hline $\begin{array}{l}\text { Total Of } \\
\text { Statements }\end{array}$ & 27 & 48 & 27 & 20 & 10 & 7 & 2 \\
\hline
\end{tabular}

Table 4.14. was constructed to show how many statements or value propositions were offered to specific stakeholders in each case since identifying the stakeholder is one of the main activities that must take place in identifying and creating stakeholder value propositions as 
Results

discussed in chapter two. This table shows that while OpenPort and ShipChain direct many of their statements to specific stakeholders, but the other three cases create more generic value propositions.

It cannot be determined whether these three cases seek out major stakeholders independently and offer specific value propositions to them privately, however, within the scope of this thesis it can be argued that these three cases fail to communicate specific and focused value propositions within their major forms of public communication, their websites, and their white papers.

Table 4.14. Stakeholder statement cross case analysis

\begin{tabular}{|c|c|c|c|c|c|c|c|c|}
\hline & $\begin{array}{l}\text { Contract } \\
\text { Management } \\
\& \\
\text { Tokenization }\end{array}$ & $\begin{array}{l}\text { Data } \\
\text { Storage } \\
\text { and } \\
\text { Movement }\end{array}$ & $\begin{array}{l}\text { Transpar } \\
\text { ency in } \\
\text { Tracking } \\
\text { and } \\
\text { Tracing }\end{array}$ & $\begin{array}{l}\text { New } \\
\text { E- } \\
\text { Market }\end{array}$ & $\begin{array}{l}\text { Cost } \\
\text { Reducti } \\
\text { on }\end{array}$ & $\begin{array}{l}\text { Risk } \\
\text { Reduct } \\
\text { ion }\end{array}$ & $\begin{array}{l}\text { Sustainabi } \\
\text { lity }\end{array}$ & $\begin{array}{l}\text { Total of } \\
\text { statements } \\
\text { directed at } \\
\text { a specific } \\
\text { stakeholder }\end{array}$ \\
\hline OpenPort & 5 & 2 & 1 & 4 & 2 & 0 & 1 & 15 \\
\hline $\begin{array}{l}\text { CargoCoi } \\
\mathrm{n}\end{array}$ & 0 & 0 & 0 & 1 & 1 & 0 & 0 & 2 \\
\hline CargoX & 0 & 0 & 0 & 0 & 0 & 0 & 0 & 0 \\
\hline $\begin{array}{l}\text { ShipChai } \\
\text { n }\end{array}$ & 1 & 1 & 2 & 5 & 0 & 0 & 1 & 10 \\
\hline $\begin{array}{l}\text { TradeLen } \\
\mathrm{s}\end{array}$ & 0 & 2 & 1 & 0 & 0 & 0 & 0 & 3 \\
\hline
\end{tabular}

\subsection{Guidelines}

A seven-step guideline was created based on the findings from studying the cases in this research and the findings from other articles presented in chapter two. In chapter two it was discussed that companies have to take on five main activities to identify and create successful value propositions, including mapping the supply chain, identifying the stakeholders, studying 
Results

the industry, market and competitive environment, engaging with stakeholders early, and creating a minimum of two value proposition one of which explains the innovative solution and the second one explains what the stakeholder will gain from their engagement.

The findings in this chapter indicate that the cases that have adopted blockchain in supply chain identify the problems they try to offer solution for and the value propositions they offer while they leverage the enabling blockchain qualities to create the value propositions. The findings in this study indicate that the companies leverage the blockchain enabling qualities to create the value propositions and these value propositions are solutions for problems that has been identified by the company.

It was also one of the findings of this study that the cases adopting blockchain often use utility tokens to help initiate the smart contracts within the blockchain and facilitate payments. The companies that include tokens as part of their solution, explain the innovative solution of tokens separate from the blockchain and offer value propositions for their tokens as well as their blockchain platforms.

Two out of the five cases in this study also included a respond to the restraining qualities of blockchain when adopted in supply chain mainly high set up costs and lack of privacy. In the case of ShipChain, a sidechain solution is offered to reduce the data storage costs on the main blockchain and in the case of TradeLens the lack of privacy issue is addressed by ensuring the stakeholders that their data will only be shared with the involved parties.

Combining the findings gathered from articles in chapter two and the findings from the five cases studied in this research, a new seven step guideline has been conducted to assist in creating successful and strong stakeholder value propositions when adopting blockchain in supply chain. 
Results

The fifth step, "state the problem the company offers a solution for" was added because this is a step taken by the companies to help the stakeholders understand how the technological solution can benefit them.

The next step which indicated companies should at least offer two value propositions has been adjusted. The companies can still offer at least two main value propositions one of which is the innovative solution value proposition. However, in this value proposition it should be taken under consideration whether utility tokens are part of the company's innovative solution. If they are, a separate value proposition must be offered for the utility tokens. The second value proposition which indicates what the stakeholders will gain from their participation must reflect that they gain a solution in line with the problem or problems the company tries to solve. It also must be directed at a specific stakeholder.

Finally, it is important for companies to try and address the blockchain restraining qualities while leveraging the enabling qualities. Mainly the challenges surrounding the high set up costs, lack of privacy and integrating the smart contracts with the status quo legal systems or updating the smart contracts after they are initiated. From the five cases within this study only two have taken any action toward the seventh step of this guideline.

Figure 4.1 is the depiction of the guidelines. it has been conducted in two main sections, adopting blockchain in supply chain management and blockchain qualities. There are seven main steps introduced under adopting blockchain in supply chain management that show the steps necessary to create a successful SVP. The sixth step which is the creation of value proposition is connected to the blockchain qualities section of the framework to show that in this step, the blockchain enabling qualities can be leveraged to create the SVP. Based on the findings in this research it is also advised that creating innovative solution for the restraining qualities of 
Results

blockchain such as offering solution for privacy restrictions due to increased transparency or lowering set up and operation costs by introducing sidechains can be introduced as SVP.

Figure 4.1. Guidelines for adopting blockchain in supply chains

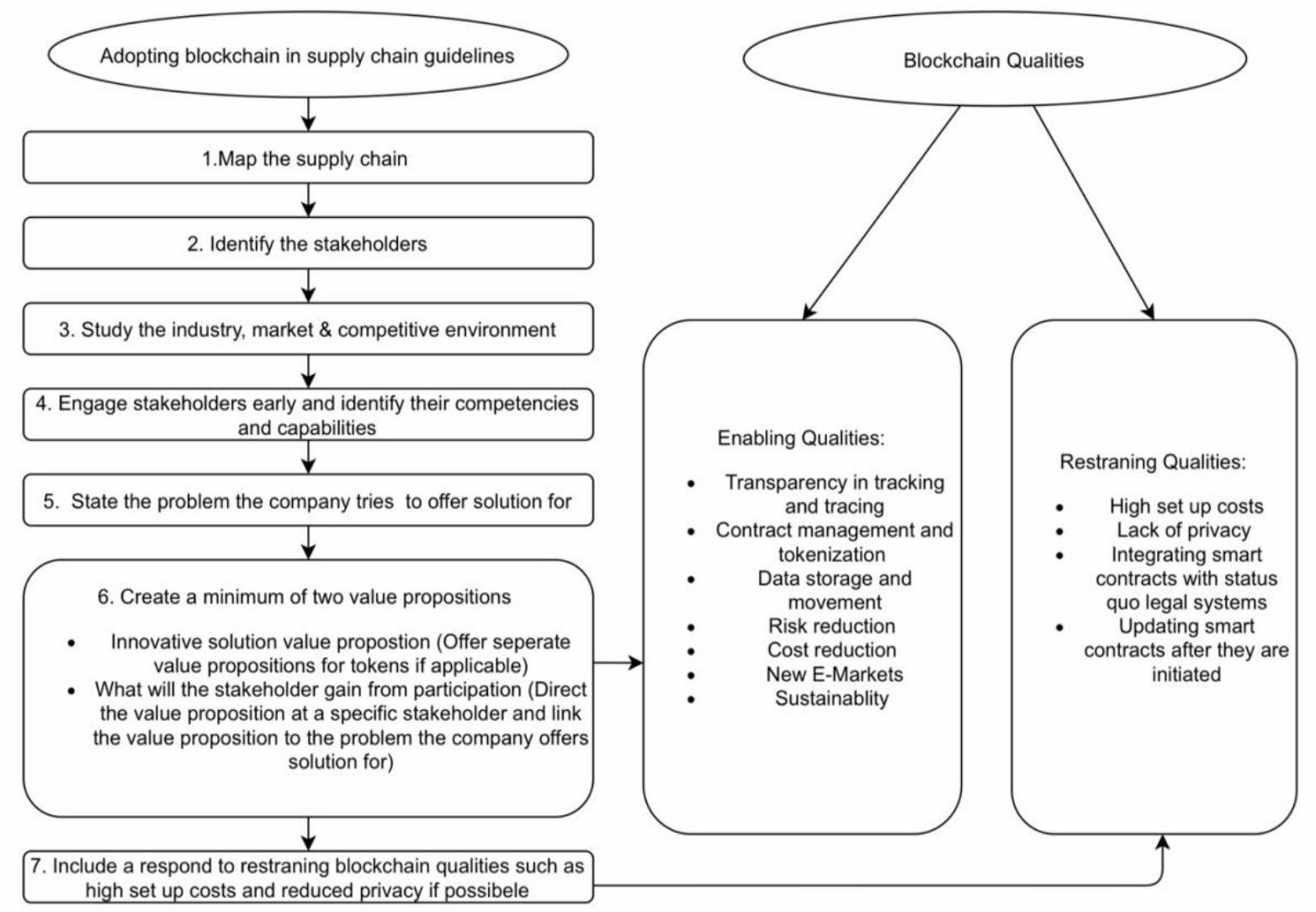

Framework 4.1 is a modification of framework 2.1 in chapter two. It shows all the elements in that framework drawn from Martinez and Bititci (2006), Rodriguez et al. (2018), Payne et al. (2017), and Wouters et al. (2018) for the stakeholder value proposition creation on the left side of the framework. The right side of the framework is a modification of blockchain quality concept drawn from Angelis and Da Silva (2019), Hald and Kinra (2019), Kshetri (2018), Chang et al. (2019), Kumar et al. (2019), Min (2019), and Allen et al. (2019). 
Results

The left side of framework has been modified to include two more steps, namely steps 5 and 6 based on the insights in chapter four of this thesis. In chapter four the findings from the descriptive data and their cross-case analysis were presented that indicate companies identify the problems they try to address and the values they offer addresses how they will eliminate and solve the problems they have introduced. So, it is suggested that this step be added to the steps necessary for successful SVP creation.

The companies in this study have also offered specific value propositions for their tokens if that is on of the services they offer. Thus, in step 6 of the framework that argues for a minimum of two value proposition creation it is argued that companies also create separate value proposition for their tokens if that is part of their services. Finally, as companies in this study have addressed some of the restraining qualities of blockchain adoption in their value proposition, it is suggested that companies not only use enabling blockchain qualities but also consider restraining qualities when creating value propositions.

The right side of the framework depict the blockchain qualities. The enabling qualities are transparency in tracking and tracing, contract management and tokenization, data storage and movement, cost reduction, risk reduction, E-markets and sustainability. The enabling blockchain qualities are lack of privacy, high set up costs, challenges in editing smart contracts after they have been initiated and integrating smart contracts in status quo legal systems. The insights from this chapter indicate that the companies in this study use transparency in tracking and tracing, contract management and tokenization, data movement and storage to create SVP more than other enabling qualities. The findings also demonstrate that companies leverage restraining blockchain qualities to create SVP through innovative solutions. The restraining qualities the companies have used to create SVP are high set up costs and lack of privacy. The companies have created SVP related to 


\section{Results}

these restraining qualities by addressing how the restraints are resolved through innovative solutions. It is therefore suggested the companies not only look at blockchain enabling qualities but also the restraining qualities when creating SVPs. 
Discussion

\section{Chapter 5. Discussion}

This chapter includes four sections. The first section answers the main questions of the research including what blockchain qualities are used to create stakeholder value proposition in shipping and logistic industry supply chains? What are the steps in creating stakeholder value proposition? What are the enabling and restraining blockchain qualities when blockchain is adopted in SCM? The next sections include recommendations for practice, research limitations, and lessons learned and future research opportunities.

\subsection{Contribution to theory}

The following section discusses the contribution of this research to theory by providing the answer to the research question. The first subsection answers the main research question. The second and third subsections answer the following question respectively; What are the steps in creating stakeholder value proposition? What are the enabling and restraining blockchain qualities when adopted in supply chain management?

\subsubsection{What blockchain qualities are used to create stakeholder value proposition} in shipping and logistics industry supply chains?

In chapter two on literature review, the steps that must be taken by companies to create stakeholder value propositions were identified by reviewing relevant articles on the topic. Based on the findings, there are five main steps to create successful stakeholder value proposition (Martinez \& Bititci, 2006; Frow \& Payne, 2011, Payne et al., 2017; Wouters et al., 2018). These five steps are 1) mapping the supply chain, 2) identifying stakeholders, 3) researching the industry, market, and competitive environment, 4) engaging the stakeholders at an early stage and determining their competencies and capabilities, and 5) creating a minimum of two value 
Discussion

propositions, one of which must explain the innovative solution while the other must explain what the stakeholder will gain from their participation (Wouters et al., 2018; Eggert et al., 2018; Rodriguez et al., 2018; Payne et al., 2017).

Chapter two also provides a review of literature on blockchain qualities when adopted in supply chains. The findings in the articles were combined to find seven enabling and four restraining qualities to blockchain when adopted in supply chains (Kshetri, 2018; Hald \& Kinra, 2019; Angelis \& Da Silva, 2019). The seven enabling qualities are: 1) transparency in tracking and tracing, 2) contract management and tokenization, 3) data storage and movement, 4) cost reduction, 5) risk reduction, 6) new e-markets, and 7) sustainability (Hald \& Kinra, 2019; Kshetri, 2018; Chang et al., 2019). The four restraining qualities are: 1) high set up costs, 2) lack of privacy, 3) problems surrounding integration of smart contracts with status quo legal systems, and 4) problems in updating smart contracts once they have been initiated (Hald \& Kinra, 2019).

Five company cases were chosen in the shipping and logistic industry, which have adopted blockchain to resolve their supply chain problems. These five companies were examined against the enabling qualities to determine what qualities were used to create stakeholder value propositions. The presentation of these five cases, the cross-case examination, and the insights introduced through the case studies are contributions of this thesis.

It was determined that among these five cases the data storage and movement, tracking and tracing, as well as contract management and tokenization are the qualities most used in creating stakeholder value proposition (OpenPort.com,2020; Thecargocoin.com, 2020; Docs.tradelens.com, 2020; Shipchainwhitepaper.io, 2020). Also, one of the findings in the present research was that the companies offer increased speed and enhanced visibility through one of the three main enabling qualities mentioned above. 
Discussion

It was also determined that the companies in most cases have generated general value propositions that are not directed at a specific stakeholder while they have determined all the stakeholders in their ecosystem (Openport.com, 2020; Thecargocoin.com, 2020; Cargox.io, 2020; IBM.com, 2020). One out of five companies had failed to generate any value propositions directed at stakeholders (Cargox.io, 2020). However, the other four had managed to offer stakeholder specific value propositions for shippers and transporters. The company case overviews also indicated that each company had explained the problem they tried to solve and tried to link their value proposition to the problem they had introduced. Further, four out of the five companies included utility tokens in their innovative solution for which they offered a separate value proposition (Openport.com, 2020; Thecargocoin.com, 2020; Cargox.io, 2020; Shipchainwhitepaper.io, 2020).

Also, two out of the five companies had created value propositions that responded to one of the restraining qualities of blockchain (Docs.tradelens.com, 2020; Shipchainwhitepaper.io, 2020). One company responded to high set-up costs by creating an innovative solution and one company created a value proposition indicating that the privacy of the stakeholder and their data will be maintained through providing the organization's data to the involved parties only.

Based on these findings, a seven-step guideline was conducted that has some adjustments on the five main steps companies must take to create successful value propositions. This guideline can be found in the last section of the results chapter. In this guideline which was created to help companies that adopt blockchain in supply chain create more successful value propositions, two steps were added to the five main steps for stakeholder value proposition creation. One of the steps added is identifying the problem the company tries to find a solution for. And one step is to respond to the restraining qualities of blockchain when possible. It is also suggested that if the companies 
Discussion

use utility tokens in their innovative solutions, they should create a separate value propositions for utility tokens. The guideline and the findings that indicate data storage and movement, contract management and tokenization and tracking and tracing are contributions to theory to fill the gap that exists as the preview studies fail to examine SVP in blockchain adoption in this industry.

\subsubsection{What are the steps in creating stakeholder value propositions?}

Multiple articles were reviewed in the terms of value proposition. The stakeholder value proposition, unlike customer value proposition is a novel subject with not so many studies and articles conducted on this matter. However, by reviewing all the articles in the subject, it was determined that there are five main steps taken by companies to create successful stakeholder value propositions (Anderson et al., 2006; Martinez \& Bititci, 2006; Wouters et al., 2018).

The five steps include mapping the supply chain, identifying the stakeholders, researching

the industry, the market and the competitive environment, engaging early with stakeholder and determining their competencies and capabilities, and developing at least two value propositions. One value proposition should explain the innovative solution and one value proposition should explain what the stakeholder will gain for their participation (Wouters et al., 2018; Rodriguez et al, 2018; Eggert et al., 2018; Martinez \& Bititci, 2006).

It was outside of the scope of this study to determine whether these steps were taken by companies when they created their value proposition, however, the findings in the result chapter indicate that certain cases have offered their value propositions in a general manner rather than direct it at a specific stakeholder while they had identified the stakeholders within their ecosystems. 
Discussion

This indicates that while the companies are successful in identifying their stakeholders, they have failed to create directed value propositions for each stakeholder.

\subsubsection{What are the blockchain enabling and restraining qualities when adopted in}

\section{supply chain?}

Articles on blockchain qualities were reviewed, and the findings were combined to create seven enabling and four restraining qualities of blockchain applications in SCM. The seven enabling qualities are: 1) transparency in tracking and tracing, 2) contract management and tokenization, 3) data storage and movement, 4) cost reduction, 5) risk reduction, 6) new e-markets and 7) sustainability (Hald \& Kinra, 2019; Kshetri, 2018; Angelis \& Da Silva, 2019; Chang et al., 2019; Allen et al., 2019). However, there were other factors introduced in the reviewed articles, such as enhanced speed and visibility, but these were not considered separate qualities for the purpose of this study because they are directly associated benefits of the seven previously mentioned enabling qualities (Kshetri, 2018; Angelis \& Da Silva, 2019). This was also confirmed after the company cases were reviewed and it was determined that the cases offer increased speed and visibility mostly as one of the benefits gained from enhanced tracking and tracing or enhanced data storage and movement.

There were also four restraining qualities introduced in the seven articles, including 1) high set up costs, 2) lack of privacy, 3) problems surrounding integration of smart contracts and status quo legal systems, and 4) updating smart contracts after they are initiated (Hald \& Kinra, 2019). It was not logical to expect companies would leverage restraining qualities to create value propositions however, two of the five cases within this study have offered creative solutions for 
Discussion

some of these restraining qualities (Docs.tradelens.com, 2020; Shipchainwhitepaper.io, 2020). One company has offered a sidechain as a solution of reduce the data storage costs, stating that by storing the detailed data on the sidechain and saving space on the main blockchain the blockchain costs will be reduced, however they do not determine how this sidechain is similar to the main blockchain in the safe and immutable storage of data but with lower costs. Another case mentioned that the privacy of the data will be ensured by sharing them with the involved parties only.

\subsection{Implications to practice}

A seven-step guideline was introduced in the end of the results section. These seven steps are an adjustment of the five main steps companies must take to create stakeholder value propositions. In other words, two new steps were added, and one step was adjusted to create a detailed guideline for practitioners on creating stakeholder value propositions when adopting blockchain technology in SCM.

One of the steps added is identifying the problem the company tries to offer solution for. All case companies in this study had identified the problem their offered solution resolves and they had explained how resolving that problem will benefit the stakeholders within their ecosystem. One of the steps, which indicates that two main value propositions must be created, was modified. It is suggested that there can still be two minimum value propositions. However, for the value proposition that offers the innovative solution, we suggest that the companies consider creating separate value propositions for their utility tokens, if they use tokens within their platforms as this seems to be the customary practice and helps stakeholder realize the value of utility tokens separate from the blockchain platform. 
Discussion

Another, concluding step was added to the framework in order to suggest that companies try to address the restraining qualities when applicable. As mentioned, two out of five case companies in this study had addressed two of the restraining qualities. One of them offered a creative solution to reduce the set-up costs and the other addressed the issues surrounding the privacy concerns stakeholders may have.

\subsection{Research limitations}

This research was conducted using secondary sources of data and information. The company cases were created using data gathered from news agencies, articles, company websites and white papers. The findings indicate that the companies in this study have not always been successful in offering a value proposition to specific stakeholders even though all of them have identified the stakeholders within their ecosystem. This suggests that these companies have failed to link value propositions to stakeholders, or they do not offer specific value propositions on their websites or white papers which may indicate failure to communicate the value propositions to potential partners. Further research is needed to answer whether these companies create value proposition on a general level or on a stakeholder level, and if they create separate value propositions for each of their stakeholders how do they communicate them to their partners if not publishing them on their websites and white papers?

Another finding of this paper is based on the number of statements gathered from company white papers and while the findings have given strong indications on which enabling qualities are used more in this field to create stakeholder value proposition, the data will be stronger if future studies evaluate a high number of cases. 
Discussion

\subsection{Future research opportunities}

There are at least three significant research opportunities for future studies. First, a deeper and continued research on enabling and restraining blockchain qualities while keeping the focus on restraining qualities is needed to help companies address the doubts of partners and move away from the idea that presents the blockchain technology as the ultimate solution. Through further research in the restraining qualities and new innovative solutions to address those restraining qualities greater stakeholder value propositions can be created.

Second, future research could choose a case study in this field, one that operates on an endto-end platform with many different stakeholders as potential partners and stakeholders within their ecosystem and conduct an extensive research on the value propositions created for each stakeholder group, including the way the value propositions are offered and communicated to the stakeholders.

Third, additional research could replicate the current study using more cases or conduct the current study in supply chains of other industries to see if the findings in regard to blockchain enabling qualities would be similar or contradictory in across industries. 
Conclusion

\section{Chapter 6. Conclusion}

This study was conducted to answer the question which blockchain qualities are used to create stakeholder value proposition in blockchain adopted supply chains. The study was conducted in six chapters. In the study, enabling and restraining blockchain qualities were identified as 1) transparency in tracking and tracing, 2) data storage and movement, 3) contract management and tokenization, 4) cost reduction, 5) risk reduction, 6) E-markets, and 7) sustainability (Kshetri, 2018; Hald \& Kinra, 2019). The necessary steps to create SVP were also identified as mapping the SC, identifying the stakeholder, considering market and industry, engaging with customer at an early stage, and creating a minimum of two value propositions (Martinez \& Bititci, 2006; Wouters et al., 2018).

Five case companies' VPs were identified and examined to find what enabling blockchain qualities were used to create the SVP. The findings indicate that especially data storage and movement, contract management and tokenization, and transparency in tracking and tracing are used to create and introduce SVP in shipping and logistic companies that operate on a blockchain based platform. Other findings of the research indicated that firms operating in this industry identified the problems they offer solution for, and four out of five case companies used token utilities. These companies offer separate value propositions for their tokens. Some companies also offer innovative solutions to resolve restraining blockchain qualities as value propositions.

As a conclusion, we believe that this study helps both scholars and practitioners to better understand how blockchain technology can aid in creating viable stakeholder value propositions in supply chains. Further, we anticipate that, in the coming years, blockchain technology will be increasingly adopted by companies across industries, and there will be ample opportunities to learn from those companies' experiences, especially in supply chain management. 
List of References

\section{List of References}

Allen, D., Berg, C., Davidson, S., Novak, M., \& Potts, J. 2019. International policy coordination for blockchain supply chains. Asia \& the Pacific Policy Studies, 6(3): 367-380.

Anderson, J. C., Narus, J. A., \& van Rossum, W. 2006. Customer Value Propositions in Business Markets. Harvard Business Review, 84(3): 90-99.

Angelis, J. \& Ribeiro Da Silva, E. 2019. Blockchain adoption: A value driver perspective. Business Horizons, [Online] 62 (3):307-314.

Bailetti, T., Tanev, S. and Keen, C. 2020. What Makes Value Propositions Distinct and Valuable to New Companies Committed to Scale Rapidly?. Technology Innovation Management Review, 10(6): 14-27.

Bailetti, T. and Tanev, S. 2020. Examining the Relationship Between Value Propositions and Scaling Value for New Companies. Technology Innovation Management Review, 10(2): $5-13$.

Ballou, R., Gilbert, S. and Mukherjee, A. 2000. New Managerial Challenges from Supply Chain Opportunities. Industrial Marketing Management, 29(1): 7-18.

Bedin, A., Capretz, M., \& Mir, S. 2021. Blockchain for Collaborative Businesses. Mobile Networks and Applications, 26(1): 277-284.

Beth, S., Burt, D., Copacino, W., Gopal, C., Lee, H., Lynch, R., \& Morris, S. 2003. Supply chain challenges. building relationships. Harvard Business Review, 81(7): 64-117.

Cahill, D., G. Baur, D., (Frank) Liu, Z., \& W. Yang, J. 2020. I am a blockchain too: How does the market respond to companies' interest in blockchain? Journal of Banking $\boldsymbol{\&}$ Finance, 113, 105740-.

Casado-Vara, R., Prieto, J., la Prieta, F.D. \& Corchado, J.M. 2018. How blockchain improves the supply chain: case study alimentary supply chain. Procedia Computer Science, 134: 393-398.

Chang, S.E., Chen, Y. \& Lu, M. 2019. Supply chain re-engineering using blockchain technology: A case of smart contract based tracking process. Technological Forecasting \& Social Change, 144: 1-11.

Chowdhury, M., Colman, A., Kabir, M., Han, J., \& Sarda, P. 2018. Blockchain Versus Database: A Critical Analysis. 17th IEEE International Conference On Trust, Security And Privacy In Computing And Communications/ 12th IEEE International Conference On Big Data Science And Engineering (TrustCom/BigDataSE), 1348-1353. 
List of References

Christopher, M. and Lee, H. 2004. Mitigating supply chain risk through improved confidence. International Journal of Physical Distribution \& Logistics Management, 34(5): 388396.

Clauson, K., Breeden, E., Davidson, C. and Mackey, T. 2018. Leveraging Blockchain Technology to Enhance Supply Chain Management in Healthcare: Blockchain in Healthcare Today, 1(3): 1-12.

Cole, R., Stevenson, M. and Aitken, J. 2019. Blockchain technology: implications for operations and supply chain management. Supply Chain Management: An International Journal, 24(4): 469-483.

Dobroszek, J. 2020. Supply chain and logistics controller - two promising professions for supporting transparency in supply chain management. Supply Chain Management, 25(5): 505-519.

Eggert, A., Ulaga, W., Frow, P., Payne, A. 2018. Conceptualizing and communicating value in business markets: From value in exchange to value in use. Industrial Marketing Management, 69: 80-90.

Eisenhardt, K., \& Graebner, M. 2007. Theory building from cases: opportunities and challenges. Academy of Management Journal, 50(1): 25-32.

Esfahbodi, A., Zhang, Y., Watson, G., \& Zhang, T. 2017. Governance pressures and performance outcomes of sustainable supply chain management - An empirical analysis of UK manufacturing industry. Journal of Cleaner Production, 155: 66-78.

Evangelista, P. and Sweeney, E. 2006. Technology usage in the supply chain: the case of small 3PLs. The International Journal of Logistics Management, 17(1): 55-74.

Fiala, P. 2005. Information sharing in supply chains. Omega, 33(5): 419-423.

Freeman, R. 1984. Strategic management : a stakeholder approach. Boston: Pitman.

Frow, P., \& Payne, A. 2011. A stakeholder perspective of the value proposition concept. European Journal of Marketing, 45(1/2): 223- 240.

Hald, K. and Kinra, A. 2019. How the blockchain enables and constrains supply chain performance. International Journal of Physical Distribution \& Logistics Management, 49(4):376-397.

Hong, J., Zhang, Y., \& Ding, M. 2018. Sustainable supply chain management practices, supply chain dynamic capabilities, and enterprise performance. Journal of Cleaner Production, 172: 3508-3519. 
List of References

Huemer, L. 2012. Unchained from the chain: Supply management from a logistics service provider perspective. Journal of Business Research, 65(2): 258-264.

Hussain, M., Khan, M., \& Al-Aomar, R. 2016. A framework for supply chain sustainability in service industry with Confirmatory Factor Analysis. Renewable and Sustainable Energy Reviews, 55: 1301-1312.

Issaoui, Y., Khiat, A., Bahnasse, A. and Ouajji, H. 2019. Smart logistics: Study of the application of blockchain technology. Procedia Computer Science, 160: 266-271.

Jensen, T., Hedman, J., \& Henningsson, S. 2019. How TradeLens Delivers Business Value With Blockchain Technology. MIS Quarterly Executive, 18(4): 221-243.

Konovalenko, I., \& Ludwig, A. 2019. Event processing in supply chain management - The status quo and research outlook. Computers in Industry, 105: 229-249.

Kshetri, N. 2018. 1 Blockchain's roles in meeting key supply chain management objectives. International Journal of Information Management, 39: 80-89.

Kumar, A., Liu, R. and Shan, Z. 2019. Is Blockchain a Silver Bullet for Supply Chain Management? Technical Challenges and Research Opportunities. Decision Sciences, 51(1): 8-37.

Kumar, K. 2001. Technology for supporting supply chain management. Association for Computing Machinery. Communications of the ACM. [Online] 44 (6): 58-61.

Li, X., Jiang, P., Chen, T., Luo, X., \& Wen, Q. 2020. A survey on the security of blockchain systems. Future Generation Computer Systems, 107: 841-853.

Martinez, V. and Bititci, U. 2006. Aligning value propositions in supply chains. International Journal of Value Chain Management, 1(1): 6-18.

Min, H. 2019. Blockchain technology for enhancing supply chain resilience. Business Horizons, 62(1): 35-45.

Nathan, S., Govindarajan, C., Saraf, A., Sethi, M., \& Jayachandran, P. 2019. Blockchain meets database: design and implementation of a blockchain relational database. Proceedings of the VLDB Endowment, 12(11): 1539-1552.

Nene, S., Westerlund, M., Leminen, S., Rajahonka, M. 2019. Benefits of blockchain-based traceability in food supply chains. ISPIM Connects Ottawa 2019 Conference Proceedings, 1-12. 
List of References

Payne, A., Frow, P., \& Eggert, A. 2017. The customer value proposition: evolution, development, and application in marketing. Journal of the Academy of Marketing Science, 45(4): 467-489.

Petersen, M., Hackius, N. and von See, B. 2018. Mapping the sea of opportunities: Blockchain in supply chain and logistics. it - Information Technology, 60(5-6): 263-271.

Pournader, M., Shi, Y., Seuring, S. and Koh, S. 2019. Blockchain applications in supply chains, transport and logistics: a systematic review of the literature. International Journal of Production Research, 58(7): 2063-2081.

Queiroz, M., Telles, R., \& Bonilla, S. 2019. Blockchain and supply chain management integration: a systematic review of the literature. Supply Chain Management: An International Journal, 25(2): 241-254.

Rodriguez, P., Mendes, E., \& Turhan, B. 2018. Key Stakeholders' Value Propositions for Feature Selection in Software-intensive Products: An Industrial Case Study. IEEE Transactions on Software Engineering, 46(12):1340-1363.

Rong, K., \& Shi, Y. 2014. Business ecosystems : constructs, configurations, and the nurturing process, London: Palgrave Macmillan.

Saberi, S., Kouhizadeh, M., Sarkis, J., \& Shen, L. 2018. Blockchain technology and its relationships to sustainable supply chain management. International Journal of Production Research, 57(7): 2117-2135.

Saberi, S., Kouhizadeh, M. and Sarkis, J. 2019. Blockchains and the Supply Chain: Findings from a Broad Study of Practitioners. IEEE Engineering Management Review, 47(3): 95-103.

Seth, N, Deshmukh S.G., \& Vrat, P. 2006. A conceptual model for quality of service in the supply chain. International Journal of Physical Distribution \& Logistics Management, 36(7): 547-575.

Schmidt, C. and Wagner, S. 2019. Blockchain and supply chain relations: A transaction cost theory perspective. Journal of Purchasing and Supply Management, 25(4):100552-.

Song, J., Sung, J. and Park, T. 2019. Applications of Blockchain to Improve Supply Chain Traceability. Procedia Computer Science, 162: 119-122.

Tönnissen, S. \& Teuteberg, F. 2019. Analysing the impact of blockchain-technology for operations and supply chain management: An explanatory model drawn from multiple case studies. International Journal of Information Management, 52: 1019553-.

Töytäri, P. and Rajala, R. 2015. Value-based selling: An organizational capability perspective. Industrial Marketing Management, 45: 101-112. 
List of References

Van Donk, D., P. 2008. Challenges in relating supply chain management and information and communication technology. International Journal of Operations \& Production Management, 28(4): 308-312.

Vargo, S., Maglio, P. and Akaka, M. 2008. On value and value co-creation: A service systems and service logic perspective. European Management Journal, 26(3): 145-152.

Wouters, M., Anderson, J., Kirchberger, M. 2018. New- Technology Startups Seeking Pilot Customers: Crafting a Pair of VPs. California Management Review, 60(4): 101-124.

Yang, C. 2019. Maritime shipping digitalization: Blockchain-based technology applications, future improvements, and intention to use. Transportation Research Part E: Logistics and Transportation Review, 131: 108-117.

Yin, R. K. 2018. Case study research and applications (6th ed.). Los Angeles, CA: SAGE Publications.

Yu, Y., Wang, X., Zhong, R., \& Huang, G. 2017. E-commerce logistics in supply chain management: Implementations and future perspective in furniture industry. Industrial Management + Data Systems, 117(10): 2263-2286.

Zalan, T. 2018. Born global on blockchain. Review of International Business and Strategy, Vol. 28 (1): 19-34.

Zhang, X., Pieter van Donk, D. and van der Vaart, T. 2011. Does ICT influence supply chain management and performance?. International Journal of Operations \& Production Management, 31(11): 1215-1247. 
List of References

\section{List of Websites:}

Anzalone, R. 2020. ShipChain Thinks Public Blockchain Can Transform Logistics For Small Business. [online] Forbes. Available at:

$<$ https://www.google.com/amp/s/www.forbes.com/sites/robertanzalone/2020/04/20/shipc hain-thinks-public-blockchain-can-transform-logistics-for-small-business/amp/> [Accessed 8 May 2020].

Built In. 2021. Making moves: How blockchain is quickly becoming a must-have in logistics. [online] Available at: $<$ https://builtin.com/blockchain/blockchain-supply-chain-logisticsuses $>$ [Accessed 7 March 2020].

Cargox.io. 2020. [online] Available at: $<$ https://cargox.io/static/files/CargoX-BusinessOverview-Technology-Bluepaper.pdf $>$ [Accessed 7 February 2020].

Disruptor Daily. 2021. 28 Startups Using Blockchain To Transform Supply Chain Management [Market Map] - Disruptor Daily. [online] Available at:

$<$ https://www.disruptordaily.com/blockchain-market-map-supply-chain-management/> [Accessed 18 March 2020].

Docs.tradelens.com. 2020. TradeLens Documentation. [online] Available at:

$<$ https://docs.tradelens.com/\#welcome-to-the-official-documentation-site-for-tradelens $>$ [Accessed 15 January 2020].

Durr, C.2020. An Introduction to CargoCoin. [online] Medium. Available at: $<$ https://medium.com/@cdurr/an-introduction-to-cargocoin-62cad86442ec $>$ [Accessed 4 June 2020].

Express Computer. 2020. Shipwaves Joins Maersk-IBM Developed TradeLens Platform In a Bid To Accelerate Digitisation. Express Computer.

Finance digest. 2020. [online] Available at: $<$ https://www.financedigest.com/openportannounces-joint-venture-with-xvc-logistics-to-introduce-blockchain-enabled-proof-ofdelivery-and-rewards-program.html> [Accessed 12 March 2020].

FreightWaves. 2020. OpenPort joins the Blockchain in Transport Alliance to further transform the logistics industry - FreightWaves. [online] Available at: $<$ https://www.freightwaves.com/news/openport-joins-bita $>$ [Accessed 8 May 2020]. 
List of References

Ibm.com. 2020. TradeLens container logistics solution. [online] Available at:

$<$ https://www.ibm.com/blockchain/solutions/container-logistics $>$ [Accessed 15 January 2020].

Manaadiar, H., 2020. Product Review : CargoX Platform - secure, trusted, instant transfer for trade documents. [online] Shipping and Freight Resource. Available at:

$<$ https://www.shippingandfreightresource.com/the-cargox-platform-secure-trustedinstant-transfer-for-trade-documents/> [Accessed 8 March 2020].

Medium. 2020. CargoCoin \& UGSA strategic partnership. [online] Available at:

$<$ https://medium.com/@thecargocoin/cargocoin-ugsa-strategic-partnership927173e5d273> [Accessed 18 March 2020].

Openport.com. 2020. [online] Available at: <https://openport.com/wpcontent/uploads/2021/02/2018.01_OpenPort-Whitepaper_Blockchain-Logistics-Protocol1.pdf $>$ [Accessed 7 June 2020].

OriginTrail.io. 2020. [online] Available at: $<$ https://origintrail.io/storage/documents/OriginTrailWhite-Paper.pdf?_cf_chl_jschl_tk_=f47c8e813c387f4c0b72fe22d82b4ed76a056adc1615150028-0-AfN_21zliIxRzfUkvgfMfKhgvK3F2wGsMIqidce7eXpmvdPK1DBjW9A2j1ae4rlnX3ONcbSqxqX5w6kVs5QqQ16upO2b 5L2Z5gMkxMy8tFYyxkd7P3jJh7AJ3LHU51BVOUJXTp_IveHwe2Oy9yuzBcDHT8StJy gXmxLWU0q6T81S79YHLVYkPn9BnjJCUfYY6iftTKdGxY26JT2T_KaDXsVBmG5u x1lnO-7HeWKQmOI-

1P4pGhjkplsUYeULTcMzsFNxadUfpgPybByXq8SyYsqygMoXLByclMRAjDQgnOQeir 0wvr_JfaVmMlrfz2CcmtLXw9ghdxXNifE1BruyCfexT3qrn3jTATWYXywBU8_ycO0cNDzpUBFj-UIMAmUQ> [Accessed 4 May 2020].

Ortynski, V.2020. The long road to electronic bill of lading adoption. [online] Medium. Available at: <https://medium.com/cargoxio/the-long-road-to-electronic-bill-of-ladingadoption-104e8d3cb471> [Accessed 10 January 2020].

Ručigaj, S. 2020. The CargoX Platform for Blockchain Document Transfer (BDT) on Ethereum makes entry into the world.... [online] Medium. Available at: 
List of References

$<$ https://medium.com/cargoxio/the-cargox-platform-for-blockchain-document-transferbdt-on-ethereum-makes-entry-into-the-world-65d9847b6ed0> [Accessed 3 February 2020].

StartUs Insights. 2021. 8 Blockchain Startups Disrupting The Supply Chain Industry. [online] Available at: $<$ https://www.startus-insights.com/innovators-guide/8-blockchain-startupsdisrupting-the-supply-chain-industry/> [Accessed 7 March 2020].

TechRepublic. 2021. 5 companies using blockchain to drive their supply chain. [online] Available at: $<$ https:/www.techrepublic.com/article/5-companies-using-blockchain-todrive-their-supply-chain/> [Accessed 20 February 2021].

Thecargocoin.com. 2020. [online] Available at: $<$ https://thecargocoin.com/docs/CargoCoinWhitepaper.pdf $>$ [Accessed 7 April 2020].

Whitepaper.io. 2020. ShipChain whitepaper - whitepaper.io. [online] Available at: $<$ https://whitepaper.io/document/359/shipchain-whitepaper $>$ [Accessed 7 March 2020].

Www3.technologyevaluation.com. 2020. TradeLens White Papers and Case Studies. [online] Available at: $<$ https://www3.technologyevaluation.com/research/vendor/tradelens.html $>$ [Accessed 12 January 202 
Appendix

Appendix A: Statements drawn from Openport.com, 2020

\begin{tabular}{|c|c|c|c|c|}
\hline & $\begin{array}{l}\text { Blockchain } \\
\text { quality }\end{array}$ & Statements adopted from OpenPort White paper & page & $\begin{array}{l}\text { Stakehold } \\
\text { er }\end{array}$ \\
\hline 1 & \multirow{7}{*}{$\begin{array}{l}\text { Contract } \\
\text { management } \\
\& \\
\text { tokenization }\end{array}$} & $\begin{array}{l}\text { "At OpenPort, we are committed to solving one of the } \\
\text { greatest challenges in the modern supply chain - the cash } \\
\text { flow problem" }\end{array}$ & $\begin{array}{l}\text { Execu } \\
\text {-tive } \\
\text { summ } \\
\text {-ary }\end{array}$ & \\
\hline 2 & & $\begin{array}{l}\text { "Digital payment via OpenPort's token (OPN), made upon } \\
\text { fulfilling the conditions of the smart contract and successful } \\
\text { ePOD, will drastically accelerate the payment cycle to the } \\
\text { benefit of all parties." }\end{array}$ & $\begin{array}{l}\text { Execu } \\
\text {-tive } \\
\text { summ } \\
\text {-ary }\end{array}$ & \\
\hline 3 & & $\begin{array}{l}\text { "either shippers purchase transport via OpenPort, or they use } \\
\text { the system standalone, and pay per transaction. This hybrid } \\
\text { system and/or service model allows us to scale rapidly and } \\
\text { embed our ePOD system to improve core business cash flow } \\
\text { for both shippers and transporters by linking payments to } \\
\text { ePOD" }\end{array}$ & 1.5 & $\begin{array}{l}\text { Shippers } \\
\& \\
\text { Transport } \\
\text { ers }\end{array}$ \\
\hline 4 & & $\begin{array}{l}\text { "Payments and clearance processes are facilitated because } \\
\text { supplier terms, letter of credit, trade finance and ePOD } \\
\text { triggered payments are all contained in smart contracts." }\end{array}$ & 2.1 & \\
\hline 5 & & $\begin{array}{l}\text { "Cash flow is vastly increased via a digital currency off- } \\
\text { ramp as the immutable ePOD triggers payments from retailer } \\
\text { to shipper and shipper to transporter, improving working } \\
\text { capital. The result to the shipper is better rates and service, } \\
\text { while the transporter receives faster payment and increased } \\
\text { volumes" }\end{array}$ & 2.1 & $\begin{array}{l}\text { Shippers } \\
\& \\
\text { Transport } \\
\text { ers }\end{array}$ \\
\hline 6 & & $\begin{array}{l}\text { "Transporters must utilize OpenPort technology to receive } \\
\text { payment, which improves their cash flow to support asset } \\
\text { operating costs and, at the same time, drives value to other } \\
\text { supply chain stakeholders especially the shipper of the } \\
\text { goods, by improving visibility and providing real-time } \\
\text { ePOD." }\end{array}$ & 2.1 & $\begin{array}{l}\text { Shippers } \\
\& \\
\text { Transport } \\
\text { ers }\end{array}$ \\
\hline 7 & & $\begin{array}{l}\text { "enterprise shippers procuring logistics receive savings in } \\
\text { improved transport rates made available by transporters, on }\end{array}$ & 2.1 & Shippers \\
\hline
\end{tabular}




\begin{tabular}{|c|c|c|c|c|}
\hline & & $\begin{array}{l}\text { the basis of low payment risk and improved settlement of } \\
\text { freight rates, (plus discounts on transport offered initially by } \\
\text { OpenPort)." }\end{array}$ & & \\
\hline 8 & & $\begin{array}{l}\text { "OPN transfer to transporter links together the ERP } \\
\text { integrated smart contract, writing of events to the ledger } \\
\text { from pick up to delivery, and the ePOD confirmation and } \\
\text { digital signature. Payments between all parties is made on } \\
\text { completion of conditions contained in the smart contract, } \\
\text { within hours of completed delivery as opposed to weeks if } \\
\text { not months of delay in the legacy payment process" }\end{array}$ & 2.3 & \\
\hline 9 & & $\begin{array}{l}\text { "Payment by OPN brings further benefits to the } \\
\text { multinational shipper beyond working capital. Transparency } \\
\text { will increase, and the possibility for corruption within the } \\
\text { procurement process is negated using OPN, as all transaction } \\
\text { history and payments are recorded to distributed ledgers } \\
\text { accessible by authorized consensus nodes running the } \\
\text { logistics protocol" }\end{array}$ & 2.3 & Shippers \\
\hline 10 & & $\begin{array}{l}\text { "OpenPort will generate the OpenPort "Open" token (OPN), } \\
\text { a secondary asset built on smart contracts within the } \\
\text { blockchain ecosystem and used in running OpenPort's } \\
\text { decentralized applications. Tokens will fuel smart contracts." }\end{array}$ & 2.2 & \\
\hline 11 & $\begin{array}{l}\text { data storage } \\
\text { and } \\
\text { movement }\end{array}$ & $\begin{array}{l}\text { "Smart contracts on Ethereum mated to OpenPort's ePOD } \\
\text { process ensures the validity and provenance of digitized } \\
\text { shipment documents. This introduces efficiencies to the } \\
\text { whole supply chain by reducing paperwork required in } \\
\text { document transmission, change of ownership procedures and } \\
\text { customs clearances" }\end{array}$ & 2.1 & \\
\hline 12 & & $\begin{array}{l}\text { "OEL means distributed technology that can be accessed by } \\
\text { any transporter, with detailed electronic proof of delivery } \\
\text { (ePOD) and shipment visibility at the individual unit level." }\end{array}$ & 1.4 & $\begin{array}{l}\text { Transport } \\
\text { er }\end{array}$ \\
\hline 13 & & $\begin{array}{l}\text { "our OpenTM (transport management) software and Driver } \\
\text { App, an application that allows truck drivers to use their }\end{array}$ & $\begin{array}{l}\text { Exec } \\
\text { u- } \\
\text { tive }\end{array}$ & $\begin{array}{l}\text { Transport } \\
\text { er }\end{array}$ \\
\hline
\end{tabular}




\begin{tabular}{|c|c|c|c|}
\hline & & $\begin{array}{l}\text { phones to capture ePOD and send data shipment data during } \\
\text { transport." }\end{array}$ & $\begin{array}{l}\text { sum } \\
\text { m- } \\
\text { ary }\end{array}$ \\
\hline 14 & & $\begin{array}{l}\text { "we have begun using blockchain technology in our } \\
\text { ecosystem to create an immutable ePOD with an } \\
\text { indisputable record of the freight's history, linked to a digital } \\
\text { agreement - a 'smart contract'." }\end{array}$ & $\begin{array}{l}\text { Exec } \\
\text { u- } \\
\text { tive } \\
\text { sum } \\
\text { m- } \\
\text { ary }\end{array}$ \\
\hline 15 & & $\begin{array}{l}\text { "because of problems related to the paper process, easily a } 1 \\
\text { trillion USD business problem as part of Asia's } 6 \text { trillion } \\
\text { USD annual retail sales market. OpenPort's innovative and } \\
\text { trusted ePOD solution has already begun to solve this } \\
\text { problem in China, India, Indonesia, Pakistan, and other } \\
\text { Asian countries." }\end{array}$ & 1.1 \\
\hline 16 & $\begin{array}{l}\text { Transparenc } \\
\text { y in tracking } \\
\text { and tracing }\end{array}$ & $\begin{array}{l}\text { "OpenPort will utilize blockchain to lead a paradigm shift in } \\
\text { the security and traceability of goods in the supply chain, and } \\
\text { create a token connecting payment to movement within our } \\
\text { transport marketplace." }\end{array}$ & 1 \\
\hline 17 & & $\begin{array}{l}\text { "We believe there is a need to directly connect the } \\
\text { movement of goods with payment, providing proof of pick- } \\
\text { up and delivery via a secure digital medium for speed and } \\
\text { traceability" }\end{array}$ & 1.2 \\
\hline 18 & & $\begin{array}{l}\text { "OpenPort has begun transforming the logistics industry in } \\
\text { the era of emerging markets consumption, becoming a } \\
\text { leading force shaping the supply chains of the future by } \\
\text { leveraging blockchain technology for improved visibility, } \\
\text { reliability, security, trust and cash flow in road transport" }\end{array}$ & 1.3 \\
\hline 19 & & $\begin{array}{l}\text { "The world of opaque sub-contracting by logistics } \\
\text { intermediaries, and cumbersome paper processes which } \\
\text { delay cash flow for all stakeholders is now being replaced by } \\
\text { clear visibility and faster settlement on the OpenPort } \\
\text { platform." }\end{array}$ & 1.3 \\
\hline
\end{tabular}


Appendix

\begin{tabular}{|c|c|c|c|c|}
\hline 20 & & $\begin{array}{l}\text { "Throughout the process, shipment tracking events can be } \\
\text { fed back to the customer's internal systems" }\end{array}$ & 1.6 & \\
\hline 21 & & $\begin{array}{l}\text { "The use of a validated, consensus-driven and immutable } \\
\text { public ledger with the ability to encrypt sensitive data for } \\
\text { shipment tracking and event reporting reinforces the } \\
\text { credibility of our 'breadcrumbs' technology." }\end{array}$ & 2.1 & \\
\hline 22 & & $\begin{array}{l}\text { "Active location tracking and status updates, via our } \\
\text { purpose-built Driver App applied to the phones of truck } \\
\text { drivers to provide data during transport, creates new } \\
\text { opportunities for the enterprise shipper to control security, } \\
\text { product quality and cost." }\end{array}$ & 1.6 & Shippers \\
\hline 23 & $\begin{array}{l}\text { Transparenc } \\
\text { y in } \\
\text { Tracking } \\
\text { and Tracing, } \\
\text { New E- } \\
\text { Market }\end{array}$ & $\begin{array}{l}\text { "we focus on maximizing existing transport asset utilization } \\
\text { through a neutral, data driven procurement marketplace and } \\
\text { delivering real-time status updates from tender through to } \\
\text { delivery for lower costs, increased control and improved } \\
\text { cash flow" }\end{array}$ & 1 & \\
\hline 24 & $\begin{array}{l}\text { New E- } \\
\text { Market }\end{array}$ & $\begin{array}{l}\text { "OpenPort is the digital logistics platform that transforms } \\
\text { domestic distribution in emerging markets by creating a } \\
\text { direct, transparent relationship between shippers and } \\
\text { transporters through our Open Enterprise Logistics (OEL) } \\
\text { model" }\end{array}$ & 1.4 & $\begin{array}{l}\text { Shippers } \\
\& \\
\text { Transport } \\
\text { ers }\end{array}$ \\
\hline 25 & & $\begin{array}{l}\text { "The fully scalable platform enables a direct data connection } \\
\text { between the shipper and the actual transport provider } \\
\text { creating unmatched visibility and significant savings for } \\
\text { multinational companies, while local transporters gain a } \\
\text { direct relationship with their largest clients" }\end{array}$ & 1.4 & $\begin{array}{l}\text { Shippers } \\
\& \\
\text { Transport } \\
\text { ers }\end{array}$ \\
\hline 26 & & $\begin{array}{l}\text { "As market rates and historical performance ratings of } \\
\text { providers will be available to OpenPort clients, we will } \\
\text { incrementally create a marketplace which brings highly } \\
\text { sought-after transparency to a fragmented and fast-growing } \\
\text { industry, fundamentally changing how goods are distributed } \\
\text { to new consumers in emerging Asia and beyond." }\end{array}$ & 1.5 & \\
\hline
\end{tabular}


Appendix

\begin{tabular}{|c|c|c|c|c|}
\hline 27 & & $\begin{array}{l}\text { "The OEL model features a free-to-use neutral marketplace } \\
\text { for transport procurement where transporters publish rates } \\
\text { and collaborate directly with large shippers for tenders, both } \\
\text { for smart contracts and on-demand ad-hoc transport } \\
\text { procurement." }\end{array}$ & 1.6 & $\begin{array}{l}\text { Transport } \\
\text { er }\end{array}$ \\
\hline 28 & & $\begin{array}{l}\text { "The marketplace allows shippers to negotiate directly, in- } \\
\text { housing their supply chain procurement while gaining } \\
\text { unprecedented visibility and tracking" }\end{array}$ & 1.6 & Shippers \\
\hline 29 & $\begin{array}{l}\text { Data storage } \\
\text { and } \\
\text { movement, } \\
\text { Transparenc } \\
\text { y in tracking } \\
\text { and tracing }\end{array}$ & $\begin{array}{l}\text { "Irrefutable, immutable and auditable ePOD and provenance } \\
\text { answers the question "exactly what got delivered, when, and } \\
\text { how"?" }\end{array}$ & 2.1 & \\
\hline 30 & $\begin{array}{l}\text { Cost } \\
\text { reduction }\end{array}$ & $\begin{array}{l}\text { "OPN allows better control of speed and lowered transaction } \\
\text { costs in an industry where margins for transporters can be } \\
\text { slim (less than } 5 \% \text {, improving over time with the adoption of } \\
\text { OpenPort technology)." }\end{array}$ & 2.2 & $\begin{array}{l}\text { Transport } \\
\text { er }\end{array}$ \\
\hline 31 & $\begin{array}{l}\text { cost } \\
\text { reduction, } \\
\text { sustainabilit } \\
\text { y }\end{array}$ & $\begin{array}{l}\text { "Today, OpenPort is allowing Mondelez and Unilever to } \\
\text { reduce costs as well as their environmental footprint by } \\
\text { utilizing the same truck on their Karachi to Lahore route } \\
\text { (Mondelez), then Lahore to Karachi (Unilever). In addition } \\
\text { to this "co-shipping" model between non-competitive } \\
\text { consumer goods companies, OpenPort also works to impact } \\
\text { the extended supply chain, allowing trucks used by raw } \\
\text { materials suppliers delivering to consumer goods } \\
\text { manufacturing locations to pick up finished goods instead of } \\
\text { leaving empty, and for distributor to point-of-sale utilization } \\
\text { of trucks used by the consumer goods manufacturer." }\end{array}$ & 2.7 & $\begin{array}{l}\text { Shippers } \\
\& \\
\text { Transport } \\
\text { ers }\end{array}$ \\
\hline
\end{tabular}


Appendix

Appendix B: Statements adopted from Thecargocoin.com, 2020

\begin{tabular}{|c|c|c|c|c|}
\hline & $\begin{array}{l}\text { Blockchain } \\
\text { Qualities }\end{array}$ & Statements Adopted from CargoCoin White paper & Page & Stakeholder \\
\hline 1 & $\begin{array}{l}\text { Contract } \\
\text { management \& } \\
\text { tokenization }\end{array}$ & $\begin{array}{l}\text { "CargoCoin is designed to utilize the platforms, both as a } \\
\text { secure transfer and storage method by the means of smart } \\
\text { contracts, as well as a payment unit for services, freight } \\
\text { and cargoes" }\end{array}$ & 5 & \\
\hline 2 & \multirow[t]{7}{*}{$\begin{array}{l}\text { data storage } \\
\text { and movement }\end{array}$} & $\begin{array}{l}\text { "exchange of documents and payment options at low cost } \\
\text { in real time." }\end{array}$ & 5 & \\
\hline 3 & & $\begin{array}{l}\text { "CargoCoin avoids the delays by providing instant } \\
\text { exchange, review and approval of documents and } \\
\text { payments between the parties involved. Further delays are } \\
\text { caused by different time zones, different public holidays, } \\
\text { etc. The blockchain is always at work } 24 / 7 \text { and does not } \\
\text { depend on human intervention" }\end{array}$ & 6 & \\
\hline 4 & & $\begin{array}{l}\text { "CargoCoinis naturally secured. It relies on the } \\
\text { blockchain's proven hashing algorithm technology. There } \\
\text { is no possibility of sensitive commercial information } \\
\text { leakage by intermediaries, such as banks, brokers, agents, } \\
\text { etc." }\end{array}$ & 7 & \\
\hline 5 & & $\begin{array}{l}\text { "While it is fully confidential it also allows for full } \\
\text { publicity of the transactions details that are to be visible by } \\
\text { all parties and the public" }\end{array}$ & 7 & \\
\hline 6 & & $\begin{array}{l}\text { "CargoCoin, not just allows but fully relies for full historic } \\
\text { storage of all transactions ever conducted, thus avoiding } \\
\text { risks of physical loss or destruction of paper documents, } \\
\text { while at the same time allowing for easy searching and } \\
\text { reviewing past information stored in the cloud." }\end{array}$ & 7 & \\
\hline 7 & & $\begin{array}{l}\text { "At all times the Smart B/L is in the block chain, secure } \\
\text { and instantly accessible by all authorized parties, at any } \\
\text { given stage, as per the pre-set smart contract conditions" }\end{array}$ & 18 & \\
\hline 8 & & $\begin{array}{l}\text { "The Smart L/C is designed and optimized to perform in } \\
\text { conjunction with the Smart B/L. This combination allows }\end{array}$ & 20 & \\
\hline
\end{tabular}


Appendix

\begin{tabular}{|c|c|c|c|c|}
\hline & & $\begin{array}{l}\text { for secure and guaranteed transactions between the } \\
\text { participants" }\end{array}$ & & \\
\hline 9 & new E-market & $\begin{array}{l}\text { "The platform target is to facilitate and optimise the } \\
\text { interaction amongst traders, freight forwarders, shipping } \\
\text { lines, booking agents as well as all other parties involved } \\
\text { in the international trade and transport of commodities and } \\
\text { cargoes." }\end{array}$ & 5 & \\
\hline 10 & & $\begin{array}{l}\text { "The platform connects importers, exporters, freight } \\
\text { forwarders, booking agents, ship brokers, ship owners, etc. } \\
\text { into a single unified marketplace" }\end{array}$ & 7 & \\
\hline 11 & & $\begin{array}{l}\text { "development of a marketplace, utilizing Smart Contracts, } \\
\text { allowing manufacturers to showcase their produce and } \\
\text { connect them directly with customers, through an } \\
\text { established link to the ship and inland transport platforms" }\end{array}$ & 7 & \\
\hline 12 & & $\begin{array}{l}\text { "Offers are presented with details -freight cost, transit } \\
\text { time, equipment availability etc. The importer proceeds to } \\
\text { the chosen bid via the CargoCoin platform. Transparency } \\
\text { is a priority.Full background and past performance of both } \\
\text { parties are available. Communication via the smart } \\
\text { platform is secure \& instant." }\end{array}$ & 12 & Shippers \\
\hline 13 & & $\begin{array}{l}\text { "The platform allows for a range of communication } \\
\text { channels. It emphasizes on simple forms in order to keep it } \\
\text { straight forward and save time.Detailed, optional fields- } \\
\text { on-demand allow for in depth interaction, as the main } \\
\text { terms negotiations develop." }\end{array}$ & 13 & \\
\hline 14 & $\begin{array}{l}\text { transparency in } \\
\text { tracking and } \\
\text { tracing }\end{array}$ & $\begin{array}{l}\text { "The platform architecture is based on the principles of } \\
\text { high level of security, transparency, traceability and } \\
\text { accountability." }\end{array}$ & 5 & \\
\hline 15 & Cost reduction & $\begin{array}{l}\text { "CargoCoin will significantly reduce costs, compared to } \\
\text { high percentages and other fine print fees that are charged } \\
\text { through the whole process by banks, couriers, insurers, } \\
\text { brokers, agents, lines, etc. Guaranteed payments will not }\end{array}$ & 6 & \\
\hline
\end{tabular}


Appendix

\begin{tabular}{|c|c|c|c|c|}
\hline & & $\begin{array}{l}\text { incur any costs, as it is the case with Bank } \mathrm{L} / \mathrm{C} \text { at the } \\
\text { moment." }\end{array}$ & & \\
\hline 16 & & $\begin{array}{l}\text { "Transaction cost is a significant amount of sea farers' } \\
\text { salaries. It is so due to the international nature of the } \\
\text { business.Payments by CargoCoin decreasethe cost and } \\
\text { arrival without delay." }\end{array}$ & 15 & $\begin{array}{l}\text { Shippers, } \\
\text { Transporter }\end{array}$ \\
\hline 17 & $\begin{array}{l}\text { contract } \\
\text { management \& } \\
\text { tokenization, } \\
\text { risk reduction }\end{array}$ & $\begin{array}{l}\text { "The CargoCoin Smart contract, block chain based, } \\
\text { cryptoB/Lensures a number of advantages:-Secure and } \\
\text { instant access, instant release, instant and secure } \\
\text { blockchain delivery, confidentiality, instant endorsement, } \\
\text { secure endorsement, eliminates fraud, quick and secure } \\
\text { draft approval, cheaper to issue, cheaper to send, cannot be } \\
\text { physically lost." }\end{array}$ & 17 & \\
\hline 18 & & $\begin{array}{l}\text { "The CargoCoin Ecosystem,itsservices and theSmart } \\
\text { B/Lutilityprovides sound foundations for decentralized } \\
\text { instant crypto transactionsby CargoCoin tokens. The } \\
\text { Smart B/L security is an element that actively promotes } \\
\text { further the Platform Crypto transactions." }\end{array}$ & 19 & \\
\hline 19 & & $\begin{array}{l}\text { "Smart L/Cin conjunction with the Smart B/Lis design by } \\
\text { default to overcomemost of the standard L/C } \\
\text { disadvantages including eliminating fraud risk, eliminating } \\
\text { bank failure or delay risk, cost saving, quick to set it up, } \\
\text { instant funds release and reciept, confidential, simple and } \\
\text { flexibility." }\end{array}$ & 20 & \\
\hline 20 & & $\begin{array}{l}\text { "CargoCoin minimises the risk of fraud and in many cases } \\
\text { completely eliminates it, by not releasing any payments } \\
\text { until the counter parties' pre-set conditions are met\& } \\
\text { publicly available proof of the payment has been made or } \\
\text { secured in a smart escrow utility. Payments will be } \\
\text { guaranteed by default. Fraudulent endorsement and } \\
\text { duplication of ownership documents is ruled out." }\end{array}$ & 6 & \\
\hline
\end{tabular}


Appendix

\begin{tabular}{|l|l|l|l|l|}
\hline 21 & Data storage & "The Cargo Coin concept fully unleashes the potential of & 5 & \\
& and & block chain crypto currencies to act, not just as a means of & & \\
Movement, & payment and store of value, but also as an interactive way \\
contract & of sending, receiving, approving, rejecting and signing & & \\
management \& & documents through the process" & & \\
Tokenization & & & & \\
\hline
\end{tabular}


Appendix

Appendix C: Statements adopted from Cargox.io, 2020

\begin{tabular}{|c|c|c|c|c|}
\hline & $\begin{array}{l}\text { blockchain } \\
\text { Qualities }\end{array}$ & Statements Adopted form CargoX white paper & page & $\begin{array}{l}\text { stakehol } \\
\text { der }\end{array}$ \\
\hline 1 & \multirow[t]{5}{*}{$\begin{array}{l}\text { contract } \\
\text { management \& } \\
\text { tokenization }\end{array}$} & $\begin{array}{l}\text { "CargoX leverages the security and decentralization of the } \\
\text { open blockchain and smart contracts and has a deep } \\
\text { pipeline of future products for the supply-chain industry." }\end{array}$ & 33 & \\
\hline 2 & & $\begin{array}{l}\text { "Security and safety of our smart contracts is assured } \\
\text { thorough vetting and auditing.All production-ready } \\
\text { CargoX smart contracts have been vetted by at least one } \\
\text { independent auditing expert." }\end{array}$ & 36 & \\
\hline 3 & & $\begin{array}{l}\text { "The blockchain-based Smart B/L works in a similar way } \\
\text { to tokens. The user can create/transfer/claim its } \\
\text { ownership." }\end{array}$ & 37 & \\
\hline 4 & & $\begin{array}{l}\text { "the CXO token now plays a fundamental utility role in } \\
\text { the backbone of the CargoX platform.Our smart contract } \\
\text { handling the issuance of Smart B/Ls requires credits in } \\
\text { order to create B/Ls, and the only way to get credits is to } \\
\text { redeem CXO tokens." }\end{array}$ & 52 & \\
\hline 5 & & $\begin{array}{l}\text { "CXO not just a pure utility token, but even places it into a } \\
\text { special subcategory - a usage token. And the decision to } \\
\text { use it as a mean of internal payment - for every Smart B/L } \\
\text { purchase - creates a unique velocity sink, which definitely } \\
\text { captures the value in the CXO." }\end{array}$ & 52 & \\
\hline 6 & $\begin{array}{l}\text { transparency in } \\
\text { tracking and } \\
\text { tracing }\end{array}$ & $\begin{array}{l}\text { "A widespread supporter base and commitment to highest } \\
\text { transparency standards made CargoX one of the most } \\
\text { market-neutral companies in the logistics with a clear } \\
\text { message that as an independent company it is open to all." }\end{array}$ & 33 & \\
\hline 7 & \multirow[t]{3}{*}{$\begin{array}{l}\text { data storage } \\
\text { and movement }\end{array}$} & $\begin{array}{l}\text { "Fast A smart B/L can be issued instantly and can be } \\
\text { immediately transferred to the legal owner of the goods, } \\
\text { with no middlemen or couriers." }\end{array}$ & 39 & \\
\hline 8 & & $\begin{array}{l}\text { "CargoX is excited to be part of a transformation that will } \\
\text { eliminate the need for paper documents in logistics." }\end{array}$ & 33 & \\
\hline 9 & & "Blockchain is the perfect vehicle for the $\mathrm{B} / \mathrm{L}$ application." & 33 & \\
\hline
\end{tabular}


Appendix

\begin{tabular}{|c|c|c|c|}
\hline 10 & & $\begin{array}{l}\text { "While all transfers of B/L ownership are stored in a } \\
\text { public blockchain, users' identities are obfuscated by their } \\
\text { blockchain addresses - their real identity visible only to } \\
\text { others sharing the same B/L." }\end{array}$ & 35 \\
\hline 11 & & $\begin{array}{l}\text { "Similarly the content of the } \mathrm{B} / \mathrm{L} \text { document is securely } \\
\text { encrypted and again visible only to involved parties." }\end{array}$ & 35 \\
\hline 12 & & $\begin{array}{l}\text { "All global trade sensitive information is hidden from } \\
\text { public view and only shown to the importer, the exporter } \\
\text { and the issuer of the Smart B/L;" }\end{array}$ & 38 \\
\hline 13 & & $\begin{array}{l}\text { "replacing traditional paper Bill of Lading documents with } \\
\text { a blockchain-based Bill of Lading platform offering a fast, } \\
\text { safe, reliable, and cost-effective digital equivalent, namely } \\
\text { the CargoX Smart B/L." }\end{array}$ & 37 \\
\hline 14 & & $\begin{array}{l}\text { "The CargoX Smart B/L records each action on the } \\
\text { blockchain together with a time-stamp. This offers a more } \\
\text { secure and transparent way of handling cargo ownership } \\
\text { transfers and prevents cargo release prior to release of } \\
\text { Smart B/L ownership to the cargo release agent. Armed } \\
\text { with this immutable data, it is easy to check whether cargo } \\
\text { cleared customs or a container actually moved from a } \\
\text { terminal at the proper time." }\end{array}$ & 39 \\
\hline 15 & & $\begin{array}{l}\text { "Smart B/Ls only optimize processes, time and costs, but } \\
\text { do so for everyone included" }\end{array}$ & 40 \\
\hline 16 & Cost reduction & $\begin{array}{l}\text { "The Smart B/L solution is based on a trusted, public, } \\
\text { decentralised platform that shaves days and hundreds of } \\
\text { dollars from the transport and archiving procedures } \\
\text { associated with bills of lading." }\end{array}$ & 37 \\
\hline 17 & & $\begin{array}{l}\text { "Paper B/Ls are sent at least three times, with couriers } \\
\text { making the process extremely expensive and slow. The } \\
\text { average cost for sending a B/L three times is around USD } \\
100 \text { and it takes up to } 10 \text { days to reach its inal destination } \\
\text { Millions of B/Ls are created every year. Want to save up } \\
\text { to } 90 \% \text { of these costs? Now's your chance." }\end{array}$ & 39 \\
\hline
\end{tabular}


Appendix

\begin{tabular}{|c|c|c|c|}
\hline 18 & risk reduction & $\begin{array}{l}\text { "No central storage to be targeted by hackers. No single } \\
\text { point of failure. Global trade's mostimportant document is } \\
\text { encrypted and storedsecurely on the blockchain, accessible } \\
\text { only through the owner's' private keys. It can never be } \\
\text { lost or stolen. The Ethereum blockchain employs the most } \\
\text { advanced cryptography, providing military-grade } \\
\text { security." }\end{array}$ & 38 \\
\hline 19 & $\begin{array}{l}\text { transparency in } \\
\text { tracking and } \\
\text { tracing, data } \\
\text { storage \& } \\
\text { movement }\end{array}$ & $\begin{array}{l}\text { "Value proposition and benefits of the smart } \mathrm{B} / \mathrm{L} \text { : create a } \\
\text { smart B/L quickly, send the } \mathrm{B} / \mathrm{L} \text { across the globe in } \\
\text { minutes and track their progross, The } \mathrm{B} / \mathrm{L} \text { is securley } \\
\text { encrypted and stored on a distributed storage system and } \\
\text { visible only to involved parties, completed } \mathrm{B} / \mathrm{L} \text { remain in } \\
\text { the archive, accessible to their owner." }\end{array}$ & 38 \\
\hline 20 & $\begin{array}{l}\text { data storage } \\
\text { and movement, } \\
\text { cost reduction, } \\
\text { transparency in } \\
\text { tracking and } \\
\text { tracing }\end{array}$ & $\begin{array}{l}\text { "No marketing sweet talk required-the use of blockchain } \\
\text { natively solves it all. Document traveling speeds go off the } \\
\text { chart, overall costs are decreased by up to } 90 \% \text {, and native } \\
\text { transparency and trackability ensure that lost or stolen } \\
\text { documents are a thing of the past." }\end{array}$ & 31 \\
\hline
\end{tabular}


Appendix

Appendix D: Statements adopted from Whitepaper.io/ShipChain, 2020

\begin{tabular}{|c|c|c|c|c|}
\hline & $\begin{array}{l}\text { blockchain } \\
\text { Qualities }\end{array}$ & Statements Adopted form ShipChain white paper & page & $\begin{array}{l}\text { stakehold } \\
\text { er }\end{array}$ \\
\hline 1 & \multirow[t]{5}{*}{$\begin{array}{l}\text { data storage } \\
\text { and movement }\end{array}$} & $\begin{array}{l}\text { "Information about loads, geo-waypoints, and basic } \\
\text { compliance information will be recorded and publicly } \\
\text { validated within the sidechain." }\end{array}$ & 7 & \\
\hline 2 & & $\begin{array}{l}\text { "Deploying blockchain technology into the freight } \\
\text { industry to encode geographic data will increase cargo } \\
\text { visibility, and thereby dramatically decrease theft. By } \\
\text { using barcodes or hardware RFID integration, assets can } \\
\text { be automatically verified each time electronic logs are } \\
\text { reported, increasing security and pro-viding peace-of-mind } \\
\text { for all parties." }\end{array}$ & 8 & \\
\hline 3 & & $\begin{array}{l}\text { "Permissioning, immutability, and encryption are inherent } \\
\text { benefits of blockchain technology, allowing select } \\
\text { individuals to access, examine, and add critical transport } \\
\text { data, but no one will have the ability to change or delete } \\
\text { existing data. By bringing accountability to every step of } \\
\text { the process, the blame game between carriers, brokers and } \\
\text { shippers is mitigated" }\end{array}$ & 8 & $\begin{array}{l}\text { Shippers } \\
\& \\
\text { Transport } \\
\text { ers }\end{array}$ \\
\hline 4 & & $\begin{array}{l}\text { "We will unify shipment tracking across the Ethereum } \\
\text { blockchain, using our ShipChain side-chain to track } \\
\text { individual encrypted geographic waypoints across each } \\
\text { smart contract." }\end{array}$ & 7 & \\
\hline 5 & & $\begin{array}{l}\text { "With this system, the meaning of each waypoint will be } \\
\text { encrypted, accessible for interpretation by only the parties } \\
\text { involved." }\end{array}$ & 7 & \\
\hline 6 & \multirow[t]{2}{*}{$\begin{array}{l}\text { transparency in } \\
\text { tracking and } \\
\text { tracing }\end{array}$} & $\begin{array}{l}\text { "This will give shippers more visibility across their supply } \\
\text { chain and allow carriers to communicate with ease, } \\
\text { reducing delays and miscommunications." }\end{array}$ & 7 & $\begin{array}{l}\text { Shippers } \\
\& \\
\text { Transport } \\
\text { ers }\end{array}$ \\
\hline 7 & & $\begin{array}{l}\text { "Imagine a fully integrated system across the entire supply } \\
\text { chain--from the moment it leaves the factory, field, or }\end{array}$ & 7 & \\
\hline
\end{tabular}




\begin{tabular}{|c|c|c|c|c|}
\hline & & $\begin{array}{l}\text { farm--to deliv-ering the finished product to the customer's } \\
\text { doorstep; federated in trustless, transparent blockchain } \\
\text { contracts. This is ShipChain, the future of shipping." }\end{array}$ & & \\
\hline 8 & & $\begin{array}{l}\text { "With the upcoming Electronic Log Device (ELD) } \\
\text { mandate from the United States Department of } \\
\text { Transportation, ShipChain will work with the most } \\
\text { popular ELD developers to integrate directly and march } \\
\text { toward our first goal: completion of Track \& Trace } \\
\text { technology." }\end{array}$ & 7 & \\
\hline 9 & & $\begin{array}{l}\text { "business development will assist these carriers with the } \\
\text { replacement of their base internal tracking with the } \\
\text { ShipChain system, allowing a greater level of visibility } \\
\text { across all of their multimodal shipping partners." }\end{array}$ & 7 & $\begin{array}{l}\text { Transport } \\
\text { ers }\end{array}$ \\
\hline 10 & & $\begin{array}{l}\text { "By encoding and encrypting waypoint information and } \\
\text { data about which loads belong in a shipment, digital } \\
\text { escrows can be used to fairly assess whether goods } \\
\text { actually arrived in a particular shipment. Conflicting } \\
\text { accounts of the whereabouts of goods are eliminated, and } \\
\text { individual players can be rewarded for their participation } \\
\text { in a system that operates without trusting any particular } \\
\text { party's story about what happened." }\end{array}$ & 8 & \\
\hline 11 & & $\begin{array}{l}\text { "Using the ShipChain Prime side-chain for granular } \\
\text { tracking, RFID and barcodes can be combined with ELD } \\
\text { integrations allowing full traceability and visibility of } \\
\text { supply, literally from farm to table." }\end{array}$ & 15 & \\
\hline 12 & \multirow[t]{2}{*}{$\begin{array}{l}\text { contract } \\
\text { management \& } \\
\text { tokenization }\end{array}$} & $\begin{array}{l}\text { "Upon delivery and confirmation, the contract will be } \\
\text { completed and recorded on the main blockchain, releasing } \\
\text { any payment escrows." }\end{array}$ & 7 & \\
\hline 13 & & $\begin{array}{l}\text { "This load system will generate a smart contract upon } \\
\text { pick-up and will hold payments in escrow until conditions } \\
\text { for release are met while using the main blockchain and } \\
\text { side-chain for tracking and cargo security monitoring" }\end{array}$ & 8 & \\
\hline
\end{tabular}


Appendix

\begin{tabular}{|c|c|c|c|c|}
\hline 14 & & $\begin{array}{l}\text { "With all necessary information held in a smart contract, } \\
\text { this process will be quicker and easier than ever before." }\end{array}$ & 11 & \\
\hline 15 & & $\begin{array}{l}\text { "Ownership of at least } 1 \text { full SHIP token grants } \\
\text { "ShipChain Membership Status." This is required to } \\
\text { access the blockchain for both the purpose of tracking } \\
\text { shipments, as well as the purpose of booking freight." }\end{array}$ & 12 & \\
\hline 16 & & $\begin{array}{l}\text { "Tokens valued at up to } 20 \% \text { of each freight transaction } \\
\text { will be given to the driver/carrier as "gamified" incentives } \\
\text { for safe and timely deliveries, as well as environment } \\
\text { focused such as reduced idle time. From there, drivers will } \\
\text { either be able to sell their tokens on exchanges, or redeem } \\
\text { those tokens via partner-ships ShipChain will form for } \\
\text { various rewards, such as gift cards, fuel discounts, and } \\
\text { more." }\end{array}$ & 12 & $\begin{array}{l}\text { Transport } \\
\text { ers }\end{array}$ \\
\hline 17 & new E markets & $\begin{array}{l}\text { "The initial step of working with these providers will } \\
\text { allow us to integrate immediately into the largest network } \\
\text { of US-based trucking freight companies, giving our } \\
\text { platform a full network of freight movement without the } \\
\text { arduous requirement of connecting to individual freight } \\
\text { companies (or even individual Owner-operator trucks) one } \\
\text { at a time." }\end{array}$ & 7 & \\
\hline 18 & & $\begin{array}{l}\text { "The Ship-Chain blockchain will supplant the need for } \\
\text { brokers by allowing carriers the ability to find shipments } \\
\text { and intelligently route their team for multimodal } \\
\text { transportation based on factors such as distance, traffic, } \\
\text { weather conditions, fuel use and more." }\end{array}$ & 8 & $\begin{array}{l}\text { Transport } \\
\text { ers }\end{array}$ \\
\hline 19 & & $\begin{array}{l}\text { "The decentralized brokerage will be an open marketplace } \\
\text { connecting shippers to carriers, and ShipChain will } \\
\text { provide the first app for cargo booking; shippers will be } \\
\text { able to log on and place an order from "Point A" to "Point } \\
\text { B" using suggested routing and shipping methods based } \\
\text { on cost, time in transit, and contents" }\end{array}$ & 9 & $\begin{array}{l}\text { Shippers } \\
\& \\
\text { Transport } \\
\text { ers }\end{array}$ \\
\hline
\end{tabular}


Appendix

\begin{tabular}{|c|c|c|c|c|}
\hline 20 & & $\begin{array}{l}\text { "The decentralized brokerage system will be comprised } \\
\text { primarily of an open marketplace connecting shippers and } \\
\text { carriers." }\end{array}$ & 10 & $\begin{array}{l}\text { Shippers } \\
\& \\
\text { Transport } \\
\text { ers }\end{array}$ \\
\hline 21 & & $\begin{array}{l}\text { "using our advanced interface to search and filter } \\
\text { compatible sea freight, customs agents, and schedule } \\
\text { handoffs between multiple drivers." }\end{array}$ & 15 & $\begin{array}{l}\text { Transport } \\
\text { ers }\end{array}$ \\
\hline 22 & & $\begin{array}{l}\text { "If for example, the shipper has five full shipping } \\
\text { containers of shoes coming from China to the United } \\
\text { States, the system will recognize that a sea carrier, rail } \\
\text { carrier, and final truck carrier will be the best op- } \\
\text { timization for cost and speed based on the size and type of } \\
\text { shipment. The shipper will then be able to see the capacity } \\
\text { on each leg, book their own routes, see estimated delivery } \\
\text { times, and have full control over their supply chain } \\
\text { without the need for a broker." }\end{array}$ & 10 & Shippers \\
\hline 23 & Sustainability & $\begin{array}{l}\text { "ShipChain is committed to making the world a better } \\
\text { place and protecting the environment from the harmful } \\
\text { effects of greenhouse gas emissions. Our plan includes a } \\
\text { retainer of } 13 \% \text { of the total supply of tokens to be } \\
\text { distributed over } 5 \text { or more years as incentives for } \\
\text { ecologically responsible driving at safe speeds. By } \\
\text { offering these rewards, we ensure that the safe and timely } \\
\text { delivery of goods is the top pri-ority for everyone" }\end{array}$ & 14 & $\begin{array}{l}\text { Transport } \\
\text { ers }\end{array}$ \\
\hline 24 & $\begin{array}{l}\text { Data Storage \& } \\
\text { Movement, } \\
\text { Cost reduction }\end{array}$ & $\begin{array}{l}\text { "The overall shipment completion will be stored on the } \\
\text { main Ethereum blockchain, and to keep costs low, } \\
\text { individual tracking waypoints and load data can be stored } \\
\text { and verified in an associated side-chain operating on the } \\
\text { ShipChain Protocol (fork of Ethereum software" }\end{array}$ & 10 & \\
\hline
\end{tabular}


Appendix

Appendix E: Statements adopted from www3.technologyevaluation.com, 2020

\begin{tabular}{|c|c|c|c|c|}
\hline & $\begin{array}{l}\text { Blockchain } \\
\text { Qualities }\end{array}$ & Statements Adopted from TradeLens solution white paper & Page & Stakeholder \\
\hline 1 & $\begin{array}{l}\text { Contract } \\
\text { managemen } \\
\mathrm{t} \text { and } \\
\text { tokenization }\end{array}$ & $\begin{array}{l}\text { "TradeLens enables the digitization and automation of } \\
\text { cross- organizational business processes integral to global } \\
\text { trade, including import and export clearance, and-thanks } \\
\text { to blockchain - ensuring key transaction information is } \\
\text { secure, immutable and auditable." }\end{array}$ & 2 & \\
\hline 2 & $\begin{array}{l}\text { Data storage } \\
\text { and } \\
\text { movement }\end{array}$ & $\begin{array}{l}\text { "TradeLens data is published directly from the source so } \\
\text { the right people can securely manage their supply chain in } \\
\text { real time." }\end{array}$ & 2 & \\
\hline 3 & & $\begin{array}{l}\text { "shippers, freight forwarders, ports and terminals, ocean } \\
\text { carriers, government authorities, customs brokers and more. } \\
\text { Each entity shares information that can be tracked, stored } \\
\text { and actioned across the platform throughout a shipment's } \\
\text { journey." }\end{array}$ & 3 & $\begin{array}{l}\text { Shippers \& } \\
\text { transporters }\end{array}$ \\
\hline 4 & & $\begin{array}{l}\text { "Powered by Hyperledger Fabric blockchain technology } \\
\text { and IBM Cloud, the platform enables the industry to share } \\
\text { information and collaborate securely." }\end{array}$ & 3 & \\
\hline 5 & & $\begin{array}{l}\text { "While the power of TradeLens comes from its ecosystem } \\
\text { members, blockchain enables the secure distribution and } \\
\text { storage of the vital information that is the heart of the } \\
\text { platform." }\end{array}$ & 10 & \\
\hline 6 & & $\begin{array}{l}\text { "Tamper-proof recording and non- repudiation for all data } \\
\text { submitted to the platform. All data is signed by the } \\
\text { submitter and recorded in the ledgers of the Trust } \\
\text { Anchors." }\end{array}$ & 10 & \\
\hline 7 & & $\begin{array}{l}\text { "Privacy of data to ensure that it is only shared with } \\
\text { relevant organizations. Only registered entities with } \\
\text { Certificates can access the ledger. Channel Level Control } \\
\text { Application Level Access Control." }\end{array}$ & 10 & \\
\hline 8 & & $\begin{array}{l}\text { "Access to a definitive and real-time source of information } \\
\text { for trade finance and trade insurance." }\end{array}$ & 4 & \\
\hline
\end{tabular}




\begin{tabular}{|c|c|c|c|}
\hline 9 & $\begin{array}{l}\text { "Data that are precise and accessible to all parties help } \\
\text { shipments move faster. TradeLens provides a real-time } \\
\text { publish and subscribe mechanism for exchanging milestone } \\
\text { data and shipping documents between the entities that are } \\
\text { involved in the shipment." }\end{array}$ & 5 & Shippers \\
\hline 10 & $\begin{array}{l}\text { "TradeLens ensures flexibility and control over who can } \\
\text { view, publish and subscribe to shipment-specific data. } \\
\text { Shipment milestones and documents are only accessible to } \\
\text { authorized parties." }\end{array}$ & 5 & \\
\hline 11 & $\begin{array}{l}\text { "TradeLens provides a framework for sharing documents } \\
\text { among trade parties, with security, version control, and } \\
\text { privacy. Authorized users with the required permissions } \\
\text { can upload, download, view and edit documents." }\end{array}$ & 6 & \\
\hline 12 & $\begin{array}{l}\text { "The TradeLens document store allows documents to be } \\
\text { securely stored, viewed, and actioned by various parties to } \\
\text { a shipment." }\end{array}$ & 6 & \\
\hline 13 & $\begin{array}{l}\text { "Structured documents, built to industry standards, provide } \\
\text { rich data that can be readily located, analyzed and } \\
\text { interpreted. The format enables efficient access, use and } \\
\text { modification of information within a document, allowing } \\
\text { for greater functionality and automation with reduced } \\
\text { repetition and error." }\end{array}$ & 6 & \\
\hline 14 & $\begin{array}{l}\text { "TradeLens document permissions are determined through } \\
\text { a combination of the organization's role and the document } \\
\text { type. The TradeLens platform then permits access to } \\
\text { documents according to the permission matrix." }\end{array}$ & 6 & \\
\hline 15 & $\begin{array}{l}\text { "Network participants assigned to a consignment can } \\
\text { immediately access shared documents and data, never } \\
\text { having to wait for a document to be sent." }\end{array}$ & 7 & \\
\hline 16 & $\begin{array}{l}\text { "With digitized documents and permissioned sharing, } \\
\text { TradeLens facilitates the move away from legacy } \\
\text { workflows (using paper or PDFs) within a single } \\
\text { organization, to automated workflows across multiple }\end{array}$ & 7 & \\
\hline
\end{tabular}




\begin{tabular}{|c|c|c|c|c|}
\hline & & $\begin{array}{l}\text { organizations that dispense with costly, repetitive and error- } \\
\text { prone manual inputs." }\end{array}$ & & \\
\hline 17 & & $\begin{array}{l}\text { "In addition to being able to download each version of a } \\
\text { document, TradeLens also performs a Consistency Check } \\
\text { to indicate a document has been verified on the blockchain. } \\
\text { Once a document (or a version of a document) is selected, } \\
\text { the document will be retrieved from the secure Blockchain } \\
\text { Document Store and the hash stored on the blockchain will } \\
\text { be compared with a newly generated hash. After this check } \\
\text { is complete, the Consistency Check will indicate that the } \\
\text { document has been verified on the blockchain and has not } \\
\text { been altered in any way." }\end{array}$ & 7 & \\
\hline 18 & $\begin{array}{l}\text { Transparenc } \\
\text { y in tracking } \\
\text { and tracing }\end{array}$ & $\begin{array}{l}\text { "It is a solution for the industry built upon a model of } \\
\text { transparency with benefits for all members of the } \\
\text { ecosystem." }\end{array}$ & 2 & \\
\hline 19 & & $\begin{array}{l}\text { "Pre-built connections to shipping lines and other actors, } \\
\text { end-to-end visibility across shipping corridors, and real- } \\
\text { time access to more information to enrich port } \\
\text { collaboration and improve terminal planning." }\end{array}$ & 4 & \\
\hline 20 & & $\begin{array}{l}\text { "Improved planning and utilization of assets given real- } \\
\text { time access to end-to-end supply chain events for } \\
\text { shipments" }\end{array}$ & 4 & \\
\hline 21 & & $\begin{array}{l}\text { "A streamlined and improved supply chain allowing for } \\
\text { greater predictability, early notification of issues, full } \\
\text { transparency to validate fees and surcharges, and less safety } \\
\text { stock inventory." }\end{array}$ & 4 & \\
\hline 22 & & $\begin{array}{l}\text { "Pre-built connections to the ecosystem, improved tools for } \\
\text { customs clearance brokerage function, and real-time access } \\
\text { to the end-to-end supply chain data to improve } \\
\text { effectiveness of track-and-trace tools." }\end{array}$ & 4 & \\
\hline 23 & & $\begin{array}{l}\text { "Importers and exporters who use TradeLens can easily } \\
\text { determine the status of their shipments through the } \\
\text { Shipment Manager user-interface (see more below) or by }\end{array}$ & 5 & Shippers \\
\hline
\end{tabular}


Appendix

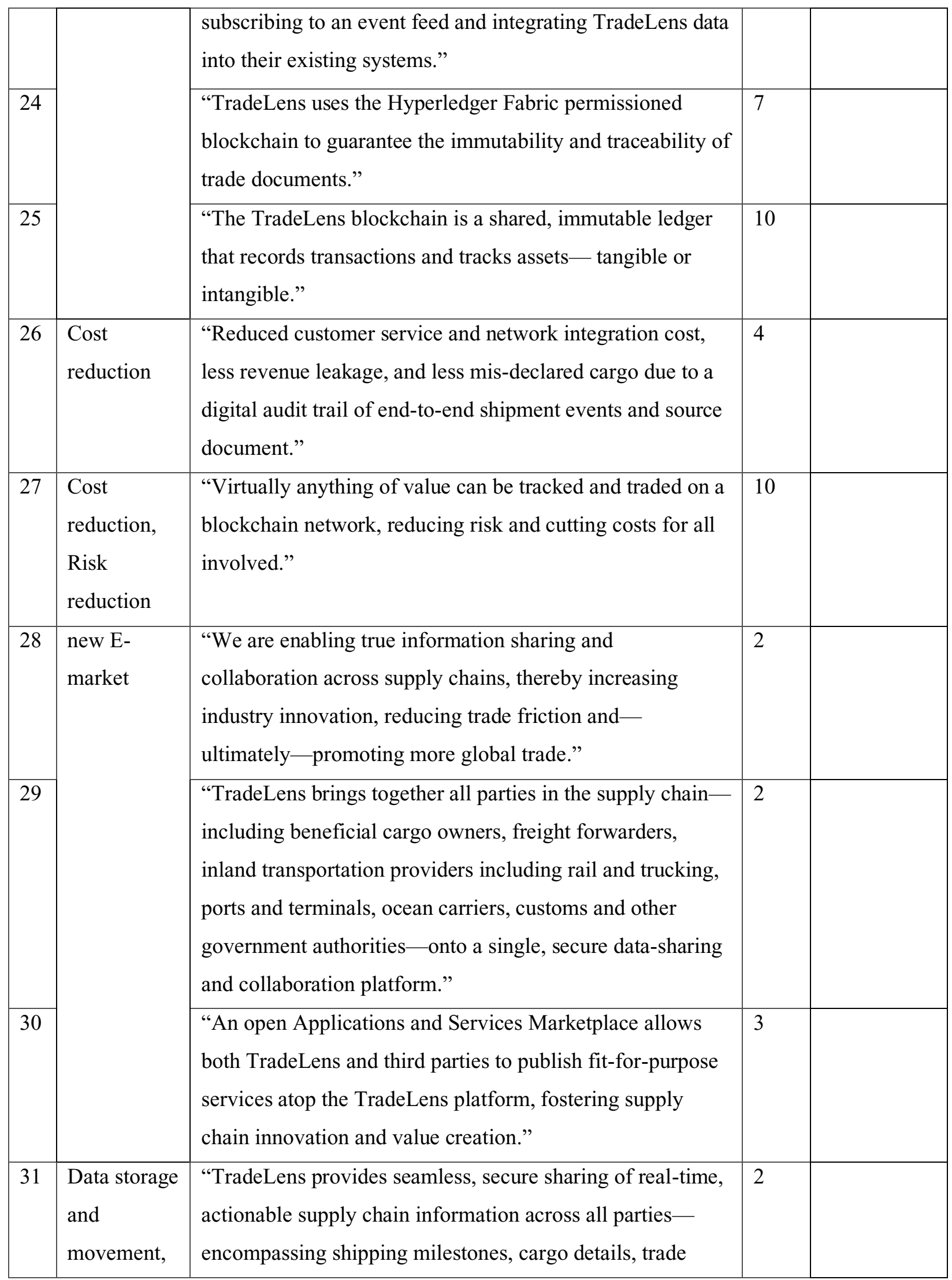


Appendix

\begin{tabular}{|l|l|l|l|l|}
\hline risk & $\begin{array}{l}\text { documents, sensor readings and more-thereby } \\
\text { empowering the consumers to mitigate problems through } \\
\text { predictability and exception handling." }\end{array}$ & & \\
\hline
\end{tabular}

